\title{
Modeling glass cooling mechanism with down-flowing water film via the smoothed particle hydrodynamics
}

\author{
D.A. Abdoh ${ }^{1}$, A.S. Ademiloye ${ }^{2}$, K.M. Liew ${ }^{1, *}$ \\ ${ }^{1}$ Department of Architecture and Civil Engineering, City University of Hong Kong, Kowloon, Hong \\ Kong, China \\ ${ }^{2}$ Zienkiewicz Centre for Computational Engineering, College of Engineering, Swansea University, Bay \\ Campus, Swansea, SA1 8EN, United Kingdom
}

\begin{abstract}
This paper presents a new attempt to investigate the cooling mechanism of glass panes with down-flowing water film during fire outbreak by simulating the heat energy conservation equation using smoothed particle hydrodynamics (SPH) method. The nature of meshfree SPH method used allows us to predict the temperature distribution efficiently in continuous flow problems in contrast with mesh-based methods. To validate and show the efficiency of the proposed SPH model, the results from our simulation at specific conditions were compared with experimental measurements and results from commercial software packages. Furthermore, the new SPH model is utilized to simulate the effects of heat flux variation, down-flowing velocity and thickness of water film on temperature distribution of glass during fire. The developed $\mathrm{SPH}$ model is well able to describe glass cooling under different conditions. The computational results show that the rate of cooling increases when velocity or thickness of down-flowing water film increases. However, the glass temperature increases when heat flux increases.
\end{abstract}

Keywords: Smoothed Particle Hydrodynamics (SPH); Heat transfer; Fire; Glass cooling; Water film; Temperature distribution

* Corresponding author.

Email address: kmliew@ cityu.edu.hk (K.M. Liew) 


\section{Introduction}

Fire interaction with glass is becoming intensively research topic because glass plays a vital role in fire spreading. Glass is a brittle material and vulnerable to fire exposure. Glass breakage allows fresh air to enter the fire compartment leading to fire spread with catastrophic consequences. Water film has been used to protect the glass during a fire [1] since water is readily available and non-toxic when exposed to heat in contrast to many chemical fire-proofing coatings [2].

Several experimental research has been conducted to study the breakage behavior of several types of glass panes during fire without water protection [3-5]. On the other hand, experiments incorporating water film are recently carried out to examine the effects of down-flowing water film on heated glass. Some of these experiments proved that water film is more efficient in protecting glass than sprinklers [6]. The most common type of water film experiment consists of standard glass pane size of $600 \times 600 \times 6 \mathrm{~mm}^{3}$, while the water source and recovery of water film system consist of nozzles fixed at the top of the glass pane, water tanks to measure the amount of unevaporated water, pipes and hydraulic pump. It was revealed that the release time of the water film is a crucial factor in glass protection because discharging the water film at early stages of fire is more efficient in protecting the glass from falling apart $[7,8]$. Other important factors affecting the efficiency of water film system are water film thickness and down-flowing velocity. In another experiment [9], it was found that uniform water film flowing on glass with average thickness of $1.5 \mathrm{~mm}$ and water flow velocity around $0.7 \mathrm{~m} / \mathrm{s}$ is efficient to protect the glass from breakage under certain fire intensity.

In recent years, the use of numerical simulation in fire engineering and safety research has gained significant boost due to the huge cost associated with performing 
fire experiments as well as the need to carry out these experiments under specific and controlled conditions. In addition, the use of numerical simulation enables researchers to explore other aspects of glass cooling mechanism that cannot be observed in controlled experiments. Several numerical research works have carried out on heat transfer problems using mesh-based techniques. For instance, heat transfer by radiation and temperature interchange between objects have been studied using a combination of finite element and Galerkin methods [10]. Conduction heat transfer cases were also investigated using the boundary element method [11]. Furthermore, the finite difference method has also been used with Laplace transform to estimate the heat transfer through glass pane with down-flowing water film [12]. Despite their attractiveness and popularity, mesh-based techniques often require the generation of excellent quality meshes and can easily lose their accuracy due to mesh distortion, especially in problems involving large deformation [13], crack propagation and/or heat transfer through continuous flowing fluid [12]. In order to overcome these limitations, several complex operations such as mesh reconstruction, tracking or remeshing $[14,15]$ have been proposed; however, they often lead to increased computational effort and cost.

On the other hand, several meshfree methods [16-22] have been proposed to circumvent the drawbacks of mesh-based techniques. Smoothed particle hydrodynamics is one of the earliest and most traditional meshfree methods used in simulating various engineering problems, particularly with the flowing motion nature. For instance, the simulation of thin fluid film was investigated by discretizing the shallow water equations using SPH method whilst accounting for significant forces like surface tension [23]. Boundary treatments play a significant role in determining the efficiency of meshfree methods in moving boundary problems. SPH method was used with improved boundary treatment to model the interaction between the cell and 
viscoelastic extracellular matrix (ECM) [24]. SPH method has also been chosen by several authors to simulate the heat transfer problems $[25,26]$. In other similar work, SPH was utilized to study the cooling process during drilling using lubricant but the ships were modeled using Discrete Element Method [27].

To the authors' knowledge, there is no previous research work where a meshfree method has been proposed for heat transfer analysis with water film application. Hence, the meshfree SPH method [28-32] is used here to simulate the glass cooling using down-flowing water film. Moreover, a combination of radiation, convection and conduction for heat transfer are considered. The remainder of the paper is structured as follows: Section 2 describes the SPH method and heat transfer equation. Section 3 handles all aspects of the proposed numerical model while the numerical results of SPH model are discussed in section 4. Conclusions are stated in section 5.

\section{Smoothed Particle Hydrodynamics (SPH)}

\subsection{Basic SPH formulation}

According to SPH terminology, the problem domain is divided into finite number of particles without any connecting mesh as shown in Fig. 1. The unknown field variable such as temperature $\left(T_{i}\right)$ is approximated at each particle using the values at nearby particles $\left(T_{j}\right)$. Kernel smoothing function $\left(W_{i j}\right)$ is used within smoothing kernel length or radius $(h)$ to interpolate the unknown field variables. These kernels are continuous and monotonically decrement functions. Also, their derivatives are continuous over the support domain [33-35]. Many types of kernel functions have been used in previous research studies. In this paper, piecewise cubic smoothing kernel function $[30,34,35]$ is adopted as shown in Eq. (1): 


$$
W(R, h)=\alpha_{d}\left\{\begin{array}{cr}
\frac{2}{3}-R^{2}+\frac{1}{2} R^{3}, & 0 \leq R<1 \\
\frac{1}{6}(2-R)^{3}, & 1 \leq R \leq 2 \\
0, & 2 \leq R
\end{array}\right.
$$

where $W(R, h)$ is the kernel smoothing function, $h$ is the kernel radius, $R$ is the ratio of particles distance over kernel radius $\left(R=\frac{r_{i j}}{h}\right), \alpha_{d}$ is the normalization factor in 2D (taken as $15 / 7 \pi h^{2}$ ) and $r_{i j}$ is the distance between main particle $i$ and nearby particle $j$ as shown in Fig. 1. If $R$ decreases, the distance between particles decreases and value of kernel smoothing function $W(R, h)$ increases. Thus, the field variable value is affected more by nearby particles. However, particles outside kernel radius with $\mathrm{R}$ value greater than 2 have zero influence.

The main general equation of SPH is shown in Eq. (2). However, the integral sign is replaced with summation since there is a limited number of particles $(N)$ as shown in Eq. (3) $[30,31,35]$ :

$$
\begin{aligned}
& F\left(r_{i}\right)=\int F\left(r_{j}\right) W_{i j}(R, h) \\
& F\left(r_{i}\right)=\sum_{j=1}^{N} \frac{m_{j}}{\rho_{j}} F\left(r_{j}\right) W_{i j}(R, h)
\end{aligned}
$$

where $F\left(r_{i}\right)$ is the unknown variable like temperature for origin (main) particle at position $r_{i}, F\left(r_{j}\right)$ is the function value for nearby particles at position $r_{j}, N$ is the total number of particles used, $m_{j}$ and $\rho_{j}$ are the mass and density of nearby particle $j$ (support particle), respectively.

The first and second derivatives of Eq. (3) are obtained by differentiating the kernel smoothing function $W(R, h)$ and using Taylor series expansion to apply the consistency conditions as shown in Eq. (4) and Eq. (5) [30,33,34]: 


$$
\begin{aligned}
& \nabla F\left(r_{i}\right)=\rho_{i} \sum_{j=1}^{N} m_{j}\left(\frac{F\left(r_{j}\right)}{\rho_{j}^{2}}+\frac{F\left(r_{i}\right)}{\rho_{i}^{2}}\right) \nabla_{i j} W_{i j}(R, h) \\
& \nabla^{2} F\left(r_{i}\right)=\sum_{j=1}^{N} \frac{m_{j}}{\rho_{j}} F\left(r_{j}\right) \nabla_{i j}^{2} W_{i j}(R, h)
\end{aligned}
$$

where $\nabla F\left(r_{i}\right)$ and $\nabla^{2} F\left(r_{i}\right)$ are the first and second derivatives of function variable respectively, $F\left(r_{j}\right)$ and $F\left(r_{i}\right)$ are the function values (field variables) for origin particle $i$ and support particles $j$ respectively, while $\nabla_{i j} W_{i j}(R, h)$ and $\nabla_{i j}{ }^{2} W_{i j}(R, h)$ are the first and second derivatives of smoothing kernel function.

\subsection{SPH discretization of heat transfer equation}

The main differential equation governing the thermal interactions between fire, water and glass is the heat transfer equation which is given by [12]:

$$
\frac{\partial T}{\partial t}=\frac{1}{\rho C_{p}}\left(k\left(\frac{\partial^{2} T}{\partial x^{2}}+\frac{\partial^{2} T}{\partial y^{2}}\right)+Q(H F)\right)-u \frac{\partial T}{\partial x}-v \frac{\partial T}{\partial y}
$$

where $T$ is the temperature, $k$ is the thermal conductivity, $\rho$ and $C_{p}$ are the density and specific heat capacity, respectively, $Q$ is the source of heat which is equivalent to heat flux $(H F), u$ and $v$ are the velocities at $x$ and $y$ directions, respectively, $\frac{\partial T}{\partial x}$ and $\frac{\partial T}{\partial y}$ are the first derivatives of temperature with respect to $x$ and $y$ directions, respectively, while $\frac{\partial^{2} T}{\partial x^{2}}$ and $\frac{\partial^{2} T}{\partial y^{2}}$ are the second derivatives of temperature.

Since the water is the only fluid in our study and it has an average constant velocity in the $y$-direction, velocity terms are deleted and Eq. (6) is simplified as follows:

$$
\frac{\partial T}{\partial t}=\frac{1}{\rho C_{p}}\left(k\left(\frac{\partial^{2} T}{\partial x^{2}}+\frac{\partial^{2} T}{\partial y^{2}}\right)+Q(H F)\right)
$$


The terms $\frac{\partial^{2} T}{\partial x^{2}}$ and $\frac{\partial^{2} T}{\partial y^{2}}$ are replaced with algebraic formulas according to Eq. (5), the result represents the discretized form of the heat transfer equation, expressed as follows:

$$
\begin{aligned}
T_{i(t+1)}=\frac{1}{\rho C_{p}} & \left(\sum_{j=1}^{N}\left(\alpha \frac{m_{j}}{\rho_{j}} T_{j}\left(\frac{\partial^{2}}{\partial x^{2}} W_{i j}(R, h)+\frac{\partial^{2}}{\partial y^{2}} W_{i j}(R, h)\right)\right)+Q\right) \times \Delta t \\
& +T_{i(t)}
\end{aligned}
$$

where:

$$
\begin{aligned}
& \frac{\partial^{2} W_{i j}(R, h)}{\partial x}=\frac{15}{7 \pi h^{2}}\left\{\begin{array}{l}
\left(\frac{-2}{h^{2}}\right)+\left(\frac{3}{2 r_{i j} h^{3}}\left(x_{i}-x_{j}\right)^{2}\right)+\left(\frac{3 r_{i j}}{2 h^{3}}\right), 0 \leq R<1 \\
\left(\frac{1}{3 h^{2}}\right)+\left(\frac{2}{3 r_{i j}{ }^{3} h}\left(x_{i}-x_{j}\right)^{2}\right)-\left(\frac{2}{3 h r_{i j}}\right), 1 \leq R \leq 2
\end{array}\right. \\
& \frac{\partial^{2} W_{i j}(R, h)}{\partial y}=\frac{15}{7 \pi h^{2}}\left\{\begin{array}{l}
\left(\frac{-2}{h^{2}}\right)+\left(\frac{3}{2 r_{i j} h^{3}}\left(y_{i}-y_{j}\right)^{2}\right)+\left(\frac{3 r_{i j}}{2 h^{3}}\right), 0 \leq R<1 \\
\left(\frac{1}{3 h^{2}}\right)+\left(\frac{2}{3 r_{i j} h^{3}}\left(y_{i}-y_{j}\right)^{2}\right)-\left(\frac{2}{3 h r_{i j}}\right), 1 \leq R \leq 2
\end{array}\right.
\end{aligned}
$$

$T_{i(t)}$ and $T_{i(t+1)}$ are the temperature values for particle $i$ at current and next time steps respectively, $m_{j}$ and $\rho_{j}$ are the mass and density for nearby particles $j$ respectively, $T_{j}$ is the temperature of particles $j$ in the current time step, $x_{i}-x_{j}$ and $y_{i}-y_{j}$ are the difference of $x$ and $y$ coordinates between particles $i$ and $j$ respectively and $\Delta t$ is the time step in seconds.

\section{Computational model}

The main configuration of the problem consists of the glass pane $(600 \times 600 \times 6$ $\mathrm{mm}^{3}$ ) fixed at the top of the water recovery tank. Thirty-five (35) points of interest were defined on the glass pane section as shown in Fig. 2(a). $T$, the temperature values at some of these points are used in the verification stage and during the numerical 
simulation of new scenarios. Fig. 2(b) shows the heat flux variation induced by a fire pool located near the glass pane [7]. Throughout this work, the origin of the coordinate system $(x=0 \mathrm{~mm}, y=0 \mathrm{~mm})$ is placed at the lower point of the exposed glass surface as shown in Fig. 2(a).

The glass pane section is discretized with 3721 fixed particles, $6 \mathrm{~mm}$ thickness and $600 \mathrm{~mm}$ height of glass pane section are divided into 61 segments to obtain the spacing values between glass particles equal $0.1 \mathrm{~mm}$ and $10 \mathrm{~mm}$ at $x$ and $y$ directions, respectively. It was found that spacing between glass particles in the $x$-direction has more effect than the spacing in $y$-direction in the simulation results because the heat is transferred mainly in the $x$-direction within glass section. However, the temperature variation between glass particles occurs at $y$-direction mainly due to down-flowing water film temperature variation from top of glass to bottom. The down-flowing water film is represented by moving particles, with a constant velocity in the $y$-direction. At each time step $(0.02 \mathrm{~s})$, five (5) new water film particles start to flow from the top of glass, at $y=600 \mathrm{~mm}$, where the spacing in the $x$-direction between water film particles is $0.1 \mathrm{~mm}$. Any water film particle that moves below the bottom of the glass pane $(y<$ $0 \mathrm{~mm}$ ) is eliminated from our SPH model. The steps employed in our numerical simulations are summarized below:

(1) Before applying the water film, heat is transferred from the fire source to the first column layer of glass particles, at $x=0 \mathrm{~mm}$, by means of radiation. Eq. (8) is reformulated and used to calculate the new temperature. Note that the second derivatives are substituted with zero because heat is transferred from the fire source and there is no interaction between domain particles as shown below:

$$
T_{i(t+1)}=\frac{Q}{\rho_{G} C_{p g}} \Delta t+T_{i(t)}
$$


where $T_{i(t+1)}$ and $T_{i(t)}$ are the new and old temperature values of the first column layer of glass, $\rho_{G}$ is the density of glass and $C_{p G}$ is the specific heat capacity of glass.

(2) Heat is transferred from the first layer of glass particles to other layers by conduction, Eq. (8) is also used but with glass properties only without heat flux term $(\mathrm{Q})$ as follows:

$T_{i(t+1)}$

$=\frac{1}{\rho_{G} C_{p g}}\left(\sum_{j=1}^{N}\left(\alpha_{G} \frac{m_{j G}}{\rho_{j G}} T_{j}\left(\frac{\partial^{2}}{\partial x^{2}} W_{i j}(R, h)+\frac{\partial^{2}}{\partial y^{2}} W_{i j}(R, h)\right)\right)+Q\right) \times \Delta t$

$+T_{i(t)}$

where $\alpha_{G}$ is the thermal diffusivity of glass, $m_{j G}$ is the mass of glass particle and $\rho_{j G}$ is the density of nearby glass particle $j$.

(3) When water flow is released on glass, rapid cooling occurs because of heat transfer between hot glass and cold water, and due to blocking heat flux from reaching the glass directly. Heat is transferred from fire to the exposed layer of water film by radiation.

$$
T_{i(t+1)}=\frac{Q}{\rho_{W} C_{p W}} \Delta t+T_{i(t)}
$$

where $T_{i(t+1)}$ and $T_{i(t)}$ are the new and old temperature values of the first column layer of water film, $\rho_{W}$ is the density of water and $C_{p W}$ is the specific heat capacity of water.

(4) Heat is transferred from the first column layer of glass to adjacent layer of water film particles by convection using Eq. (12) to calculate the temperature drop in glass. However, the temperature increment in water film particles adjacent to hot 
glass surface is computed using Eq. (12) but replacing glass with water properties as follows:

$T_{i(t+1)}$

$=\frac{1}{\rho_{W} C_{p W}}\left(\sum_{j=1}^{N}\left(\alpha_{W} \frac{m_{j W}}{\rho_{j W}} T_{j}\left(\frac{\partial^{2}}{\partial x^{2}} W_{i j}(R, h)+\frac{\partial^{2}}{\partial y^{2}} W_{i j}(R, h)\right)\right)+Q\right) \times \Delta t$

$+T_{i(t)}$

where $\alpha_{W}$ is the thermal diffusivity of water, $m_{j W}$ is the mass of water particle and $\rho_{j W}$ is the density of nearby water particles $j$.

(5) Heat transferred by conduction from first exposed layer of water film particles, at $x=-0.5 \mathrm{~mm}$ in case of water film thickness equals $0.5 \mathrm{~mm}$, to all other layers of water film is computed using Eq. (14).

(6) The cooling process continues when heat is transferred from remaining hot layers of glass to the cold layers. This process can be described using Eq. (12). The continuous flow of water prevents evaporation but when the down-flowing velocity is very slow, the rate of evaporation increases.

The above procedures are repeated at each time step $(0.02 \mathrm{~s})$ until total simulation time (500 s) is covered. All material properties for glass and water are summarized in Table 1. The kernel radius $h$ employed in our SPH simulations between glass particles is 12 $\mathrm{mm}$ and $0.8 \mathrm{~mm}$ for water film particles. Fig. 3 shows the summary of temperature calculation procedures for glass and water film particles based on SPH model for each time step. Fig. 4 illustrates the sequence of radiation, convection and conduction occurring in glass cooling in our SPH formulation. All computations were carried out with an in-house MATLAB code. 


\section{Results and discussion}

\subsection{Validation}

To validate the numerical model described above, previous experiment measurements and commercial software packages results are compared with our SPH model. Down-flowing velocity and water film thickness equal to $0.645 \mathrm{~m} / \mathrm{s}$ and $0.5 \mathrm{~mm}$, respectively, are considered in the validation stage with heat flux variation shown in Fig. 2(b) [7].

Temperature variation with time at both exposed and ambient surfaces of glass pane measured from the experiment [7] and temperature values obtained from Ansysfluent are compared with SPH numerical results as shown in Fig. 5. Temperature increases until it reaches maximum value around $60{ }^{\circ} \mathrm{C}$ and $50{ }^{\circ} \mathrm{C}$ at exposed and unexposed surfaces respectively. The water film is released at $76 \mathrm{~s}$ and a sharp drop in glass pane temperature was observed. The temperature variation at $(x=0 \mathrm{~mm}, y=300$ $\mathrm{mm}$ ) and ( $x=6 \mathrm{~mm}, y=300 \mathrm{~mm}$ ) corresponding to points $\mathrm{P} 3$ (exposed) and P33 (ambient) are shown in Fig.5 (a) and Fig. 5(b) respectively. Our numerical simulation results in close agreement with experimental measurements in Ref. [7] and those obtained from Ansys-fluent, thus indicating the efficiency of our proposed SPH model. However, the temperature value measured by the experiment at P33 starts to increase again after $170 \mathrm{~s}$ and reaches a new maximum value at around $230 \mathrm{~s}$ (see Fig. 5(b)). The observed discrepancy between our SPH simulation and the experimental result can be attributed to the initiation of unseen cracks due to temperature difference between exposed and unexposed surfaces that cause some amount of heat to reach the ambient surface without conduction through glass section particularly when heat flux reaches its maximum value at $230 \mathrm{~s}$. 
Fig. 6 and Fig. 7 show the heat temperature map for entire glass pane at several time intervals obtained by using our SPH model and Ansys-fluent, respectively. Temperature distribution obtained from our SPH model and Ansys-fluent shows a similar trend, where the temperature of water film increases from the top (initial temperature) to the bottom of the glass. In general, the surface temperature of water film layer exposed to fire is higher than the temperature of the water film layer that is adjacent to the glass. Unless the temperature of glass is extremely high, in that case the absorbed heat by adjacent layers of water film at early stage of cooling is higher than the heat transferred to exposed water film layer. The drop in temperature during cooling decreases from exposed (at $x=0 \mathrm{~mm}$ ) to unexposed surface $(x=6 \mathrm{~mm})$ and from top $(y=600 \mathrm{~mm})$ to bottom $(y=0 \mathrm{~mm})$ of glass. Accordingly, the least influenced area from water film cooling is located at the bottom of unexposed surface of glass.

To further affirm the validity and efficiency of our SPH model, additional measurements of temperature variations obtained from the numerical model were compared with simulation results from Ansys-CFX and Autodesk-CFD software. Figs. 8(a-g) show the temperature variations at several other points (P3, P8, P13, P18, P23, P28 and P33) on the glass pane. The drop in temperature at the exposed surface (P3, Fig. 8(a)) is steeper when compared to unexposed surface (P33, Fig. 8(g)). We conclude that the time required for cooling increases when the distance from the exposed surface increases. All temperature values are also aligned indicating the robustness of the SPH model. Moreover, our SPH model is faster than the commercial software packages, for instance, single time step took only $0.107 \mathrm{~s}$ using our SPH model while it took around 8.5 s using Ansys-CFX on the same computer because Ansys-CFX requires 219303 elements and 443576 nodes to simulate the problem efficiently while our SPH model requires much fewer number of particles - around 3954 particles, 3721 particles for 
glass and 233 particles for down-flowing water film per second (when velocity equals $0.645 \mathrm{~m} / \mathrm{s})$. Accordingly, our SPH model overcomes fundamental drawback of using mesh-based methods (commercial software packages) by decreasing the computational efforts tremendously. By presenting our SPH model here, we hope to motivate adopting SPH method in the software development to solve similar problems.

A more detailed study about the effects of SPH parameters, kernel radius $h$ (glass) and the number of glass particles is carried out on the required computational time and accuracy of obtained results. We observed that the kernel radius $(h)$ of glass has little or no effect on the simulation results due to the nature of the problem examined. The kernel radius $(h)$ of glass is only used to compute the heat transfer between first layer of glass $(x=0 \mathrm{~mm})$ to the remaining glass particles $(x>0 \mathrm{~mm})$, where the critical stage is the heat transferring between the water film particles $(x=-0.1 \mathrm{~mm})$ to the first layer of glass particles $(x=0 \mathrm{~mm})$ by convection. The computational time increases from $0.049 \mathrm{~s}$ to $0.163 \mathrm{~s}$ when the number of glass particles increases as shown in Table 2 , the maximum time is recorded when the number of glass particles equals 5776 .

Fig. 9 shows temperature variation after applying water film within 20 seconds, where the temperature variations are very steep from $77 \mathrm{~s}$ to $97 \mathrm{~s}$ and the result differences are uppermost, using different numbers of glass particles $(2601,3721$, 5776,7056) at three points (P3, P18 and P33). As depicted in Fig. 9, all the results obtained are well aligned. However, the differences in temperature variation between SPH results at different numbers of glass particles decrease when the number of particles increases. We observed that the difference between experimental measurements and SPH results reduces with an increase in the number of glass particles in most time periods, for instance, at points P3 and P33 using 7056 glass particles, the SPH simulation with a higher number of glass particles gives better results, however, 
the overall difference in comparison to using fewer number of glass particles is not significant as shown in Fig. 9(a) and Fig. 9(c). A more detailed comparison is shown in Table 2, where the differences in temperature obtained by SPH model and experiment at $90 \mathrm{~s}$ for $\mathrm{P} 3$ are $0.2 \%$ and $0.45 \%$ when glass particles are 5776 and 3721 , respectively. Moreover, the additional computational cost time caused by increasing the glass particles more than 3721 limits the usage of a higher number of glass particles. The same previous observation is drawn on P33 between Ansys-CFX, Autodesk-CFD and SPH model results.

Following the successful validation of our SPH model, it was then employed to predict the temperature distribution of glass at different cases of heat flux variation, thickness and down-flowing velocity of the water film.

\subsection{Down-flowing velocity}

Our numerical model is utilized to examine the effects of the down-flowing velocity of water film on temperature distribution of glass. We considered two cases of down-flowing velocity of the water film at $0.4 \mathrm{~m} / \mathrm{s}$ and $0.8 \mathrm{~m} / \mathrm{s}$. Figs. 10 and 11 show the heat map temperature of glass after applying water film when down-flowing velocity equals $0.4 \mathrm{~m} / \mathrm{s}$ and $0.8 \mathrm{~m} / \mathrm{s}$, respectively. Fig. 10 shows that the temperature difference between glass particles at the same $x$-coordinate is less than the temperature difference shown in Fig. 11. However, the temperature difference between glass particles at the same $y$-coordinate decreases when velocity increases from $0.4 \mathrm{~m} / \mathrm{s}$ to $0.8 \mathrm{~m} / \mathrm{s}$. Also, the average temperature values at the glass mid-section $(2 \mathrm{~mm}<x<4$ $\mathrm{mm}, 200 \mathrm{~mm}<y<400 \mathrm{~mm}$ ) are around $42{ }^{\circ} \mathrm{C}$ and $34{ }^{\circ} \mathrm{C}$ at $100 \mathrm{~s}$ when water film velocity equals $0.4 \mathrm{~m} / \mathrm{s}$ and $0.8 \mathrm{~m} / \mathrm{s}$, respectively. Accordingly, the temperature drops by about $23.5 \%$ at $100 \mathrm{~s}$ when water film velocity increases by double. 
Figs. 12 and 13 show the temperature variation with time after applying water film at some selected points when water film velocity equals $0.4 \mathrm{~m} / \mathrm{s}$ and $0.8 \mathrm{~m} / \mathrm{s}$, respectively. It is clear that when down-flowing velocity of water film increases, the temperature decreases furthermore. For instance, the temperature at point P18 drops from $56{ }^{\circ} \mathrm{C}$ to $39{ }^{\circ} \mathrm{C}$ when the velocity of water film equals to $0.4 \mathrm{~m} / \mathrm{s}$, while it drops from $56{ }^{\circ} \mathrm{C}$ to $31^{\circ} \mathrm{C}$ when the velocity equals to $0.8 \mathrm{~m} / \mathrm{s}$ as shown in Fig. 12(b) and Fig. 13(b). When the down-flowing velocity of water film increases, the exposure time of the water film to heat is lower, thus the temperature of water film is lower when compared with lower down-flowing velocity. The temperature of down-flowing water film plays a vital role in the thermal behavior of glass. Accordingly, the temperature drop in glass increases when the water film temperature decreases.

\subsection{Heat flux}

To investigate the influence of heat flux on temperature distribution in glass, two additional heat flux variation curves with time were obtained by multiplying the heat flux variation curve with time used in the experiment (Fig. 2(b)) with factors 1.2 and 0.8. These new additional heat flux variations with time have a maximum heat flux value of $18 \mathrm{~kW} \cdot \mathrm{m}^{-2}$ and $12 \mathrm{~kW} \cdot \mathrm{m}^{-2}$, respectively. Figs. 13 and 14 show the heat map temperature of glass after applying water film when maximum heat flux equals 18 $\mathrm{kW} \cdot \mathrm{m}^{-2}$ and $12 \mathrm{~kW} \cdot \mathrm{m}^{-2}$, respectively. When heat flux variation increases, the temperature also increases as shown in Figs. 15 and 16. For example, temperature increments at points P18 $(y=300 \mathrm{~mm})$ and P20 $(y=100 \mathrm{~mm})$ due to increasing heat flux from $12 \mathrm{~kW} \cdot \mathrm{m}^{-2}$ to $18 \mathrm{~kW} \cdot \mathrm{m}^{-2}$ are approximately $3{ }^{\circ} \mathrm{C}$ and $7^{\circ} \mathrm{C}$, respectively, refer to Figs. 16(b) and 17(b). We can conclude that upper parts of glass $(y>300 \mathrm{~mm})$ are affected more by the heat flux increment than the lower parts $(y<300 \mathrm{~mm})$. 


\subsection{Water film thickness}

Our SPH model was also employed to examine the effects of increasing water film thickness. Fig. 18 shows the heat map temperature of glass for water film thickness equals to $0.8 \mathrm{~mm}$. When water film thickness increases from $0.5 \mathrm{~mm}$ (verification stage) to $0.8 \mathrm{~mm}$, the overall reduction in glass temperature increases as shown in Fig. 19 because there are more water layers which in turn protects the glass. For instance, the temperature at point $\mathrm{P} 18$ (center of glass) drops until it reaches $30{ }^{\circ} \mathrm{C}$ and $33{ }^{\circ} \mathrm{C}$ after 55 seconds from applying water film when its thickness equals $0.8 \mathrm{~mm}$ and $0.5 \mathrm{~mm}$, respectively.

In all numerical model simulations described above, the temperature of the glass drops sharply at point locations near the exposed surface when compared with far point locations. However, the overall reduction in glass temperature is higher in the upper section $(y>300 \mathrm{~mm})$ of the glass in comparison with its lower section $(y<300 \mathrm{~mm})$ because the water film temperature increases as it flows from the top to bottom of glass.

\section{Concluding remarks}

In this study, we presented a new attempt to comprehensively simulate heat transfer during a fire and how glass panes are protected with down-flowing water film using the smoothed particle hydrodynamics ( $\mathrm{SPH})$ method. Heat transfer equation was discretized for both glass and water film particles using SPH method whilst taking into consideration all the three known heat transfer modes - radiation, convection and conduction.

The resulting model was tested by comparing experiment measurements from the literature with our numerical results. Additionally, our SPH model is faster to produce similar simulation results than obtained from Ansys-fluent, Ansys-CFX and Autodesk- 
CFD. Moreover, the effects of SPH parameters like the number of glass particles on both computational time and accuracy of obtained results are examined.

The validated model was then employed to simulate glass cooling mechanism due to down-flowing water film under fire scenarios and configurations. Our numerical results show that glass temperature can be decreased by increasing the velocity and thickness of the down-flowing water film. For instance, average percentage of temperature drop in glass is about $23.5 \%$ at middle sector $(2 \mathrm{~mm}<x<4 \mathrm{~mm}, 200 \mathrm{~mm}$ $<y<400 \mathrm{~mm}$ ) when velocity of water film increases from $0.4 \mathrm{~m} / \mathrm{s}$ to $0.8 \mathrm{~m} / \mathrm{s}$ (double) at $100 \mathrm{~s}$. Conversely, the overall glass temperature increases when heat flux variation increases. The efficiency of the water film system can be enhanced with a proper combination of velocity and thickness of water film for each heat flux variation by using our SPH model.

Additional work is underway to derive a new set of empirical equations that can describe the mathematical relationship between different physical parameters (such as heat flux, water film release time, down-flowing velocity and thickness of water film) and temperature distribution of both glass and water film.

\section{Acknowledgements}

The authors gratefully acknowledge the supports provided by the Research Grants Council of the Hong Kong Special Administrative Region, China (Project No. 9042644, CityU 11205518). The first author, D.A. Abdoh, acknowledges the UGC-Postgraduate Studentship awarded by the Hong Kong Government to support his PhD program in the Department of Architecture and Civil Engineering, City University of Hong Kong, Hong Kong, China.

Declarations of interest: None 


\section{References}

[1] W.C. Hu, S.D. Nurcholik, S.K. Lee, T.H. Lin, Evaluations on heat resistance of curtains with water film in a fire, J. Chinese Inst. Eng. Trans. Chinese Inst. Eng. A/Chung-Kuo K. Ch'eng Hsuch K'an. 39 (2016) 615-622. https://doi.org/10.1080/02533839.2016.1146092.

[2] C. Bedon, Structural Glass Systems under Fire: Overview of Design Issues, Experimental Research, and Developments, Adv. Civ. Eng. $2017 \quad$ (2017). https://doi.org/10.1155/2017/2120570.

[3] Y. Wang, Q. Wang, J.X. Wen, J. Sun, Investigation of thermal breakage and heat transfer in single, insulated and laminated glazing under fire conditions, Appl. Therm. Eng. 125 (2017) 662-672. https://doi.org/10.1016/j.applthermaleng.2017.07.019.

[4] Y. Wang, Q. Wang, G. Shao, H. Chen, Y. Su, J. Sun, L. He, Fracture behavior of a fourpoint fixed glass curtain wall under fire conditions, Fire Saf. J. 67 (2014) 24-34. https://doi.org/10.1016/j.firesaf.2014.05.002.

[5] Y. Wang, Q. Wang, G. Shao, H. Chen, Y. Su, J. Sun, L. He, J.X. Wen, R. Zong, Experimental study on thermal breakage of four-point fixed glass façade, Fire Saf. Sci. 11 (2014) 666-676. https://doi.org/10.3801/IAFSS.FSS.11-666.

[6] C.W. Wu, T.H. Lin, Full-scale evaluations on heat resistance of glass panes incorporated with water film or sprinkler in a room fire, Build. Environ. 42 (2007) 3277-3284. https://doi.org/10.1016/j.buildenv.2006.08.017.

[7] Q. Wang, G. Shao, Y. Wang, H. Zhao, J. Sun, L. He, Thermal breakage and fallout behaviors of non-tempered glass under the effect of water film, J. Fire Sci. 33 (2015) 390-404. https://doi.org/10.1177/0734904115599668.

[8] G. Shao, Q. Wang, H. Zhao, Y. Wang, H. Chen, Y. Su, J. Sun, L. He, Maximum temperature to withstand water film for tempered glass exposed to fire, Constr. Build. Mater. 57 (2014) 1523. https://doi.org/10.1016/j.conbuildmat.2014.01.094.

[9] C.W. Wu, T.H. Lin, M.Y. Lei, T.H. Chung, C.C. Huang, W.T. Chiang, Fire resistance tests of a glass pane with down-flowing water film, J. Chinese Inst. Eng. Trans. Chinese Inst. Eng. 
A/Chung-Kuo K. Ch'eng Hsuch K'an. 31 (2008) 737-744. https://doi.org/10.1080/02533839.2008.9671428.

[10] J. Argyris, J. Szimmat, An analysis of temperature radiation interchange problems, Comput. Methods Appl. Mech. Eng. 94 (1992) 155-180. https://doi.org/10.1016/00457825(92)90145-A.

[11] K. Masashi, T. Hidetosi, T. Masataka, Boundary element analysis of nonlinear transient heat conduction problems, Comput. Methods Appl. Mech. Eng. 62 (1987) 321-329. https://doi.org/10.1016/0045-7825(87)90066-1.

[12] H.T. Chen, S.K. Lee, Estimation of heat-transfer characteristics on the hot surface of glass pane with down-flowing water film, Build. Environ. 45 (2010) 2089-2099. https://doi.org/10.1016/j.buildenv.2010.03.005.

[13] L.W. Zhang, A.S. Ademiloye, K.M. Liew, Meshfree and Particle Methods in Biomechanics: Prospects and Challenges, Arch. Comput. Method E. 26 (2019) 1547-1576. https://doi.org/10.1007/s11831-018-9283-2.

[14] J.M. Hyman, Numerical methods for tracking interfaces, Phys. D Nonlinear Phenom. 12 (1984) 396-407. https://doi.org/10.1016/0167-2789(84)90544-X.

[15] J.M. Floryan, H. Rasmussen, Numerical methods for viscous flows with moving boundaries, Appl. Mech. Rev. 42 (1989) 323-341. https://doi.org/10.1115/1.3152416.

[16] G.W. Wei, Y.B. Zhao, Y. Xiang, Discrete singular convolution and its application to the analysis of plates with internal supports. Part 1: Theory and algorithm, Int. J. Numer. Methods Eng. (2002) 913-946. https://doi.org/10.1002/nme.526.

[17] Y. Xiang, Y.B. Zhao, G.W. Wei, Discrete singular convolution and its application to the analysis of plates with internal supports. Part 2: Applications, Int. J. Numer. Methods Eng. (2002) 947-971. https://doi.org/10.1002/nme.527. 
[18] P. Zhuang, Y.T. Gu, F. Liu, I. Turner, P.K.D.V. Yarlagadda, Time-dependent fractional advection-diffusion equations by an implicit MLS meshless method, Int. J. Numer. Methods Eng. (2011) 1346-1362 . https://doi.org/10.1002/nme.3223.

[19] Q. Liu, F. Liu, Y.T. Gu, P. Zhuang, J. Chen, I. Turner, A meshless method based on Point Interpolation Method (PIM) for the space fractional diffusion equation, Appl. Math. Comput. (2015) 930-938. https://doi.org/10.1016/j.amc.2015.01.092.

[20] Z.J. Meng, H. Cheng, L.D. Ma, Y.M. Cheng, The hybrid element-free Galerkin method for three-dimensional wave propagation problems, Int. J. Numer. Methods Eng. 117 (2019) 15-37. https://doi.org/10.1002/nme.5944.

[21] F. Liu, Y. Cheng, The Improved Element-Free Galerkin Method Based on the Nonsingular Weight Functions for Inhomogeneous Swelling of Polymer Gels, Int. J. Appl. Mech. 10 (4) (2018). https://doi.org/10.1142/S1758825118500473.

[22] F. Liu, Q. Wu, Y. Cheng, A meshless method based on the nonsingular weight functions for elastoplastic large deformation problems, Int. J. Appl. Mech. 11 (1) (2019). https://doi.org/10.1142/S1758825119500066.

[23] S. Härdi, M. Schreiner, U. Janoske, Simulating thin film flow using the shallow water equations and smoothed particle hydrodynamics, Comput. Methods Appl. Mech. Eng. 358 (2020) 112639. https://doi.org/10.1016/j.cma.2019.112639.

[24] T. Heck, B. Smeets, S. Vanmaercke, P. Bhattacharya, T. Odenthal, H. Ramon, H. Van Oosterwyck, P. Van Liedekerke, Modeling extracellular matrix viscoelasticity using smoothed particle hydrodynamics with improved boundary treatment, Comput. Methods Appl. Mech. Eng. 322 (2017) 515-540. https://doi.org/10.1016/j.cma.2017.04.031.

[25] R. Rook, M. Yildiz, S. Dost, Modeling transient heat transfer using SPH and implicit time integration, Numer. Heat Transf. Part B Fundam. 51 (2007) 1-23. https://doi.org/10.1080/10407790600762763. 
[26] J.H. Jeong, M.S. Jhon, J.S. Halow, J. Van Osdol, Smoothed particle hydrodynamics: Applications to heat conduction, Comput. Phys. Commun. 153 (2003) 71-84. https://doi.org/10.1016/S0010-4655(03)00155-3.

[27] D. Schnabel, E. Özkaya, D. Biermann, P. Eberhard, Modeling the motion of the cooling lubricant in drilling processes using the finite volume and the smoothed particle hydrodynamics methods, Comput. Methods Appl. Mech. Eng. 329 (2018) 369-395. https://doi.org/10.1016/j.cma.2017.09.015.

[28] R.A. Gingold, J.J. Monaghan, Smoothed particle hydrodynamics: Theory and application to non-spherical stars, Mon. Not. R. Astron. Soc. 181 (1977) 375-89.

[29] G.R. Liu, M.B. Liu, Smoothed Particle Hydrodynamics: A Meshfree Particle Method, World Sci. Publishing Co. Pte. Ltd. Chapter 2 \& Chapter 3 (2003).

[30] L. Wang, F. Xu, Y. Yang, J. Wang, A dynamic particle refinement strategy in Smoothed Particle Hydrodynamics for Fluid-Structure Interaction problems, Eng. Anal. Bound. Elem. 100 (2019) 140-149. https://doi.org/10.1016/j.enganabound.2018.01.012.

[31] R. Vignjevic, J. Campbell, J. Jaric, S. Powell, Derivation of SPH equations in a moving referential coordinate system, Comput. Methods Appl. Mech. Eng. 198 (2009) 2403-2411. https://doi.org/10.1016/j.cma.2009.02.027.

[32] J.L. Cercos-Pita, M. Antuono, A. Colagrossi, A. Souto-Iglesias, SPH energy conservation for fluid-solid interactions, Comput. Methods Appl. Mech. Eng. 317 (2017) 771-791. https://doi.org/10.1016/j.cma.2016.12.037.

[33] M.B. Liu, G.R. Liu, Smoothed particle hydrodynamics (SPH): An overview and recent developments, 2010. https://doi.org/10.1007/s11831-010-9040-7.

[34] M.B. Liu, G.R. Liu, K.Y. Lam, Constructing smoothing functions in smoothed particle hydrodynamics with applications, J. Comput. Appl. Math. 155 (2003) 263-284. https://doi.org/10.1016/S0377-0427(02)00869-5

[35] M. Liu, Z. Zhang, Smoothed particle hydrodynamics (SPH) for modeling fluid-structure interactions, Sci. China Physics, Mech. Astron. $62 \quad$ (2019) 984701. https://doi.org/10.1007/s11433-018-9357-0. 
Figures

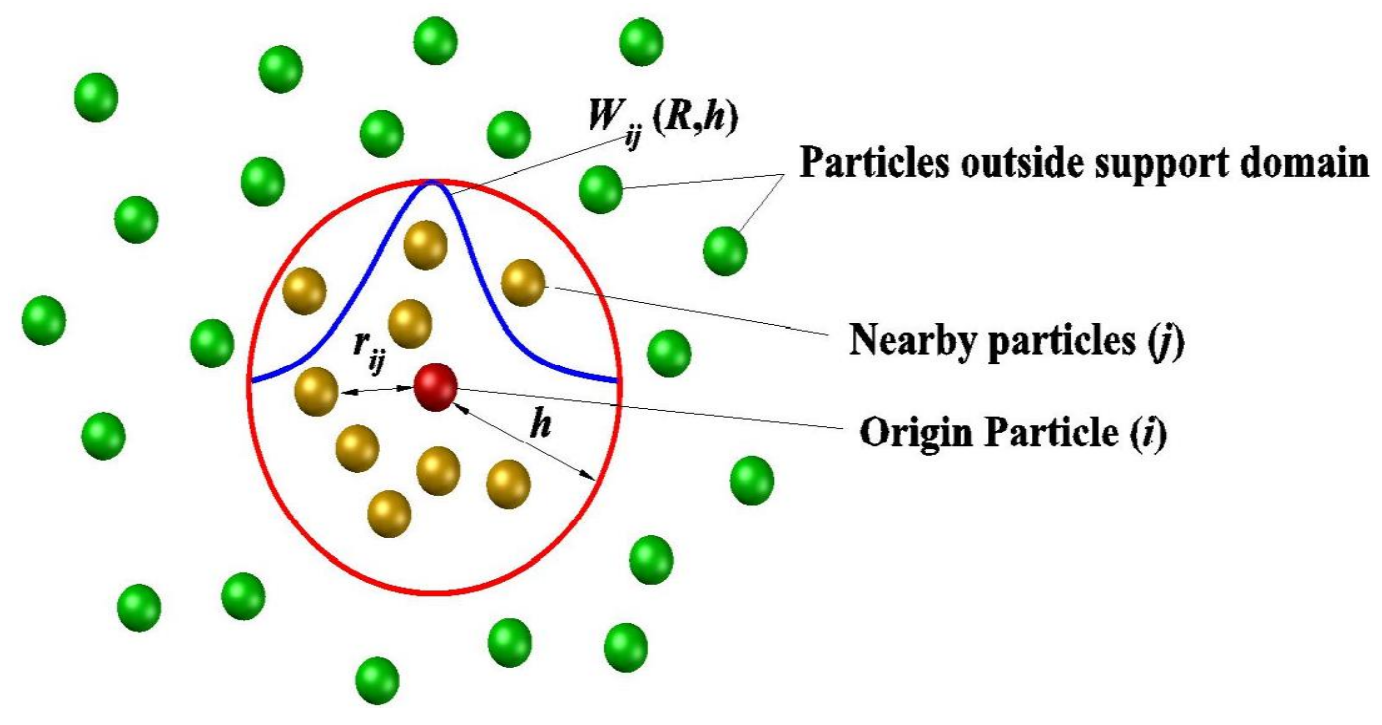

Fig. 1. SPH illustration diagram in 2D. The red circle is the support domain of origin particle $i$, the influence of nearby particles $j$ is weighted by kernel function $W_{i j}(R, h)$.

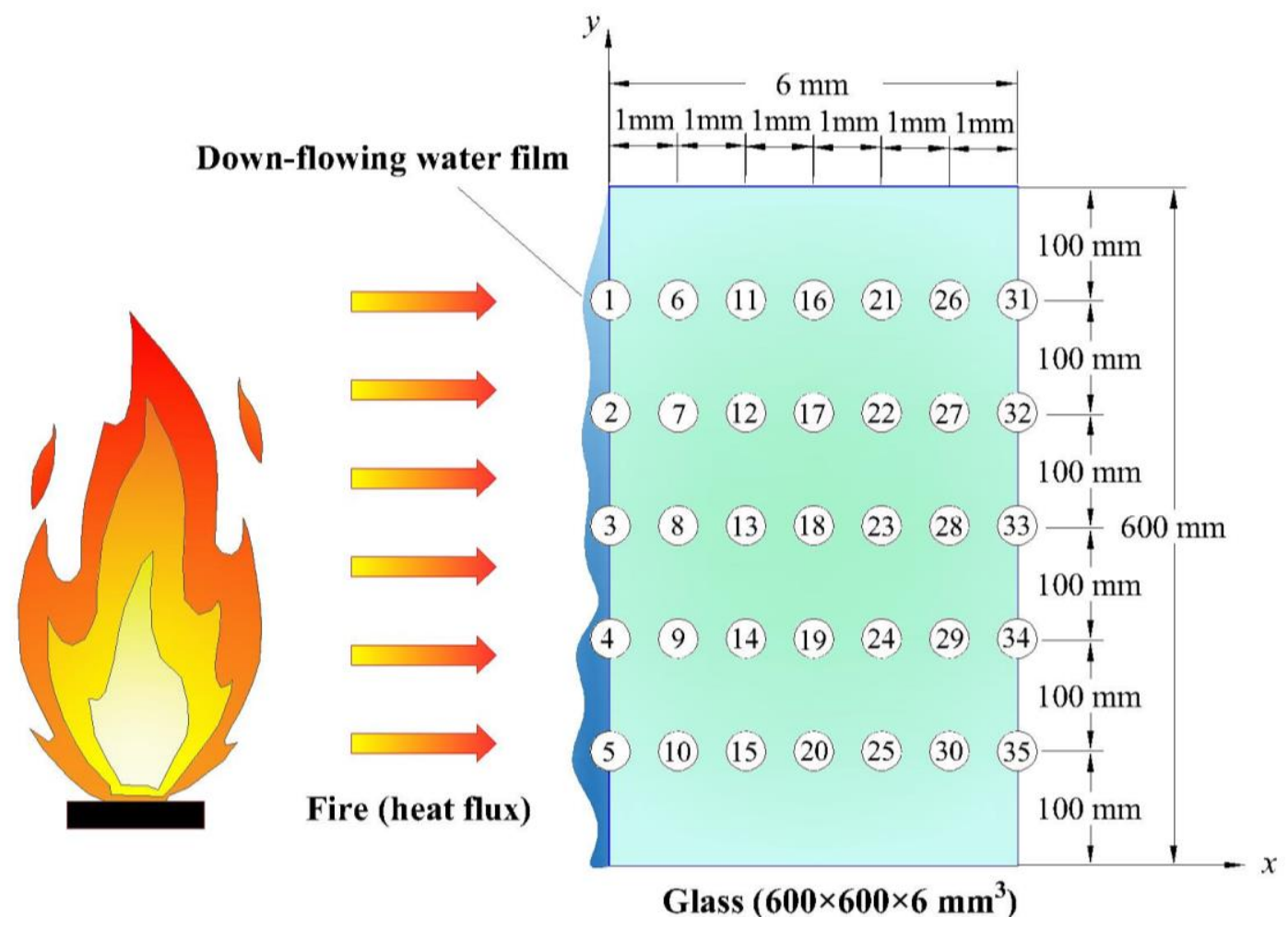

(a) 


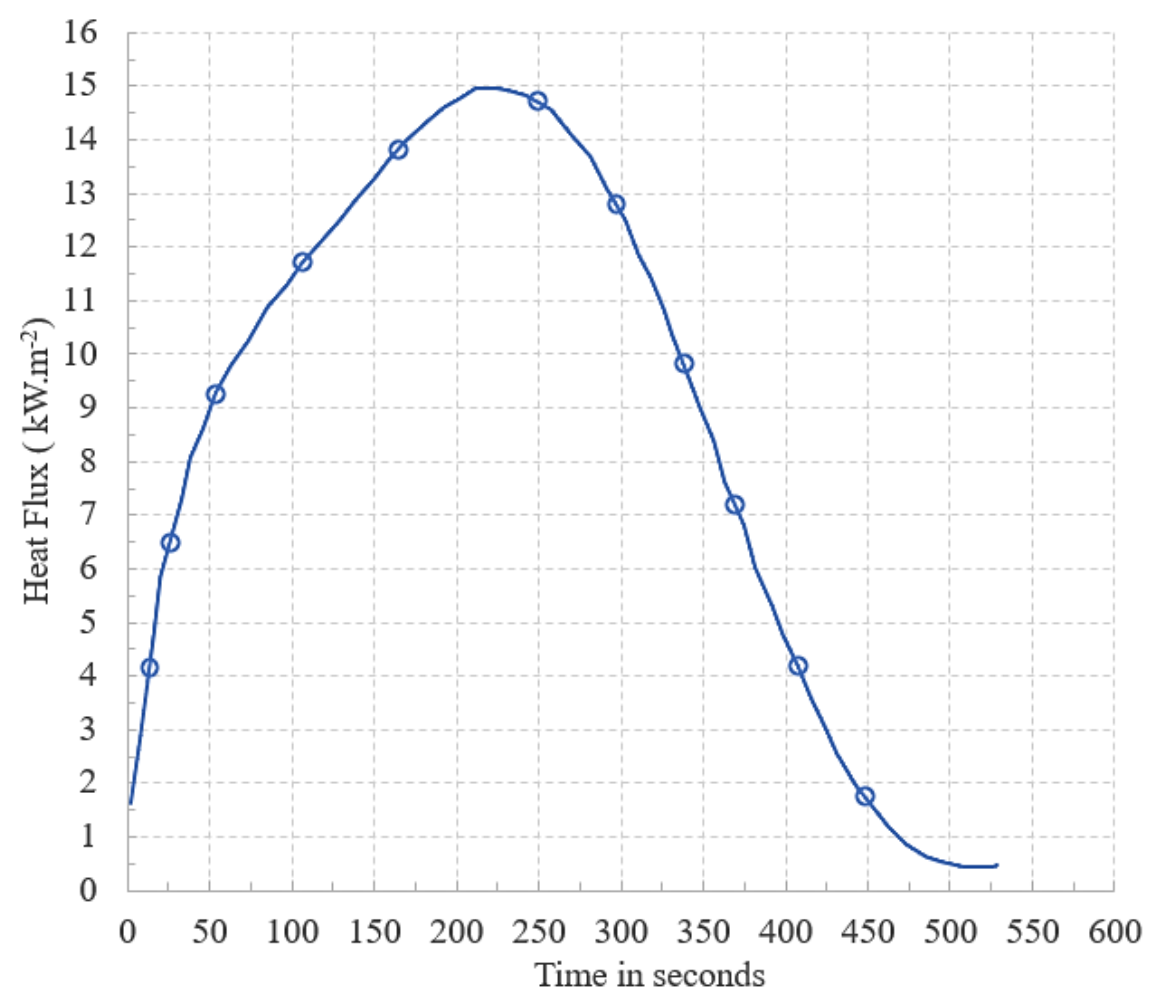

(b)

Fig. 2. Problem description diagram: (a) Geometry diagram which shows 35 points of interest on the glass pane section, the origin of the coordinate system is located below point No. (5) by $100 \mathrm{~mm}$. Water flows down from top $(y=600 \mathrm{~mm})$ to below $(y=0.0$ $\mathrm{mm}$ ); (b) Heat flux variation with time used in the verification stage, the maximum heat flux value equals approximately $15 \mathrm{~kW} \cdot \mathrm{m}^{-2}$. 


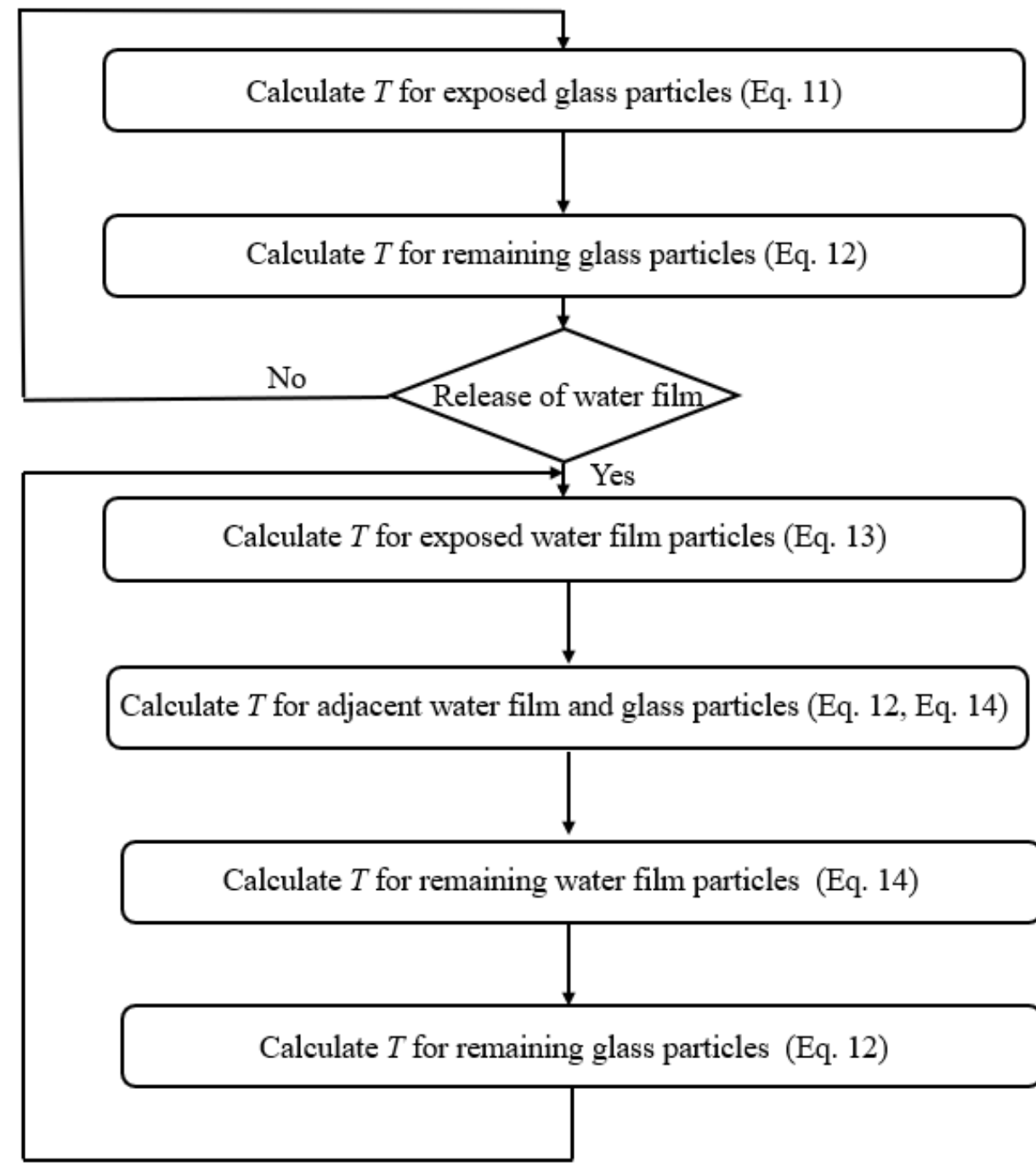

Fig. 3. Flowchart showing all procedures for a time step in the SPH simulation. The first two calculations are carried only until water film is released, the remaining calculation steps are responsible for cooling. 


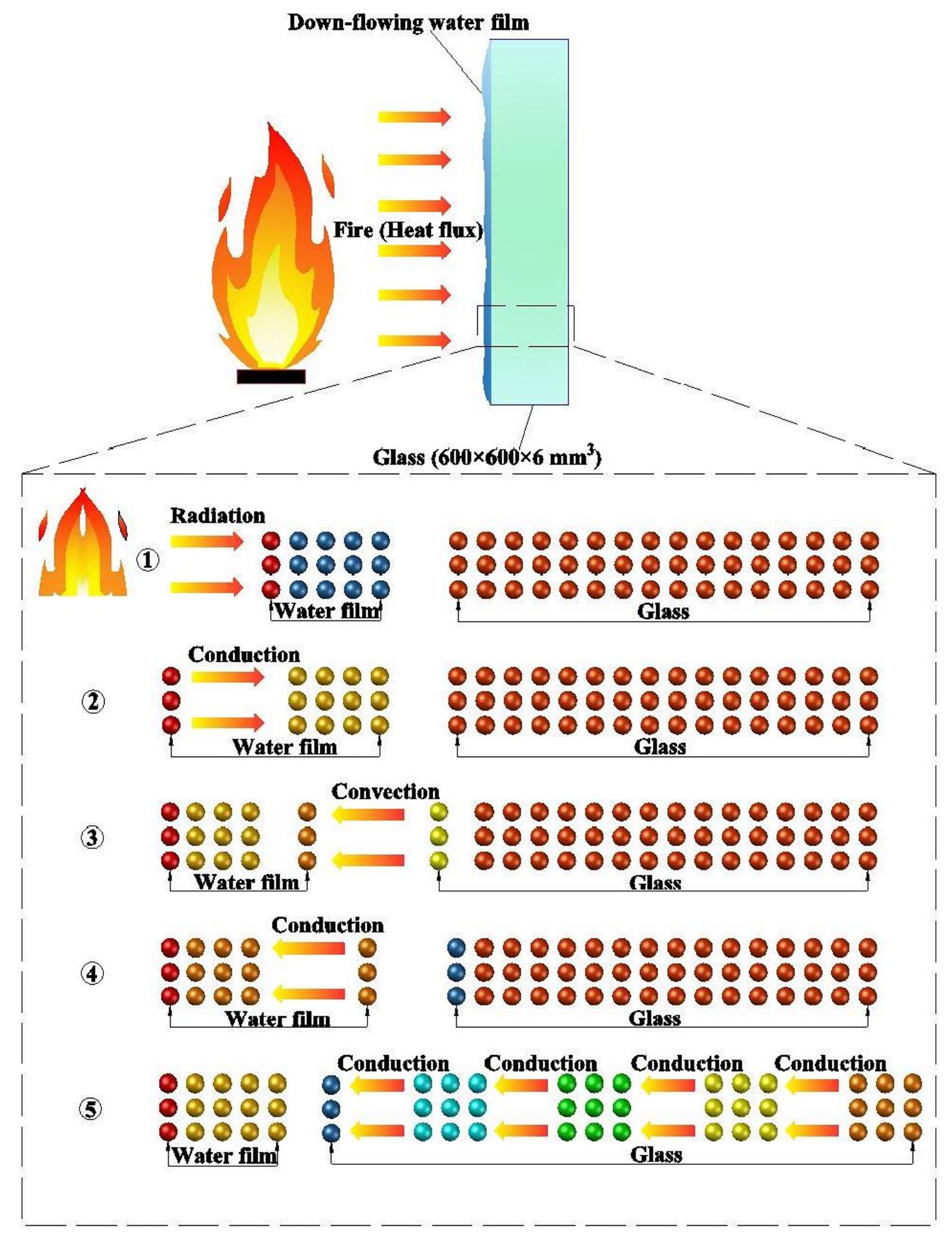

Fig. 4. Glass cooling mechanism of down-flowing water film used in the SPH model. Heat transfer by radiation, convection and conduction are occurring in the order shown. 


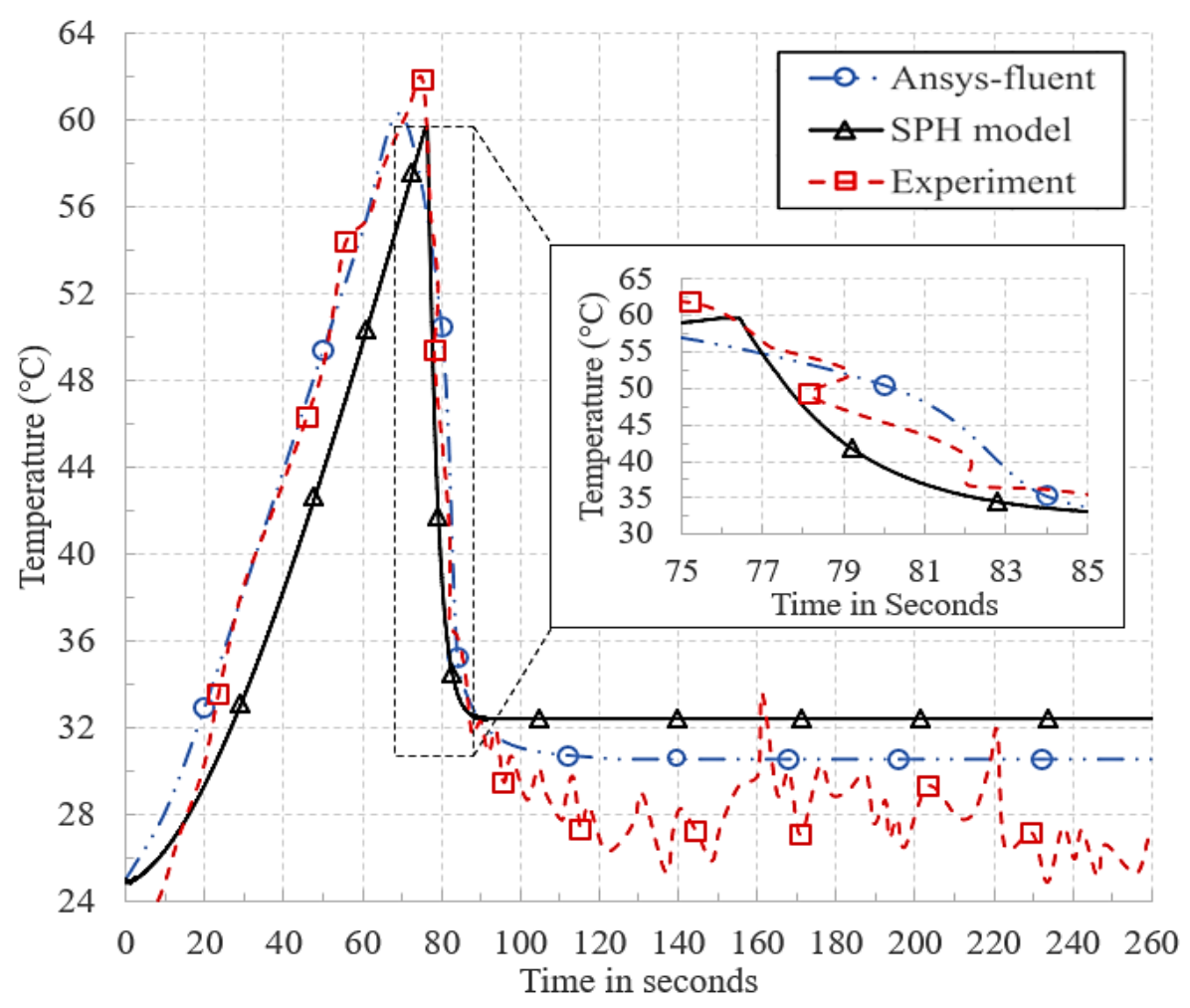

(a)

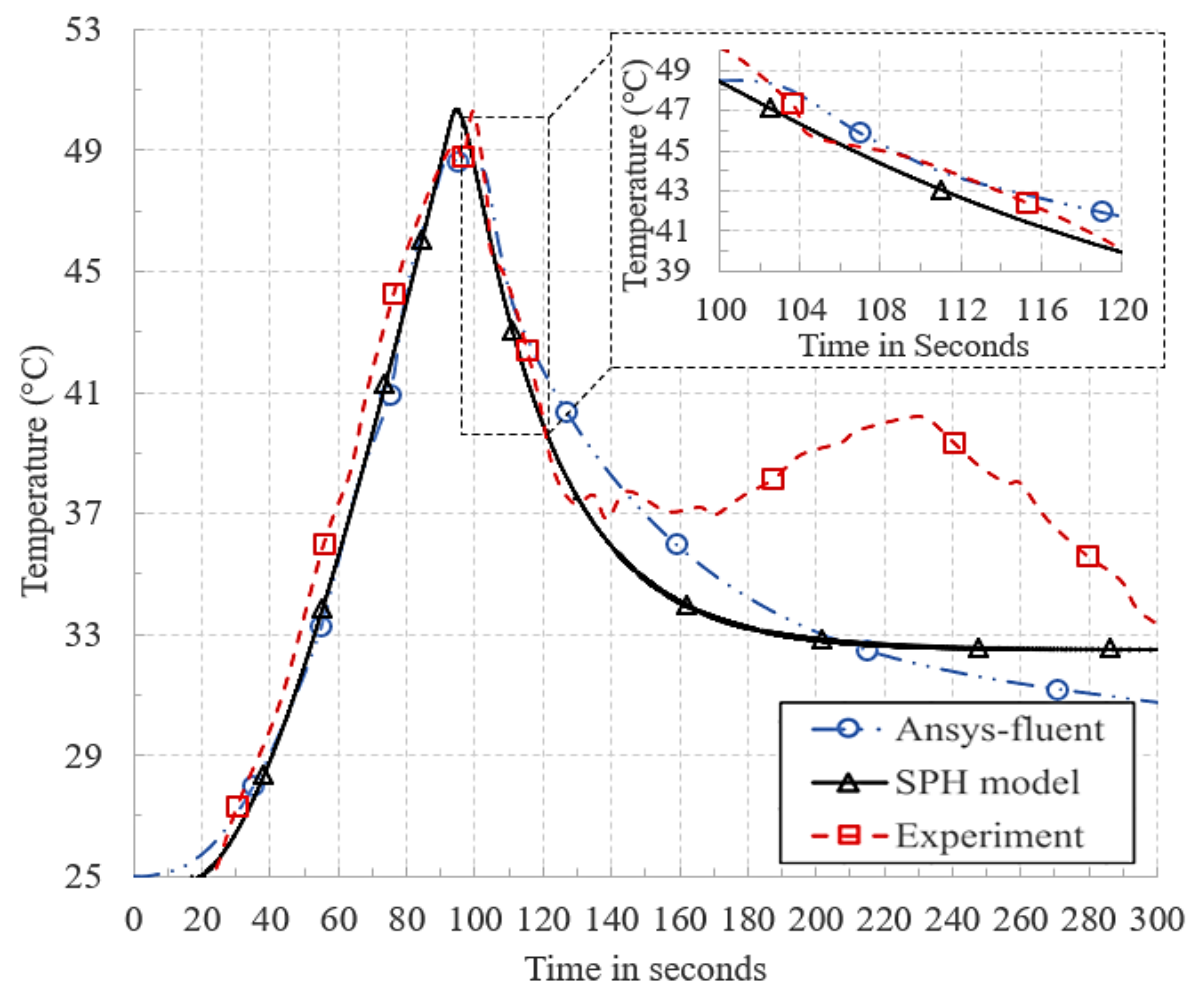

(b)

Fig. 5. Temperature variation with time using SPH model, Ansys-Fluent and experiment: (a) At point P3 (exposed surface); (b) At Point P33 (ambient surface). 
Temperature $\left({ }^{\circ} \mathrm{C}\right)$

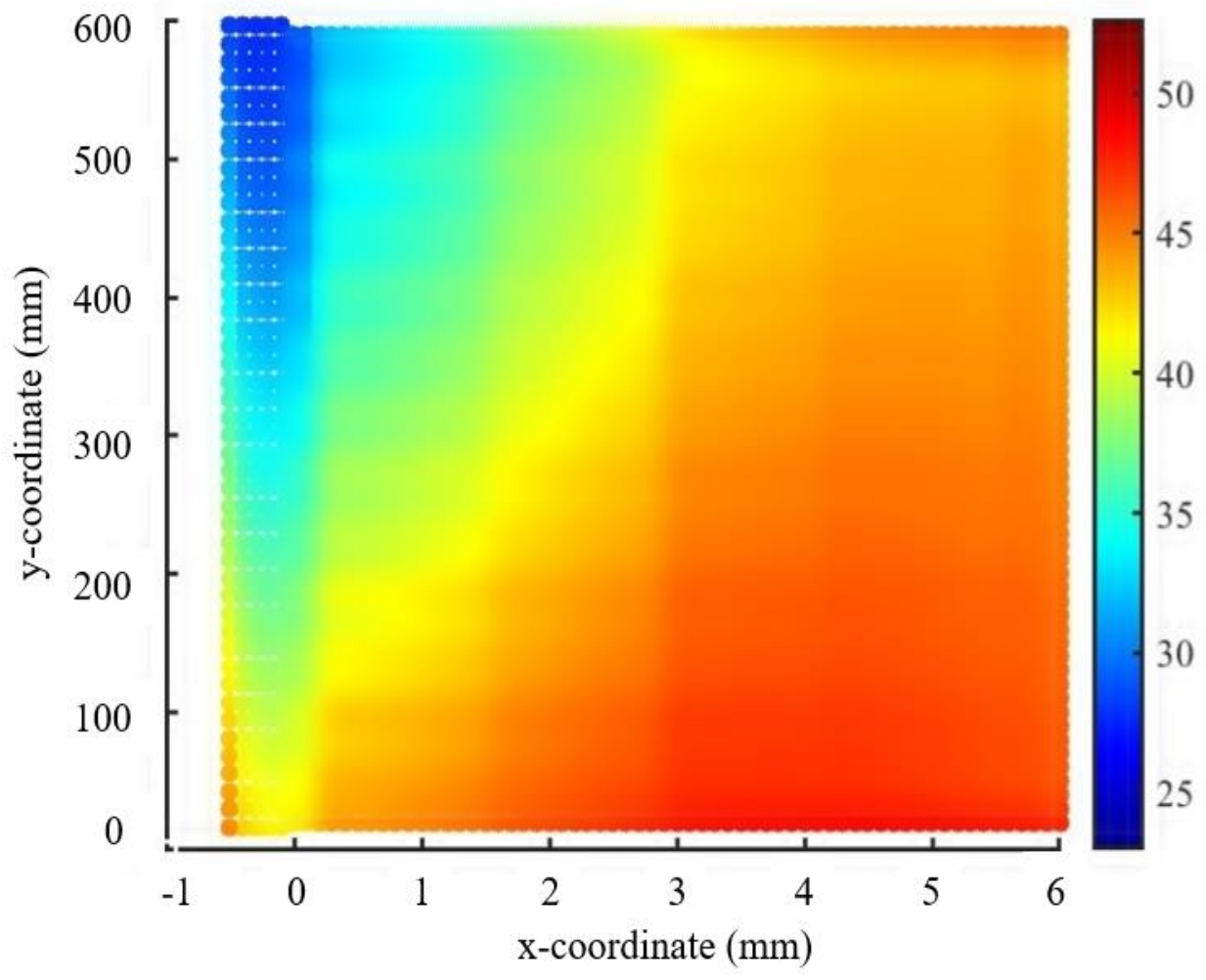

(a)

Temperature $\left({ }^{\circ} \mathrm{C}\right)$

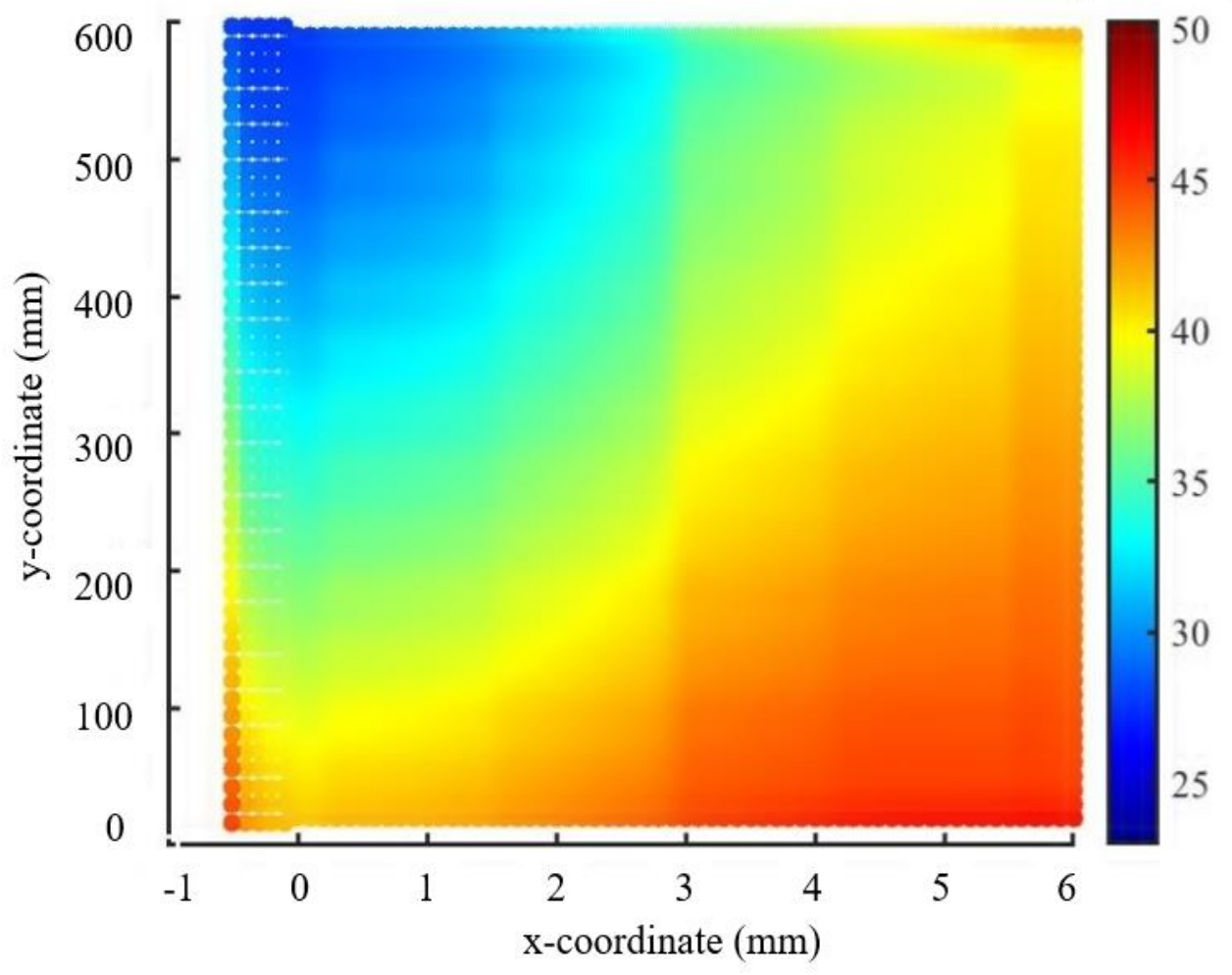

(b) 
Temperature $\left({ }^{\circ} \mathrm{C}\right)$

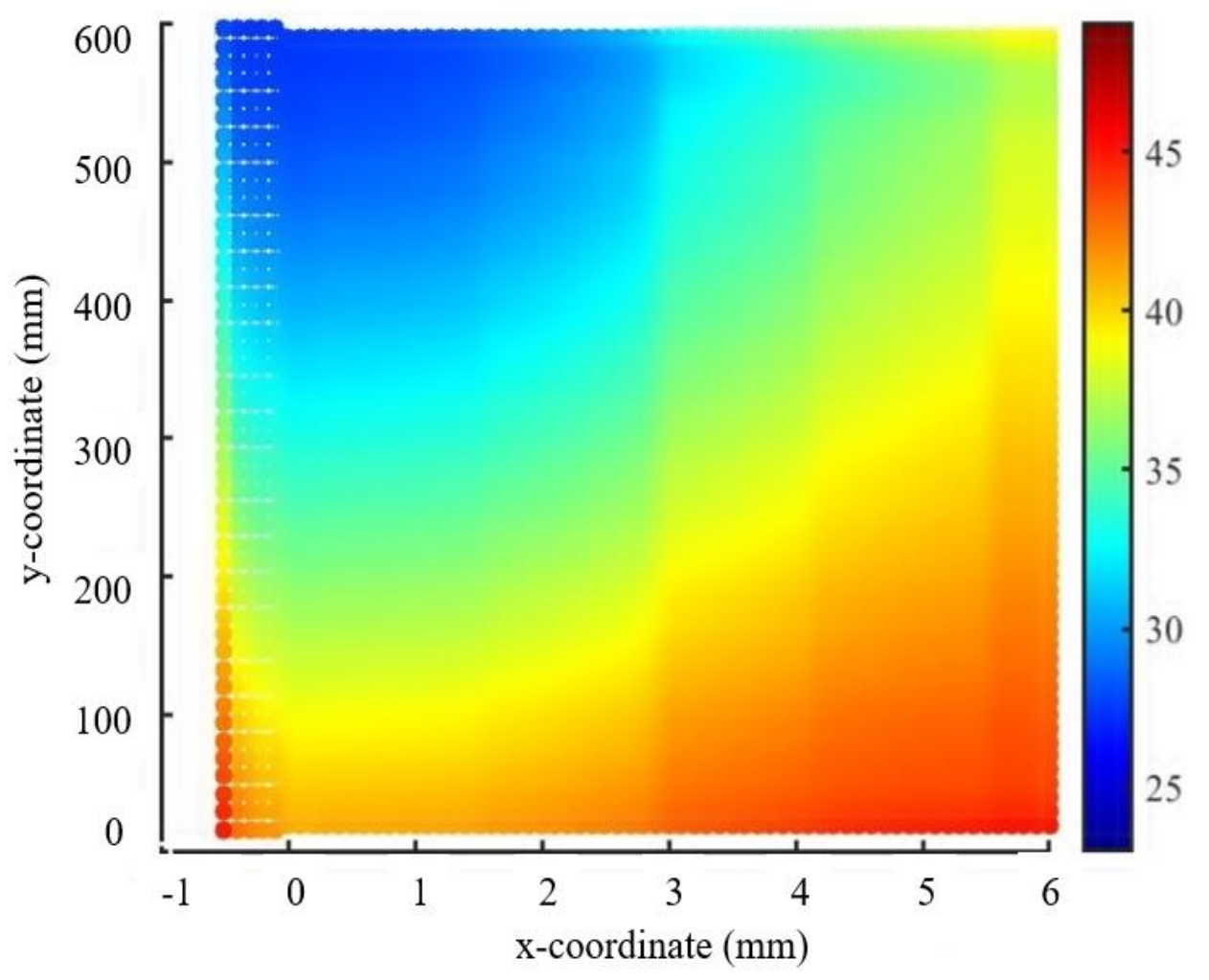

(c)

Temperature $\left({ }^{\circ} \mathrm{C}\right)$

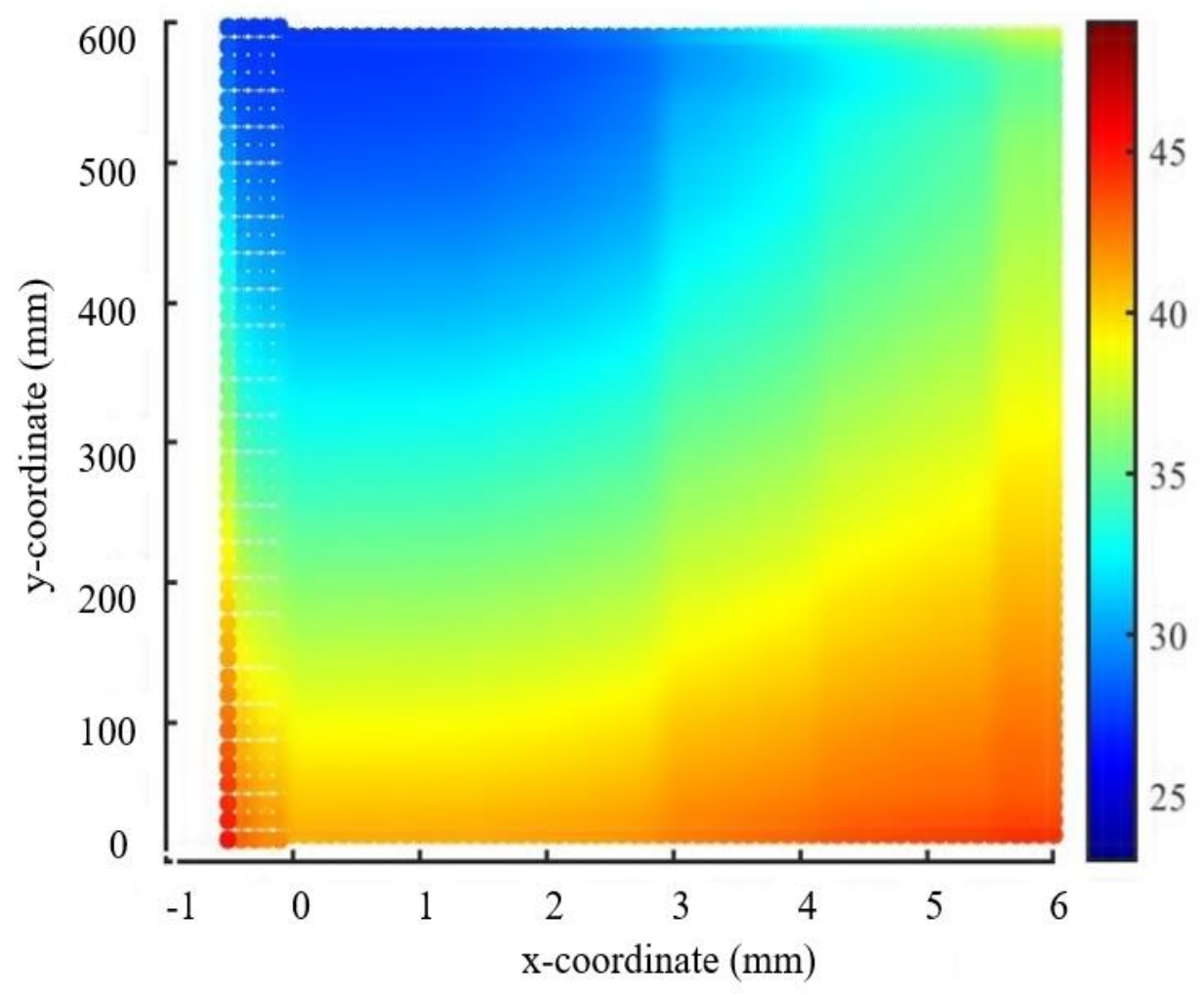

(d) 


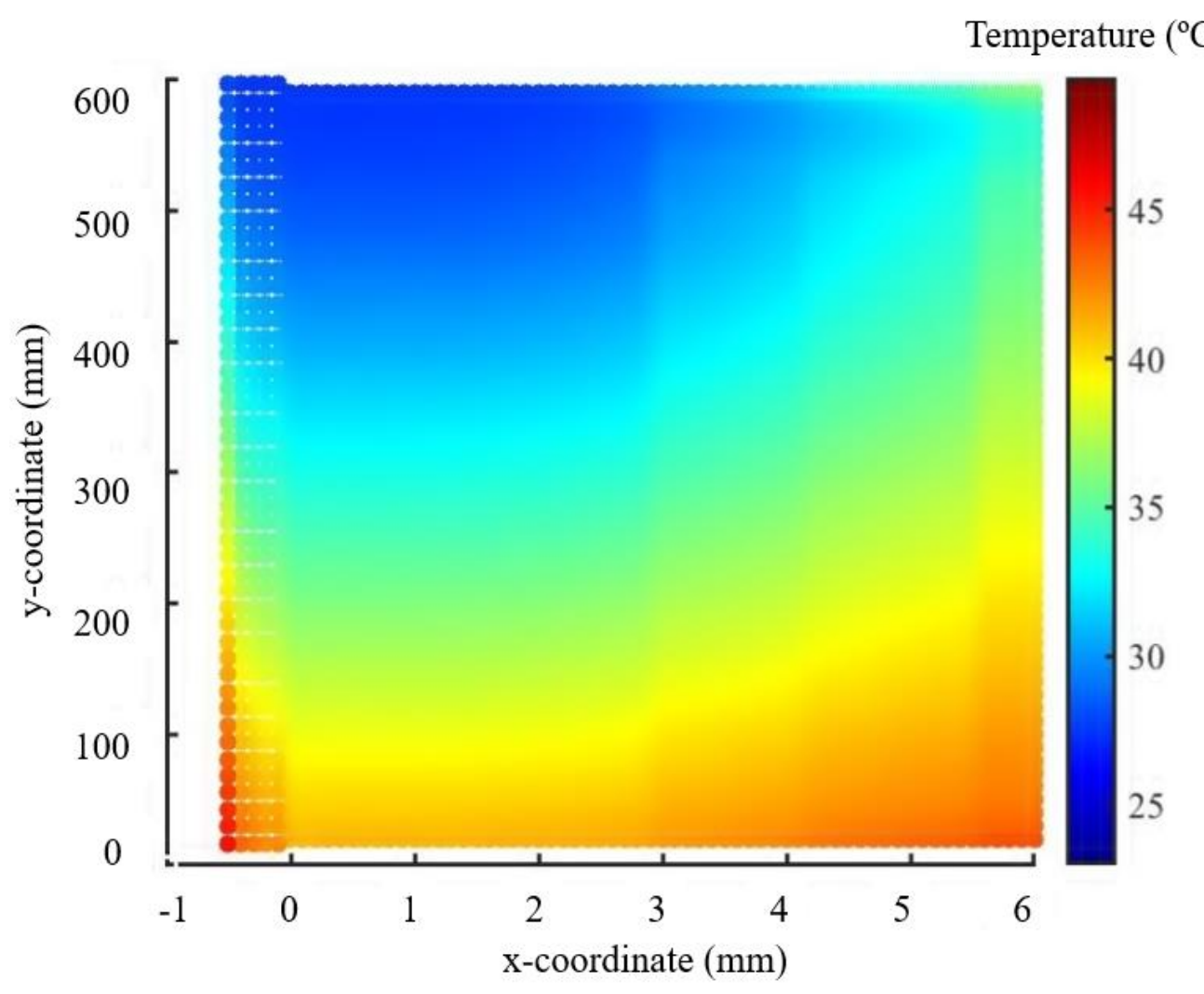

(e)

Temperature $\left({ }^{\circ} \mathrm{C}\right)$

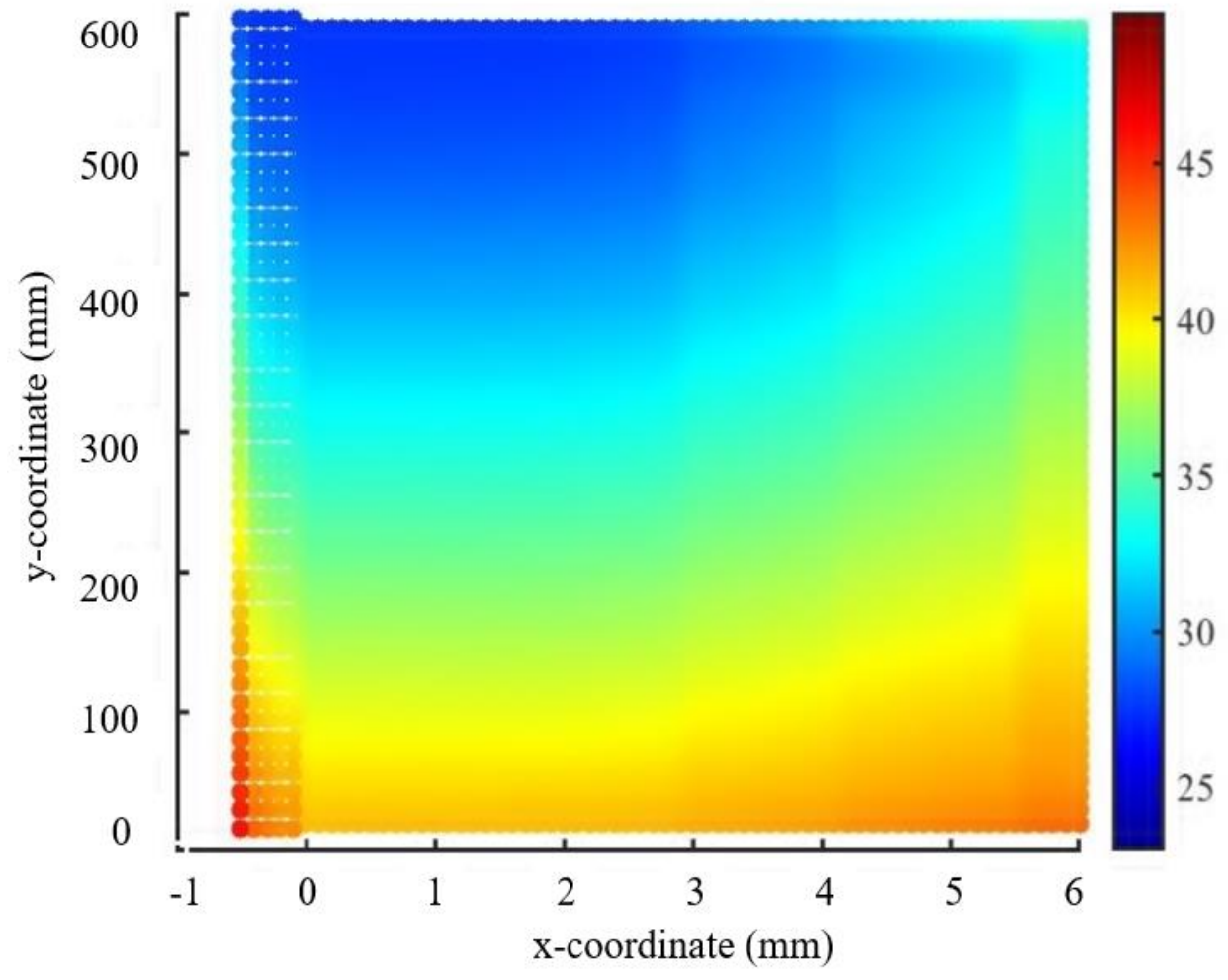

(f) 
Temperature $\left({ }^{\circ} \mathrm{C}\right)$

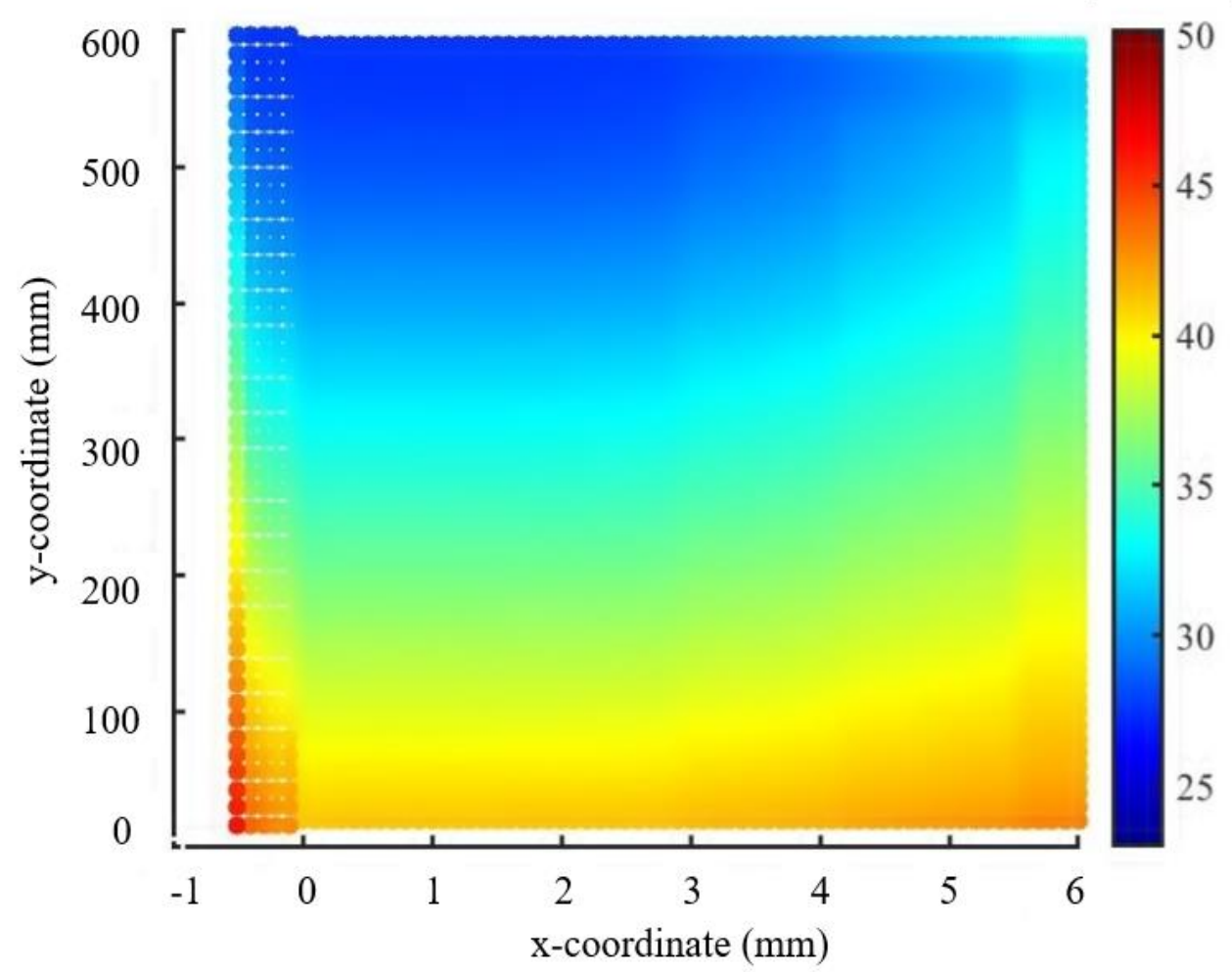

(g)

Temperature $\left({ }^{\circ} \mathrm{C}\right)$

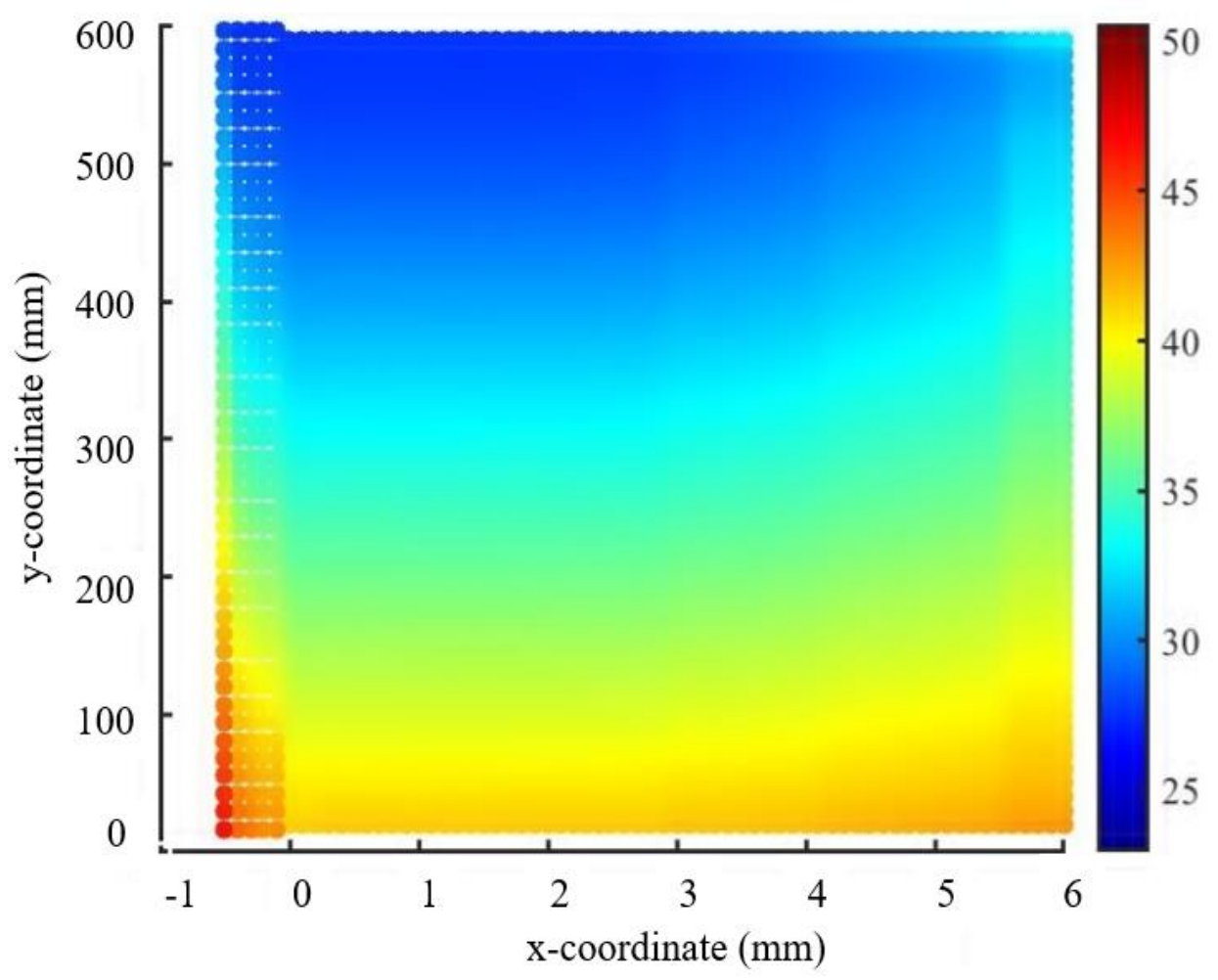

(h) 
Temperature $\left({ }^{\circ} \mathrm{C}\right)$

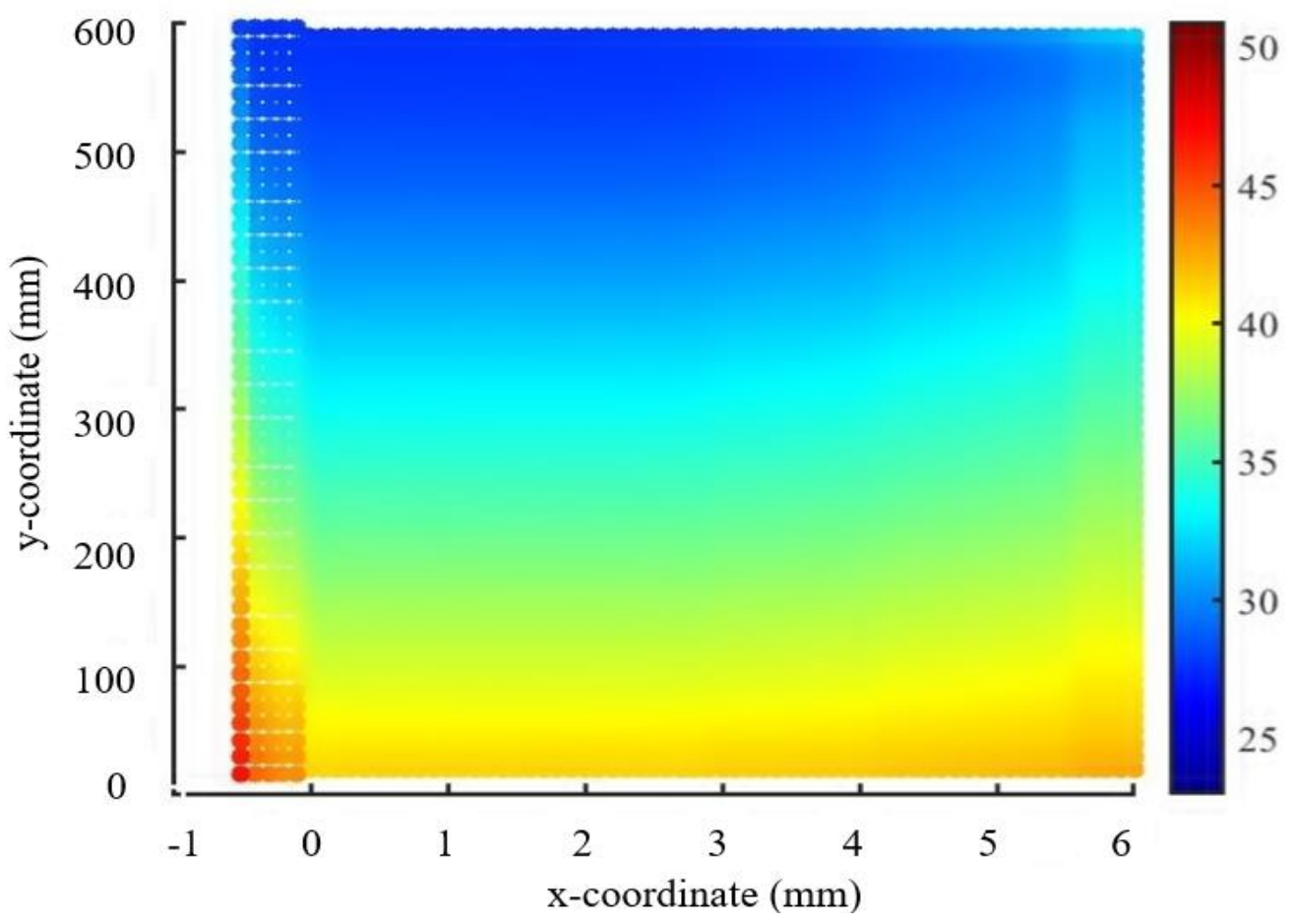

(i)

Temperature $\left({ }^{\circ} \mathrm{C}\right)$

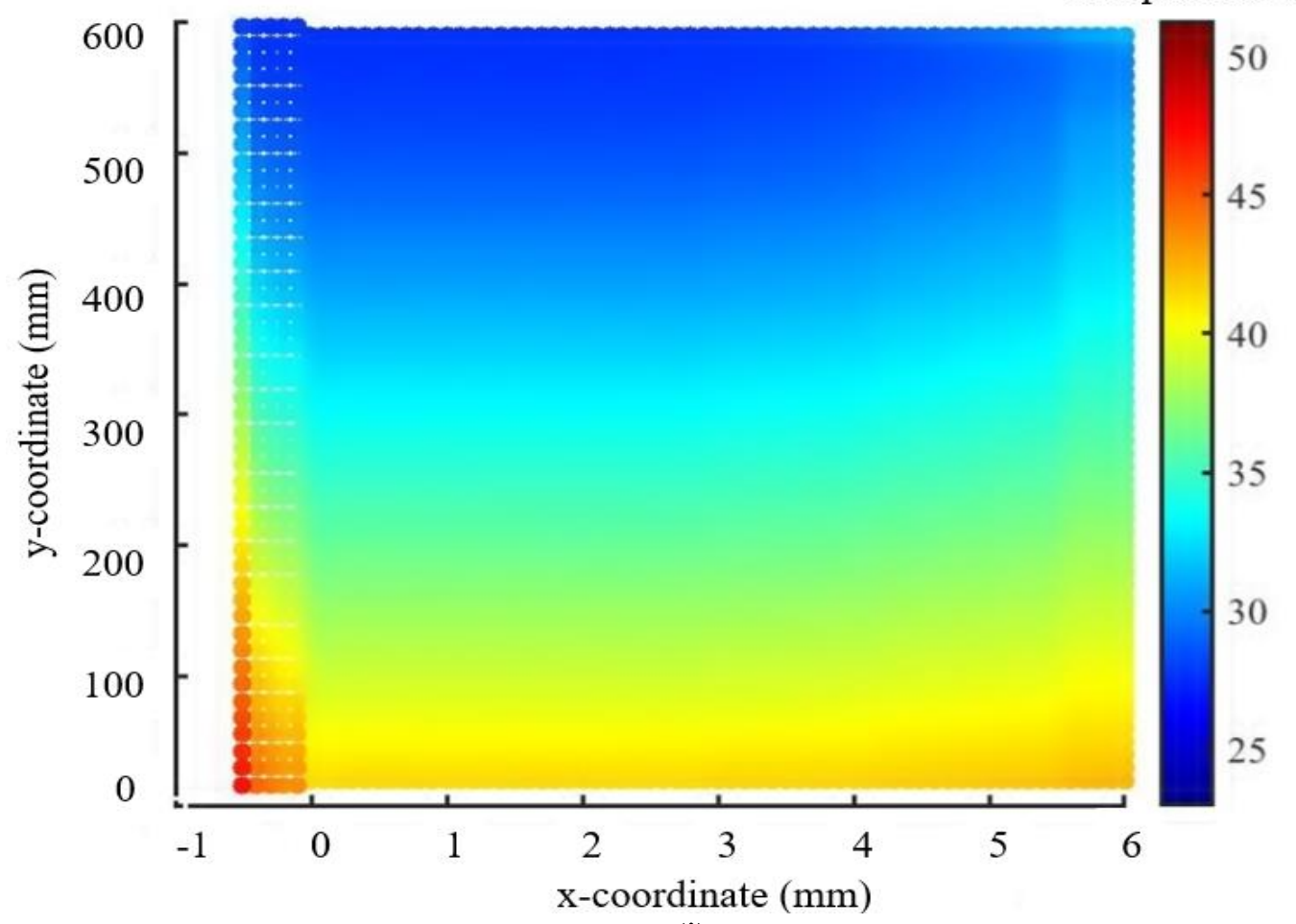

(j)

Fig. 6. Heat map of temperature $\left({ }^{\circ} \mathrm{C}\right)$ in glass and water film using our SPH model, where water film particles are located at negative $x$-coordinate $(\mathrm{x}<0)$ : (a) At 86 seconds; (b) At 91 seconds; (c) At 96 seconds; (d) At 101 seconds; (e) At 106 seconds; (f) At 111 seconds; (g) At 116 seconds; (h) At 121 seconds; (i) At 127 seconds; (j) At 132 seconds. 


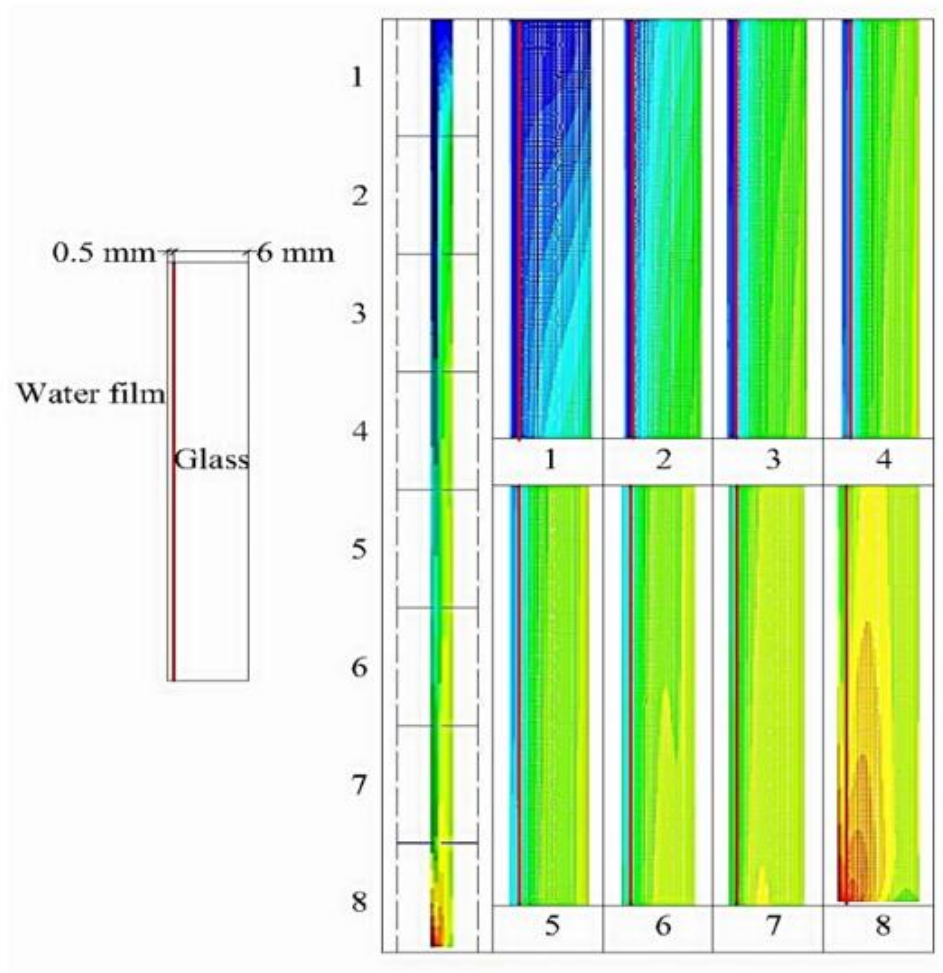

(a)

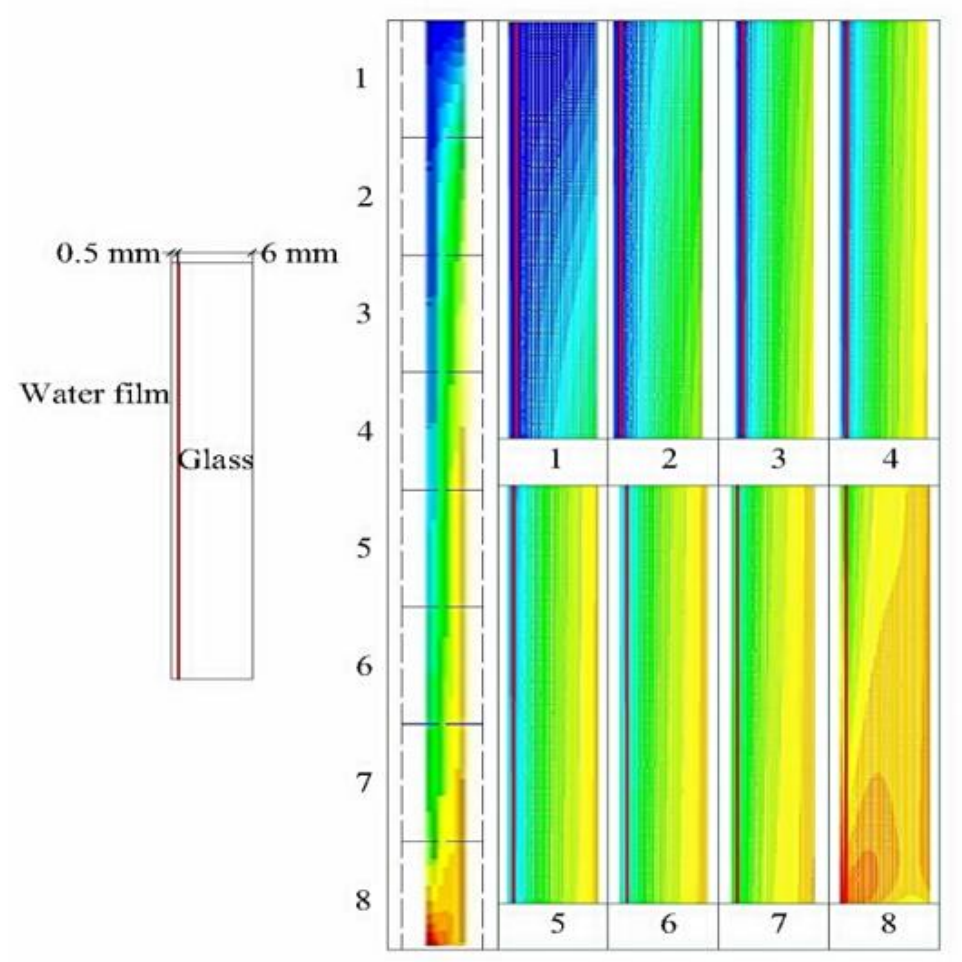

(b)
Temperature $\left({ }^{\circ} \mathrm{C}\right)$

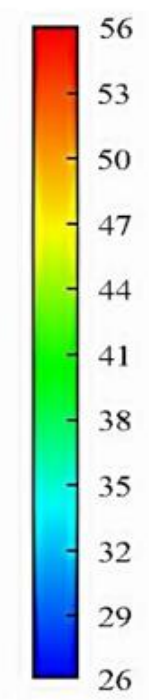

Temperature $\left({ }^{\circ} \mathrm{C}\right)$

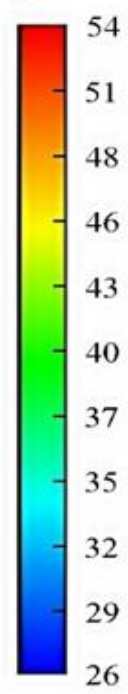




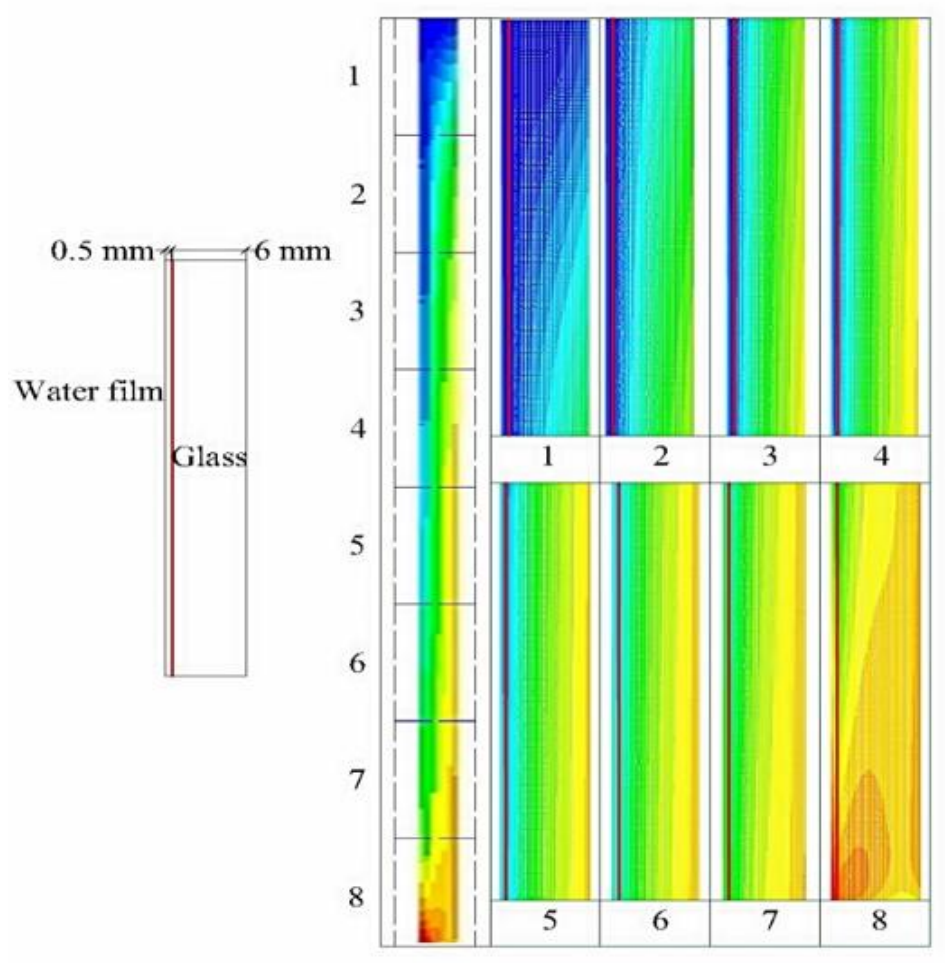

Temperature $\left({ }^{\circ} \mathrm{C}\right)$

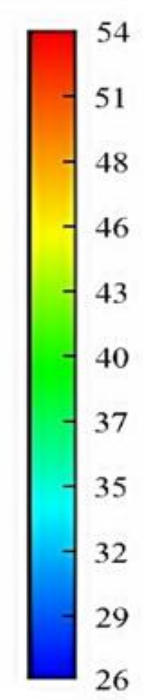

(c)

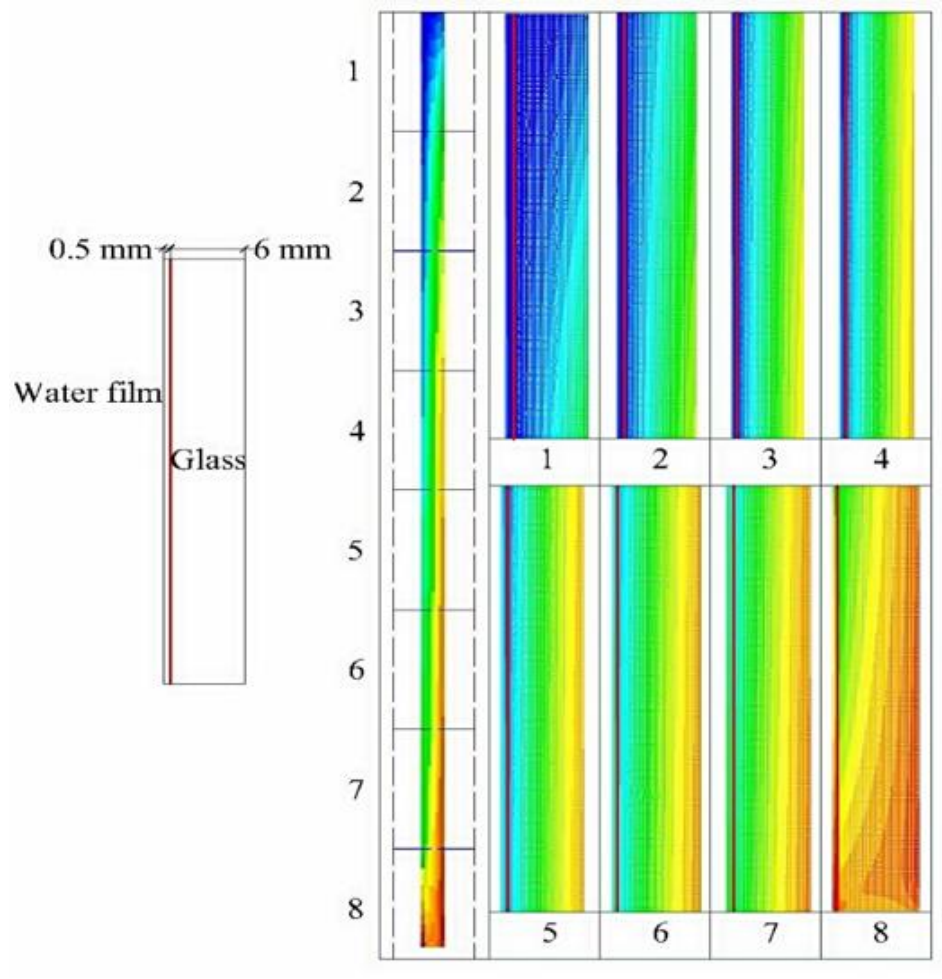

Temperature $\left({ }^{\circ} \mathrm{C}\right)$

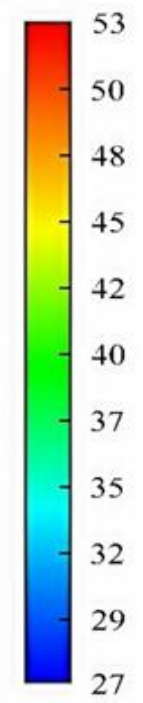

(d) 


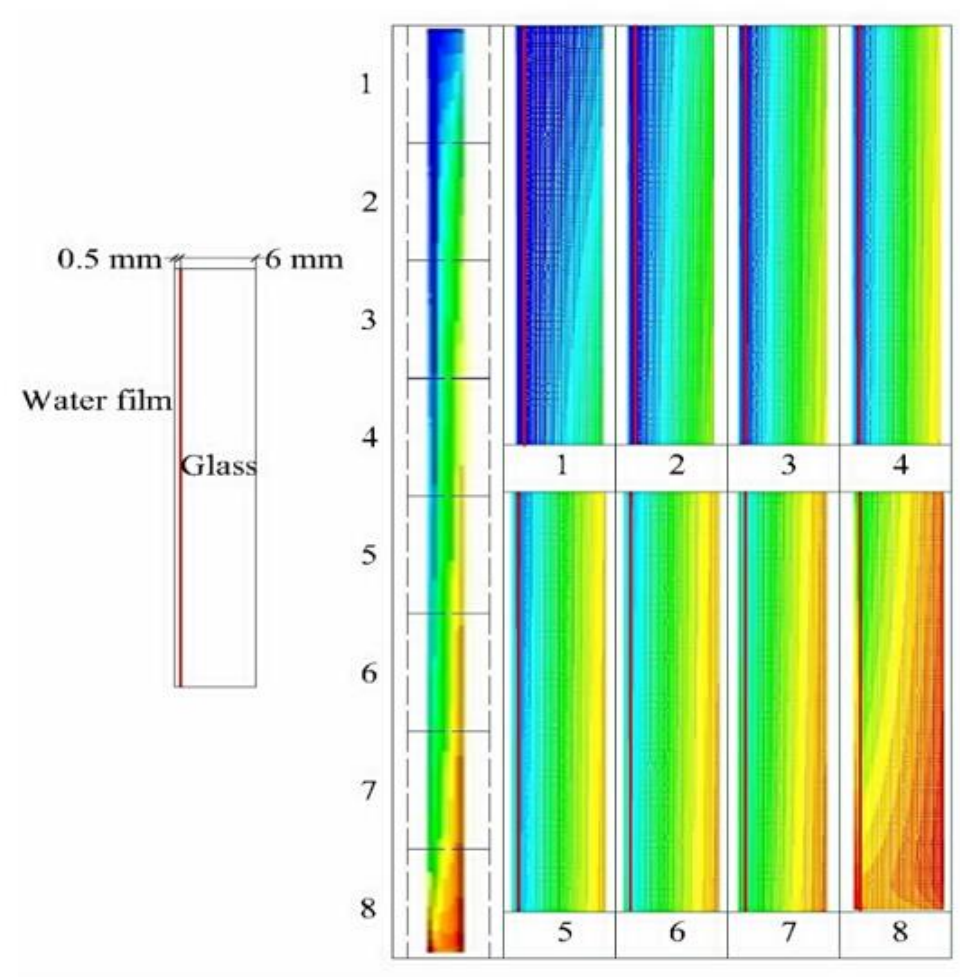

(e)

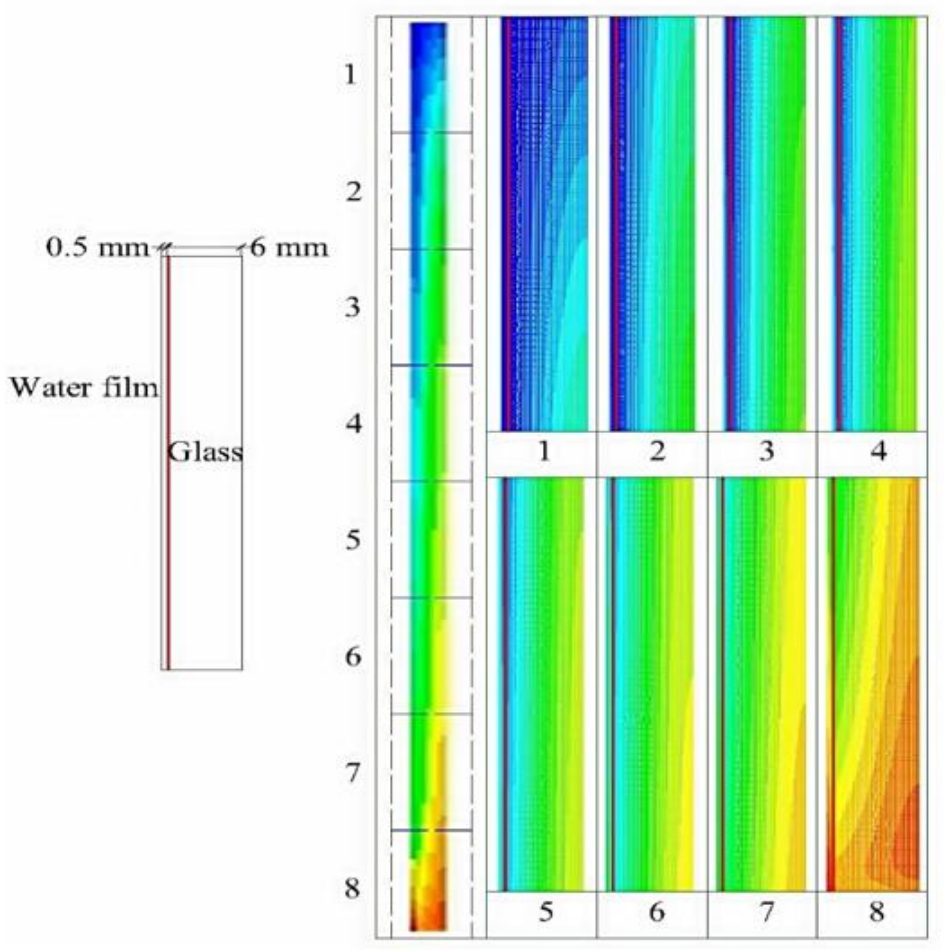

(f)
Temperature $\left({ }^{\circ} \mathrm{C}\right)$

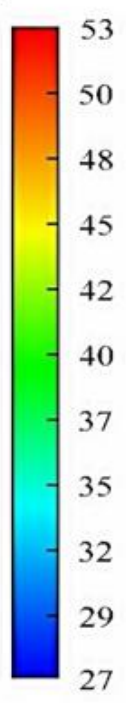

Temperature $\left({ }^{\circ} \mathrm{C}\right)$

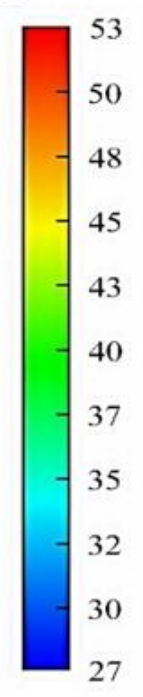




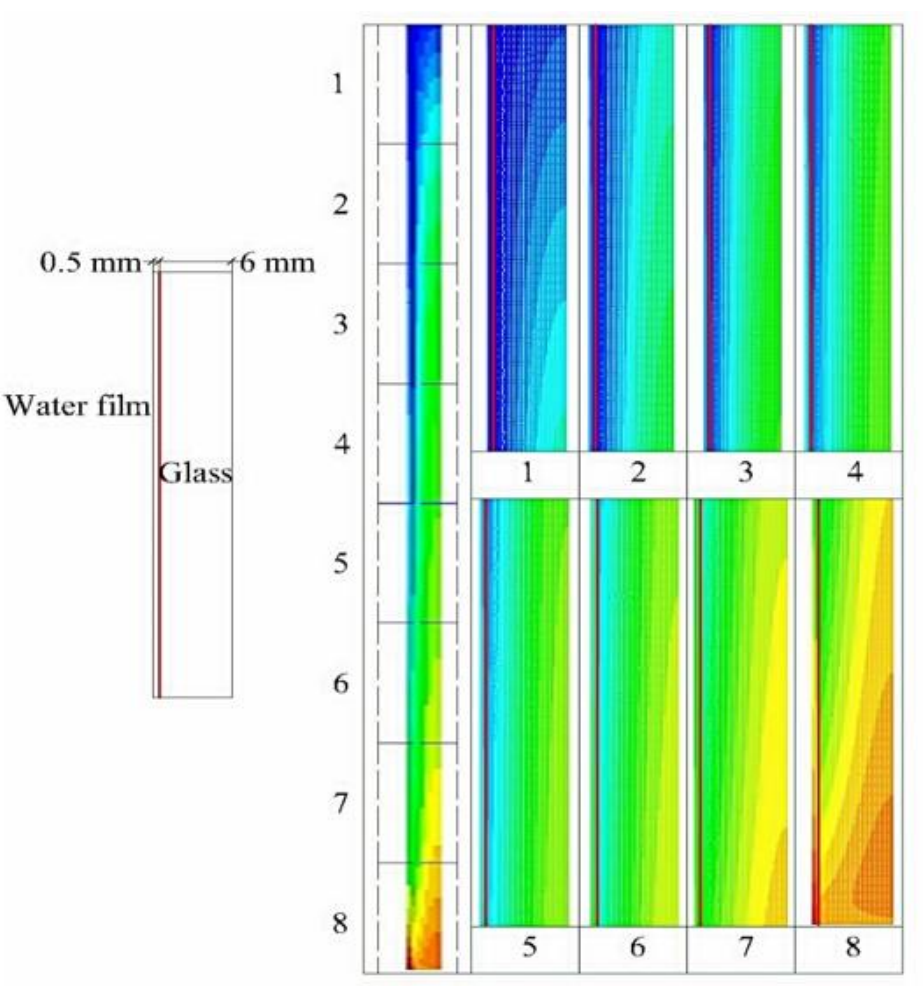

Temperature $\left({ }^{\circ} \mathrm{C}\right)$

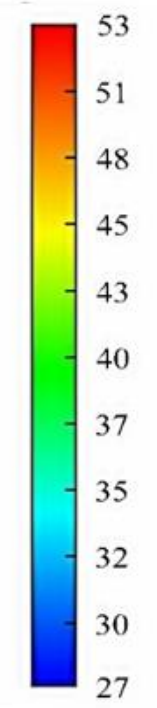

(g)

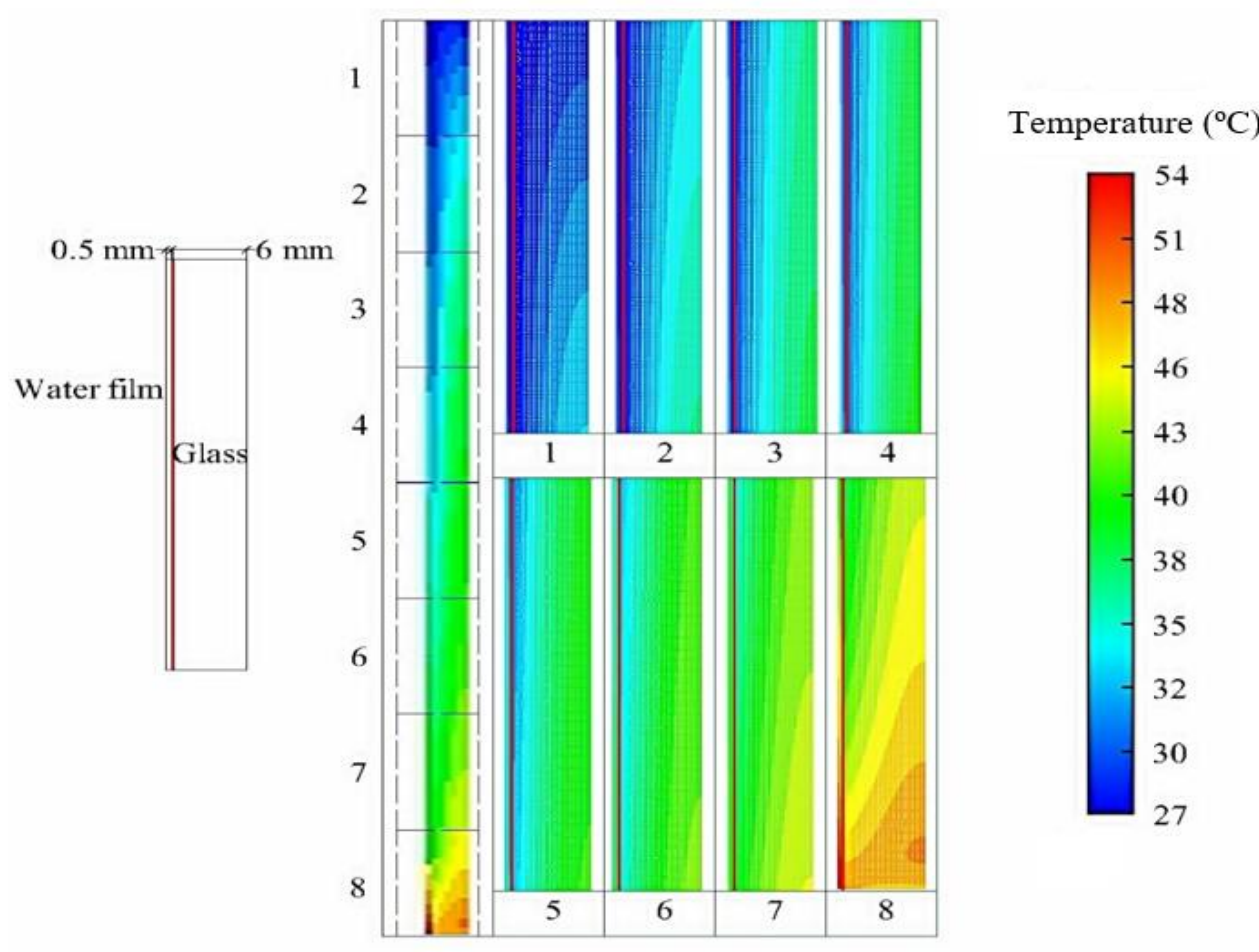

(h) 


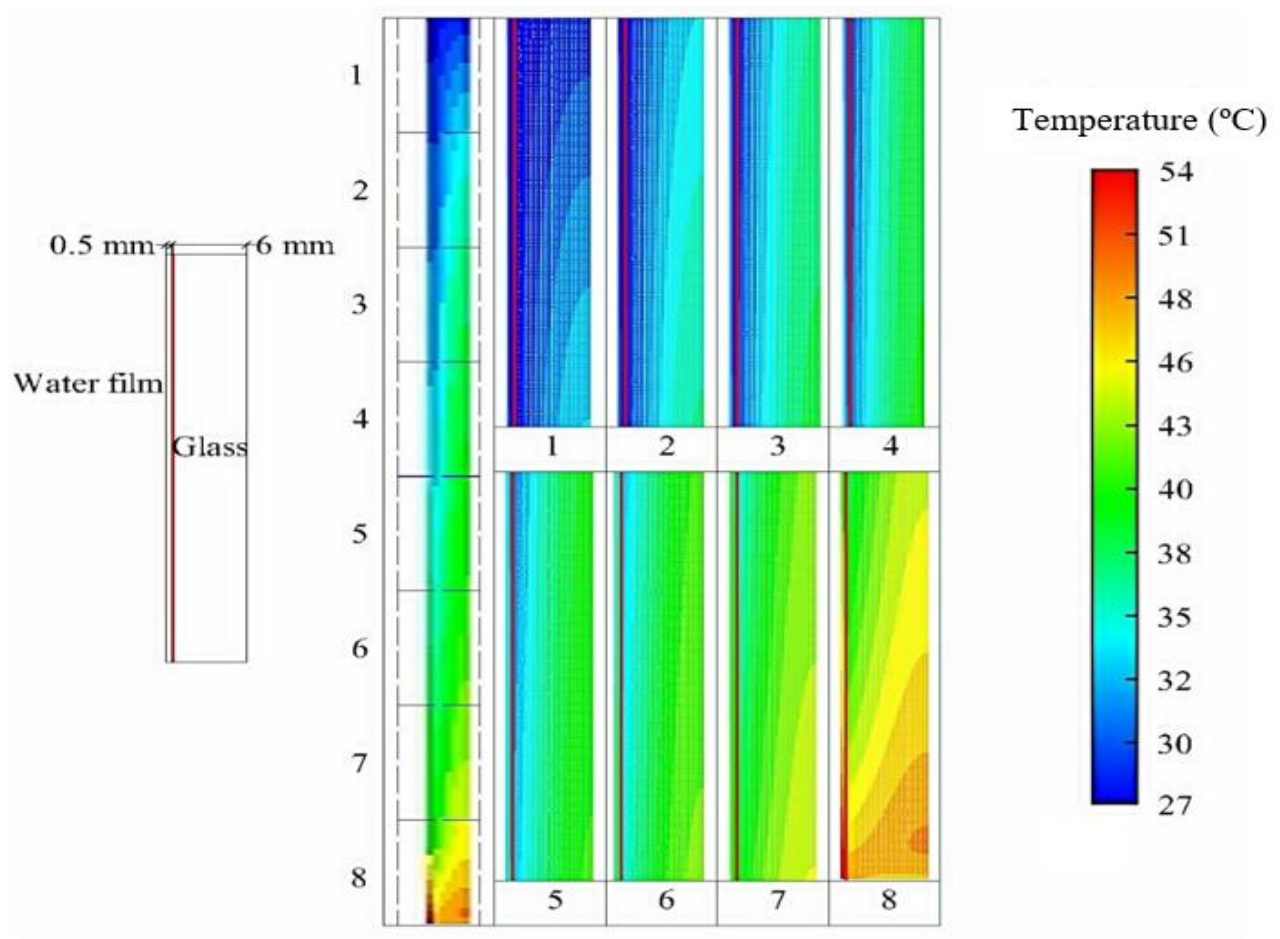

(i)

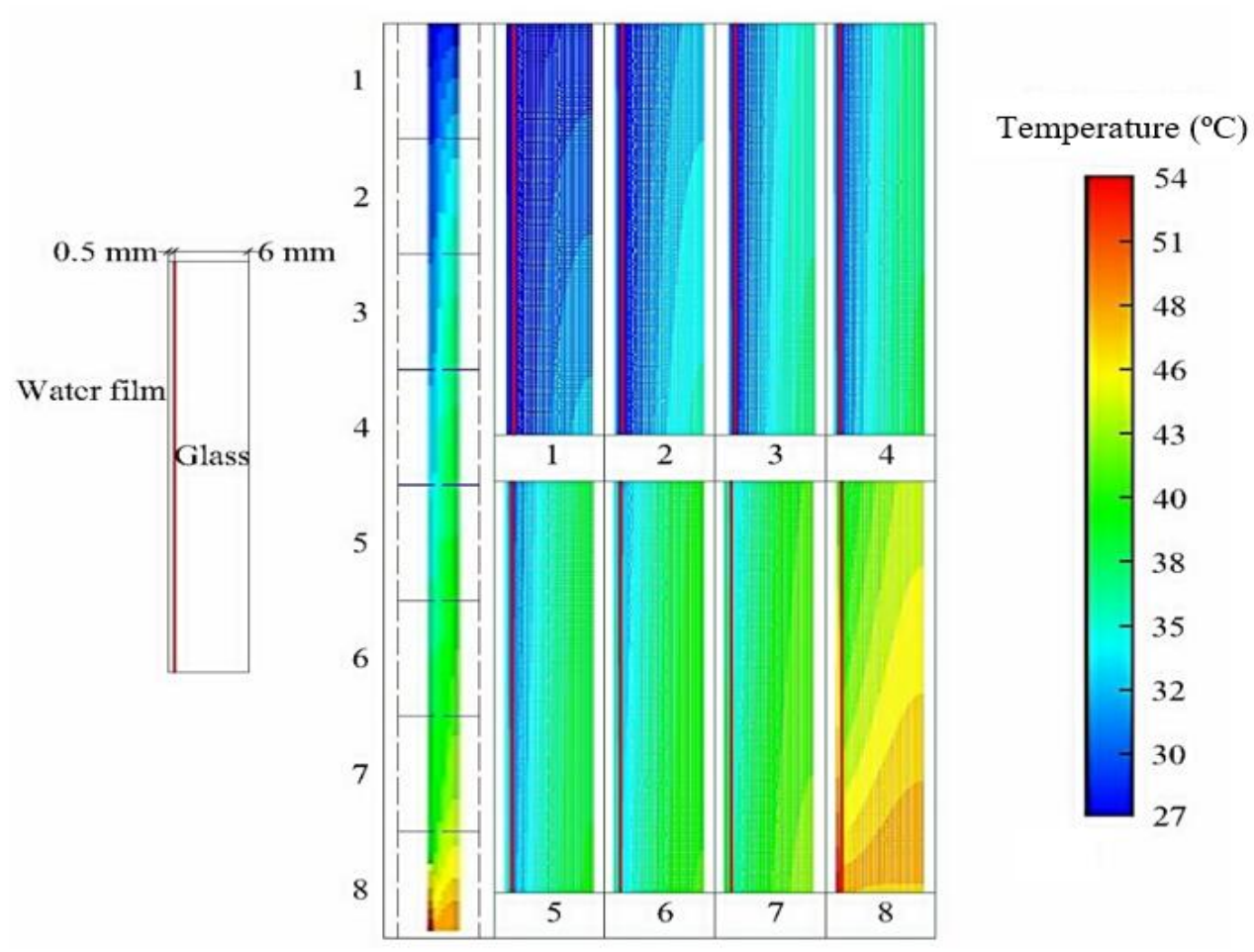

(j)

Fig. 7. Heat map of temperature $\left({ }^{\circ} \mathrm{C}\right)$ in glass and water film using Ansys-fluent, where the water film is located behind (left) the red line: (a) At 86 seconds; (b) At 91 seconds; (c) At 96 seconds; (d) At 101 seconds; (e) At 106 seconds; (f) At 111 seconds; (g) At 116 seconds; (h) At 121 seconds; (i) At 127 seconds; (j) At 132 seconds. 


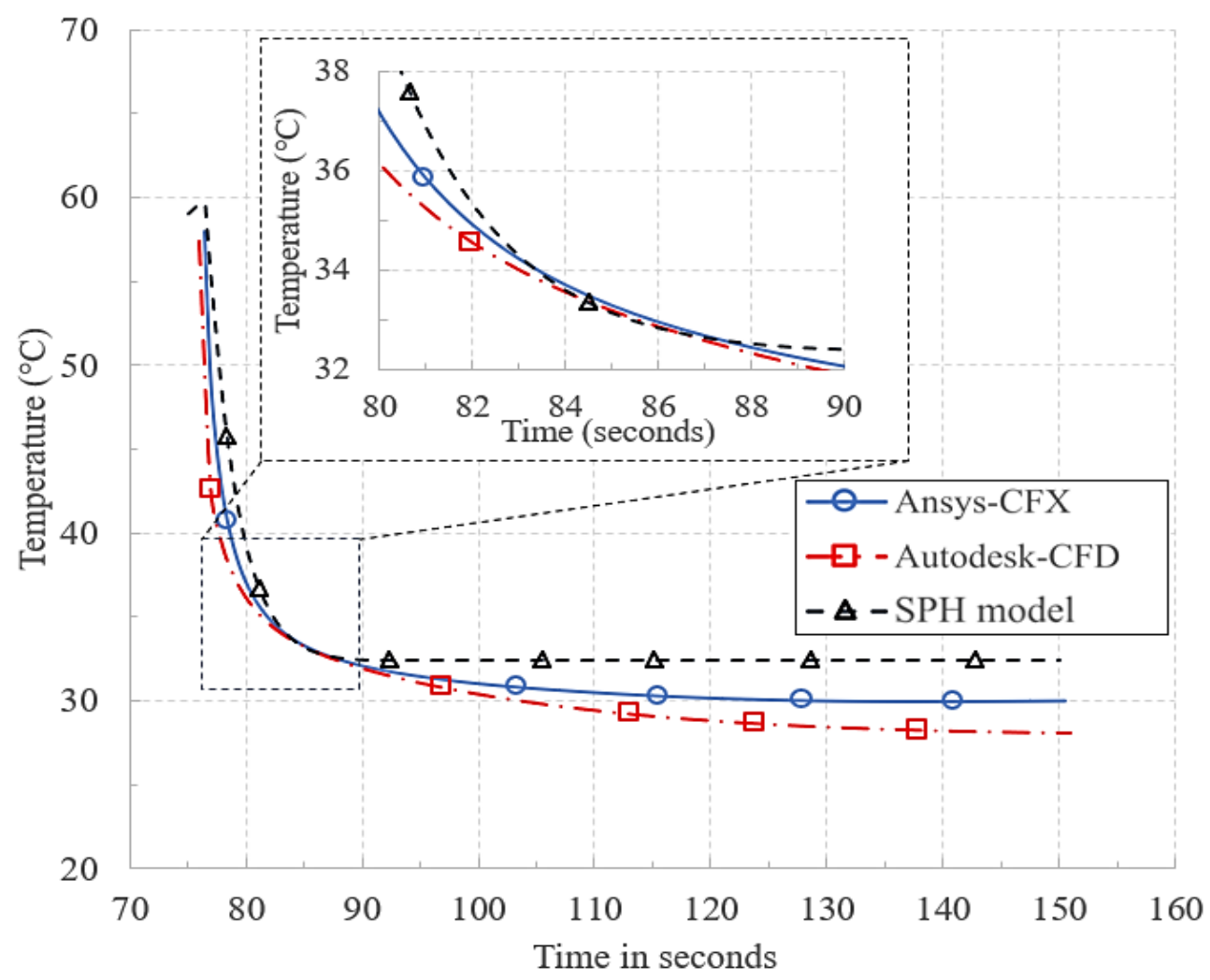

(a)

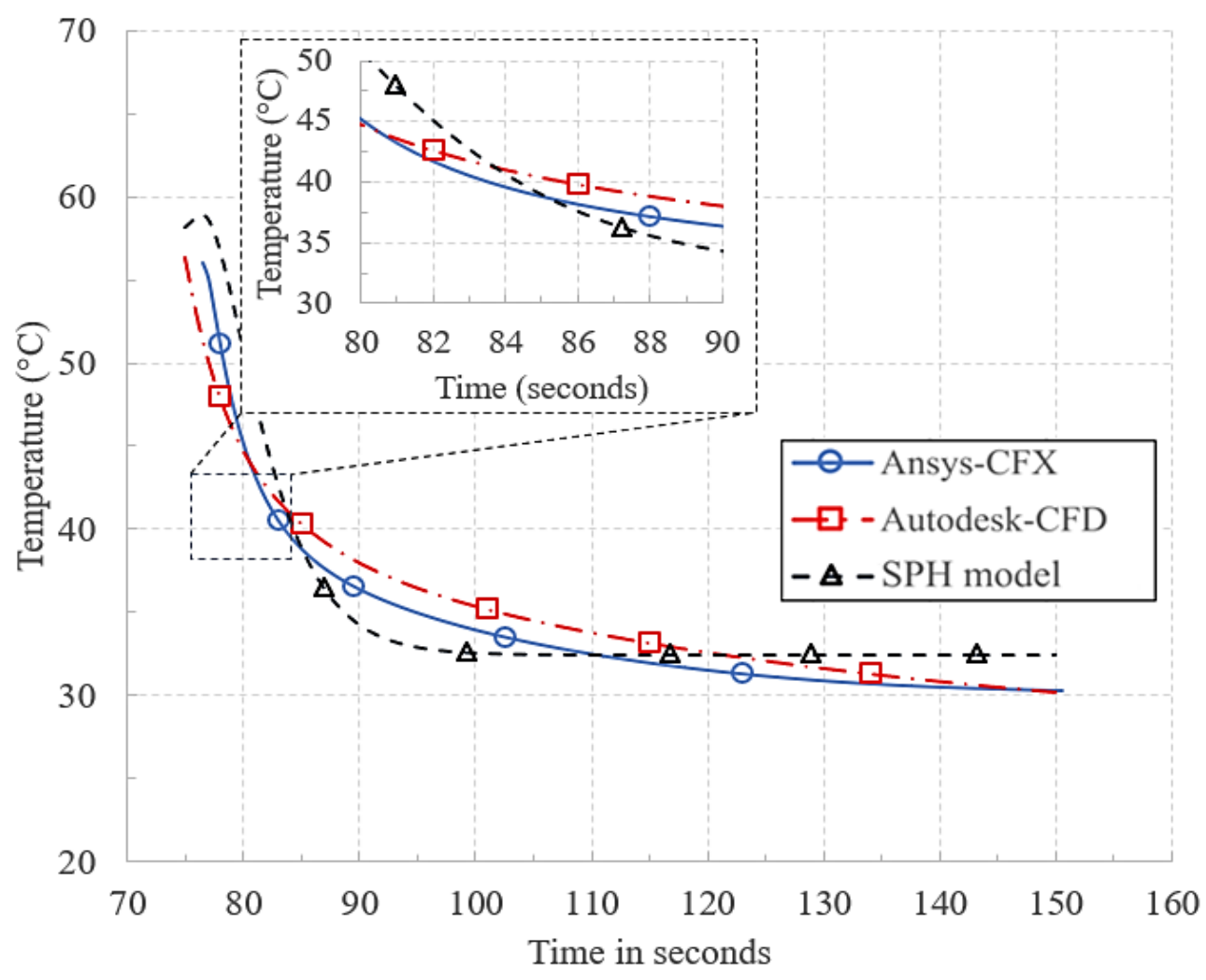

(b) 


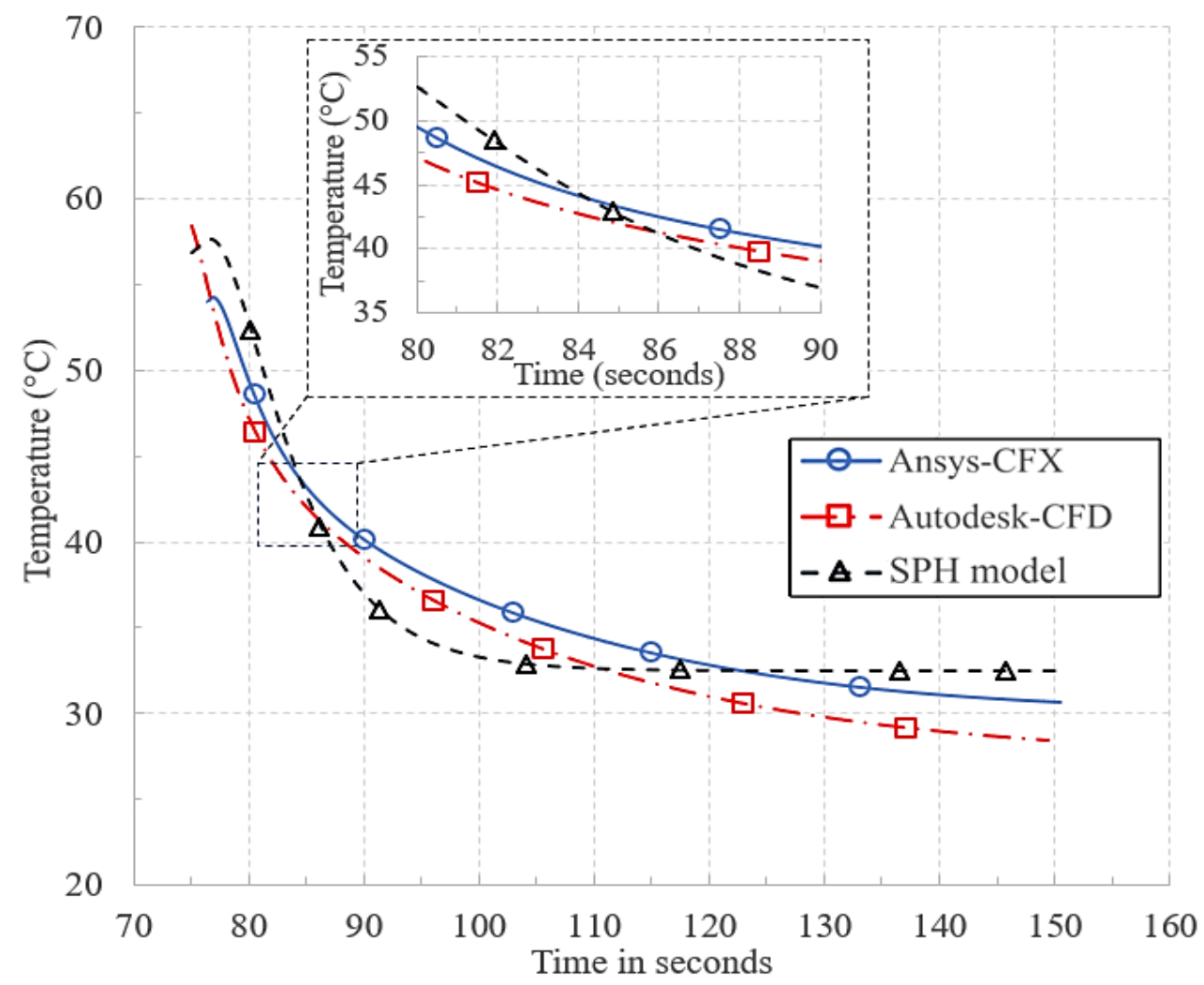

(c)

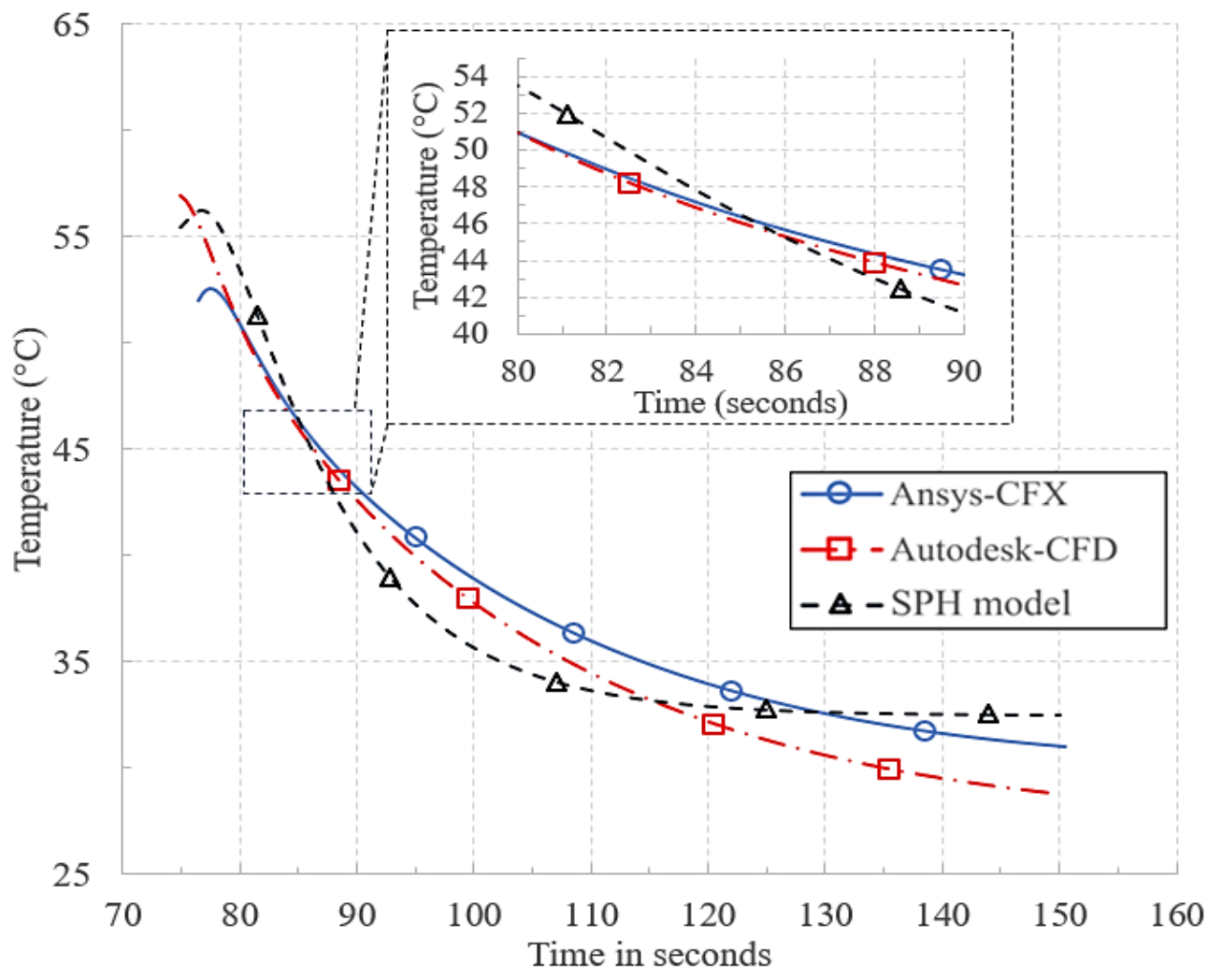

(d) 


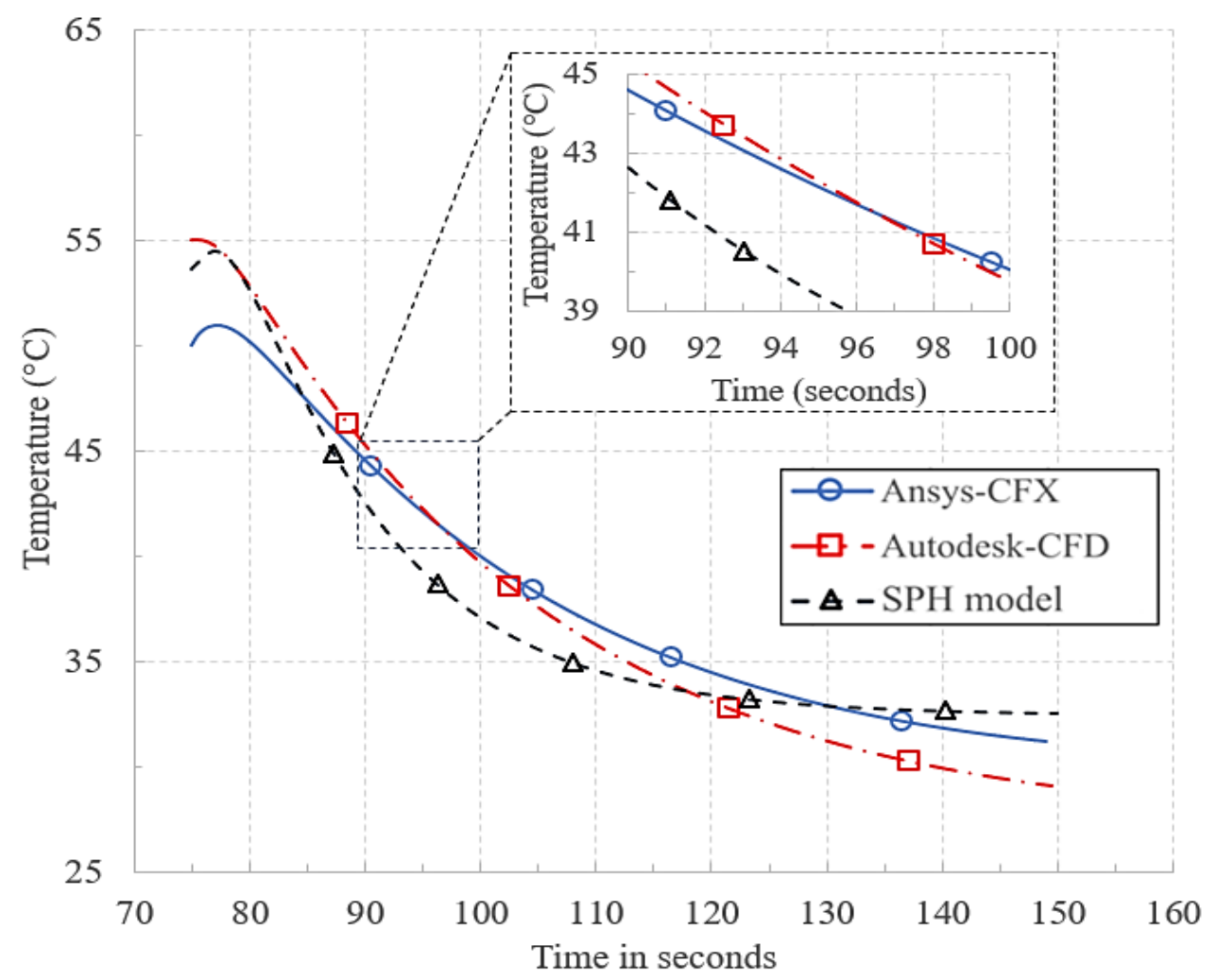

(e)

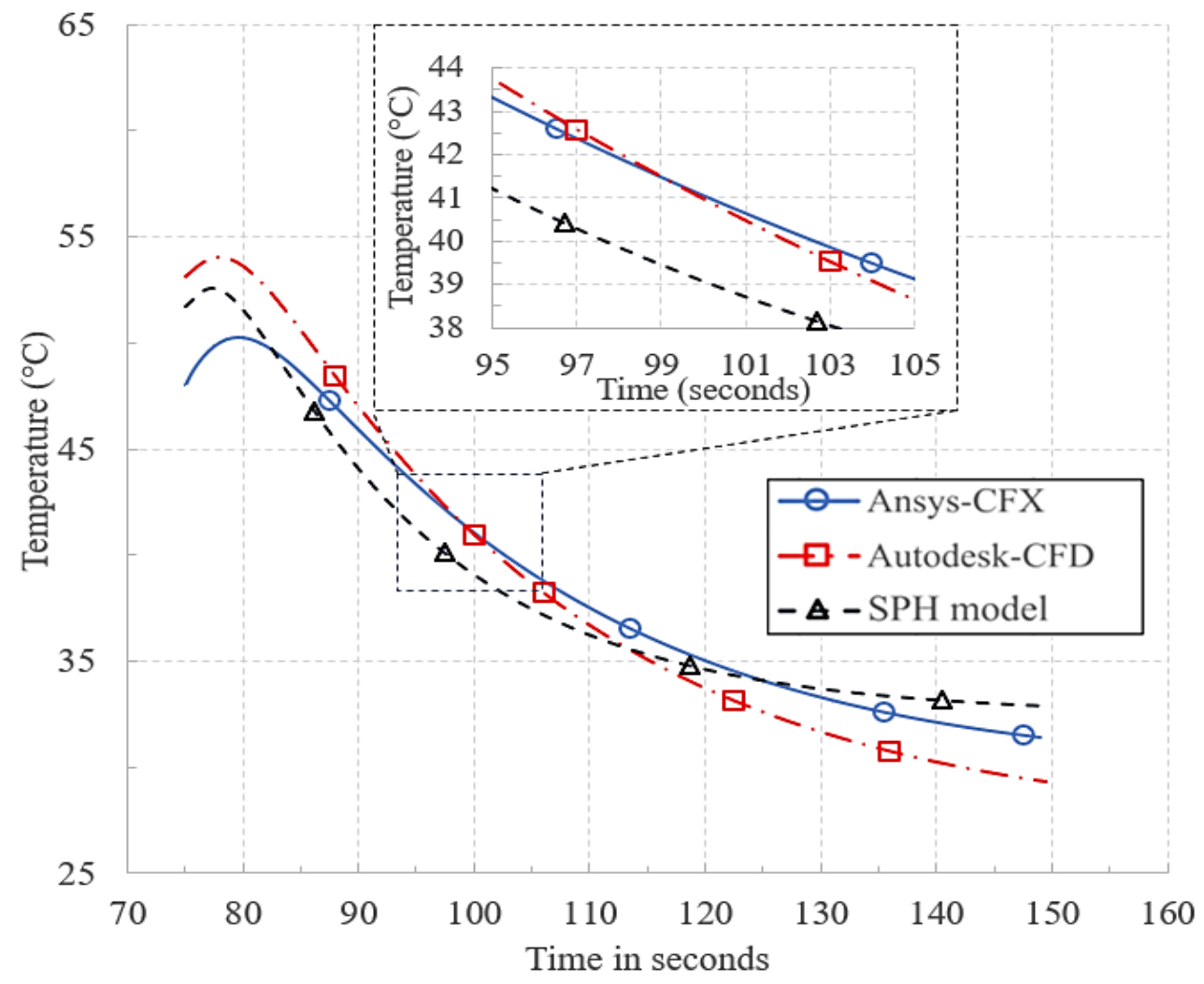

(f) 


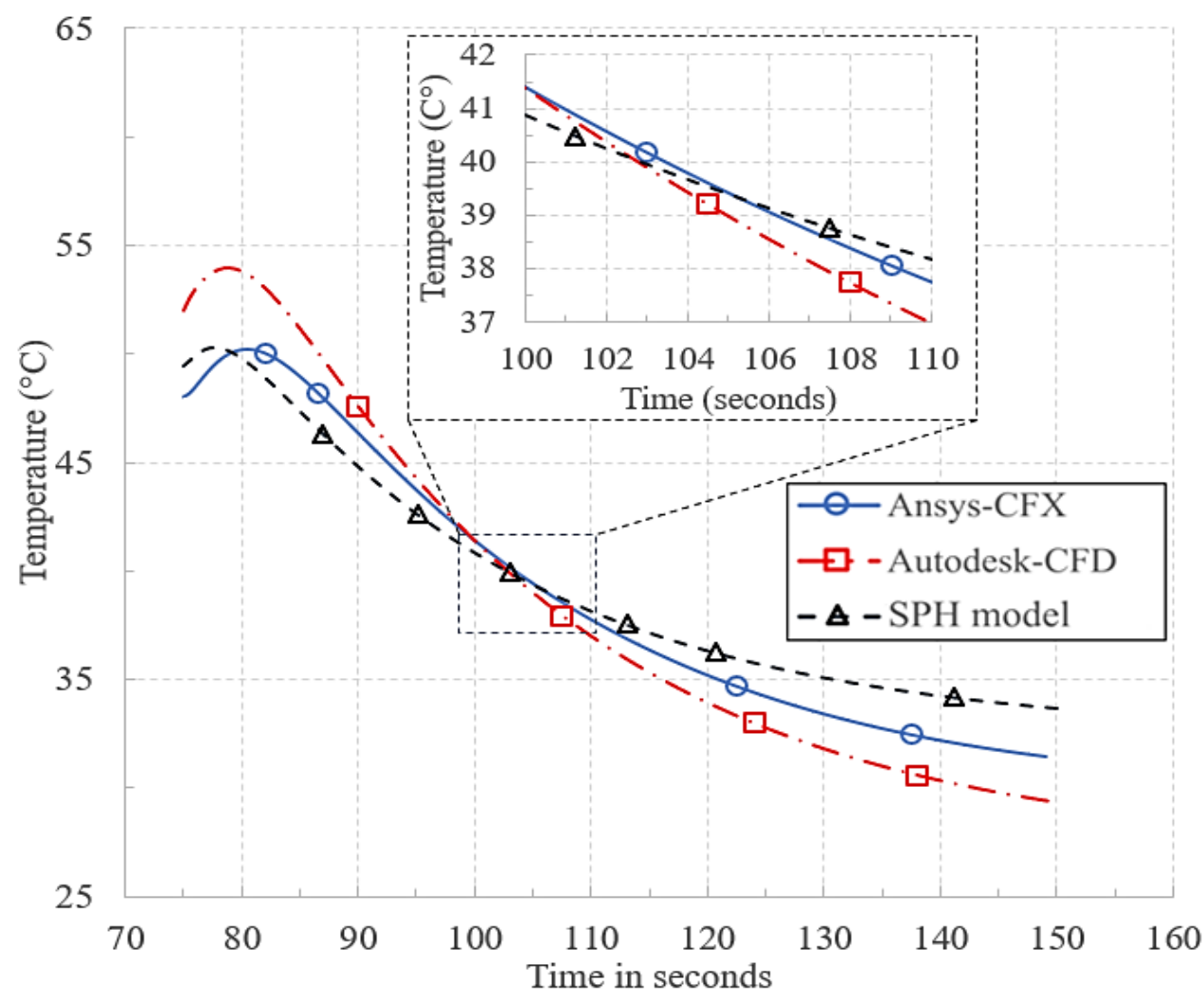

(g)

Fig. 8. Temperature variation with time after applying water film using our SPH model, Ansys-CFX and Autodesk-CFD: (a) At point P3; (b) At Point P8; (c) At Point P13; (d) At Point P18; (e) At Point P23; (f) At Point P28; (g) At Point P33. 


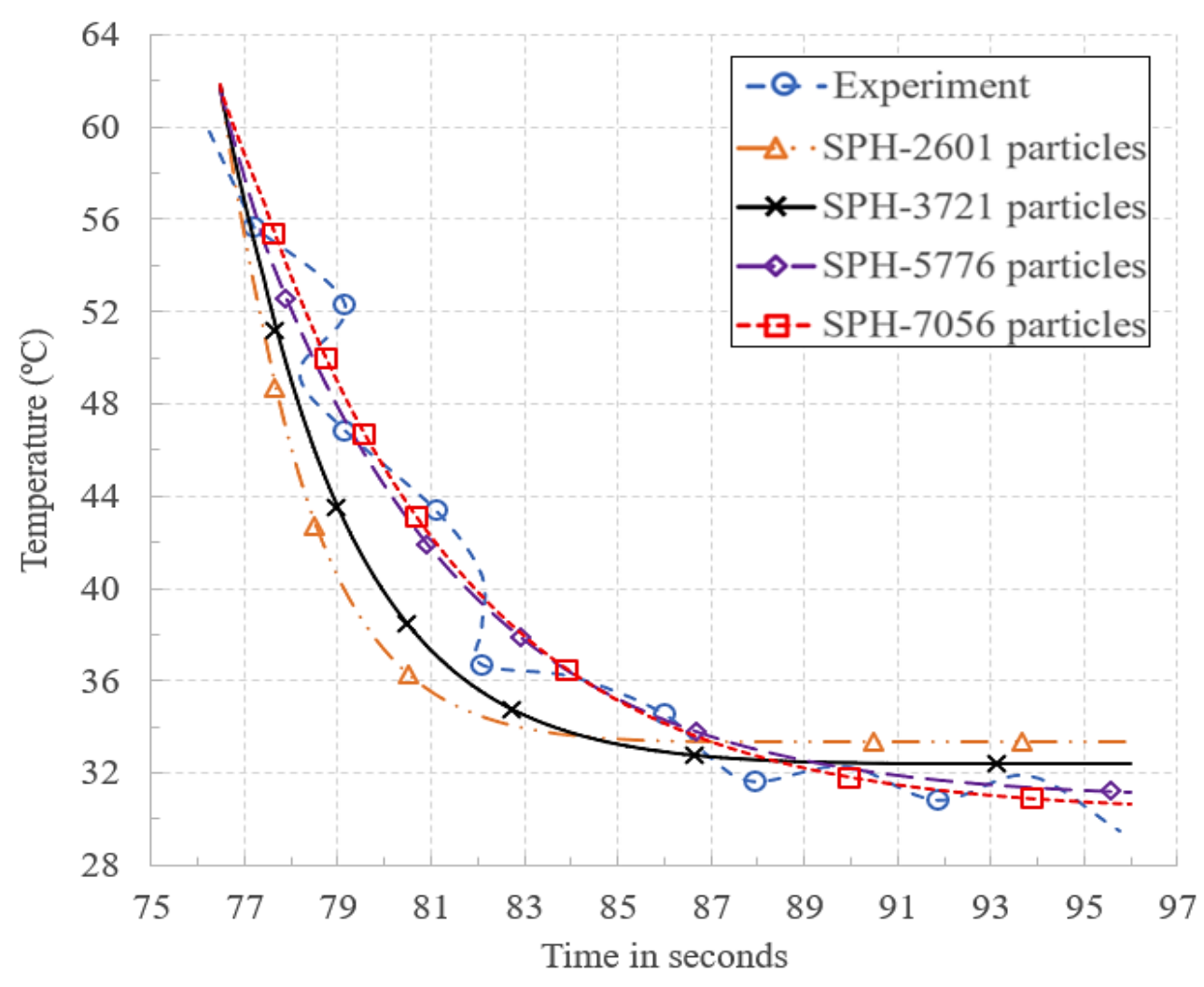

(a)

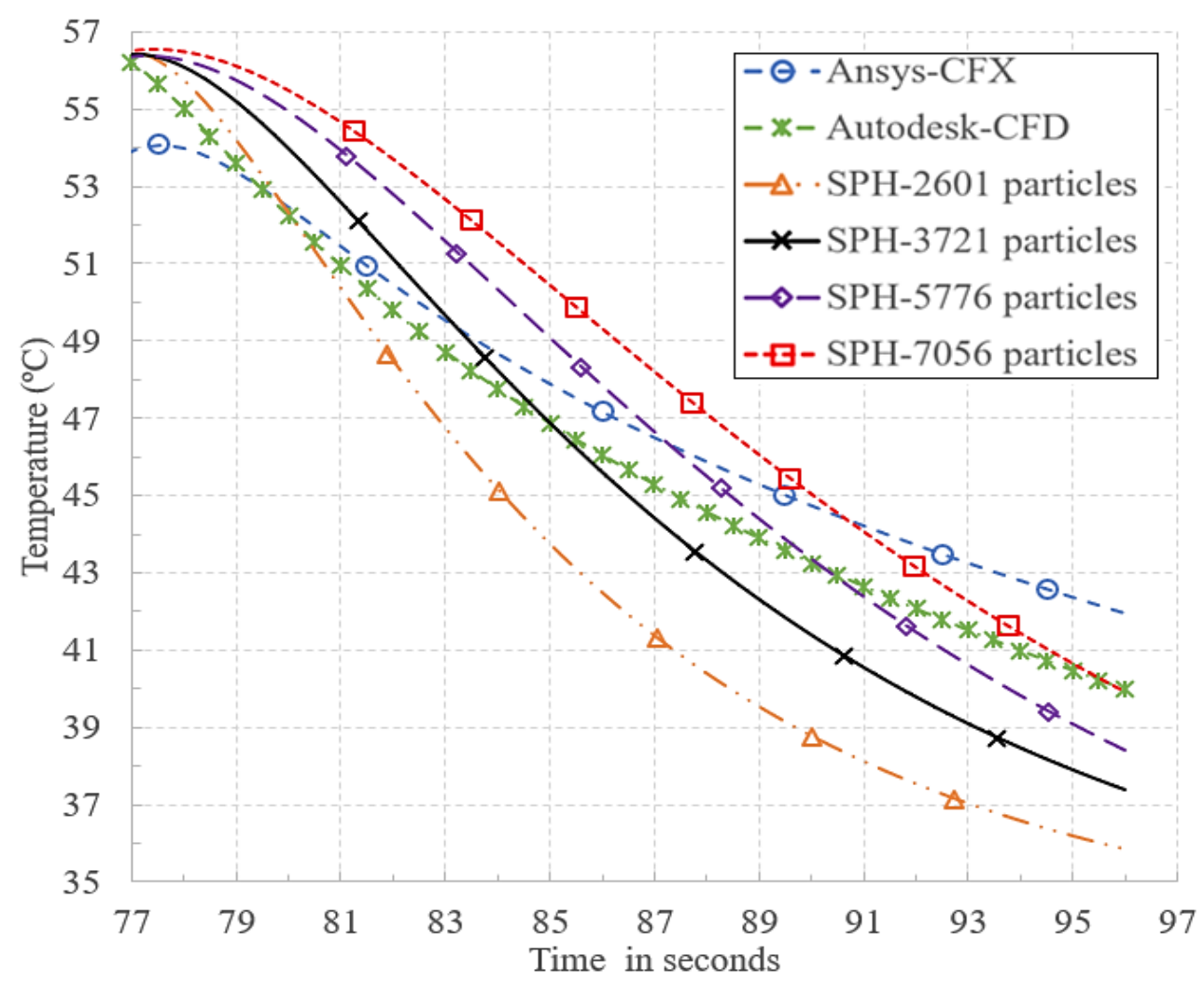

(b) 


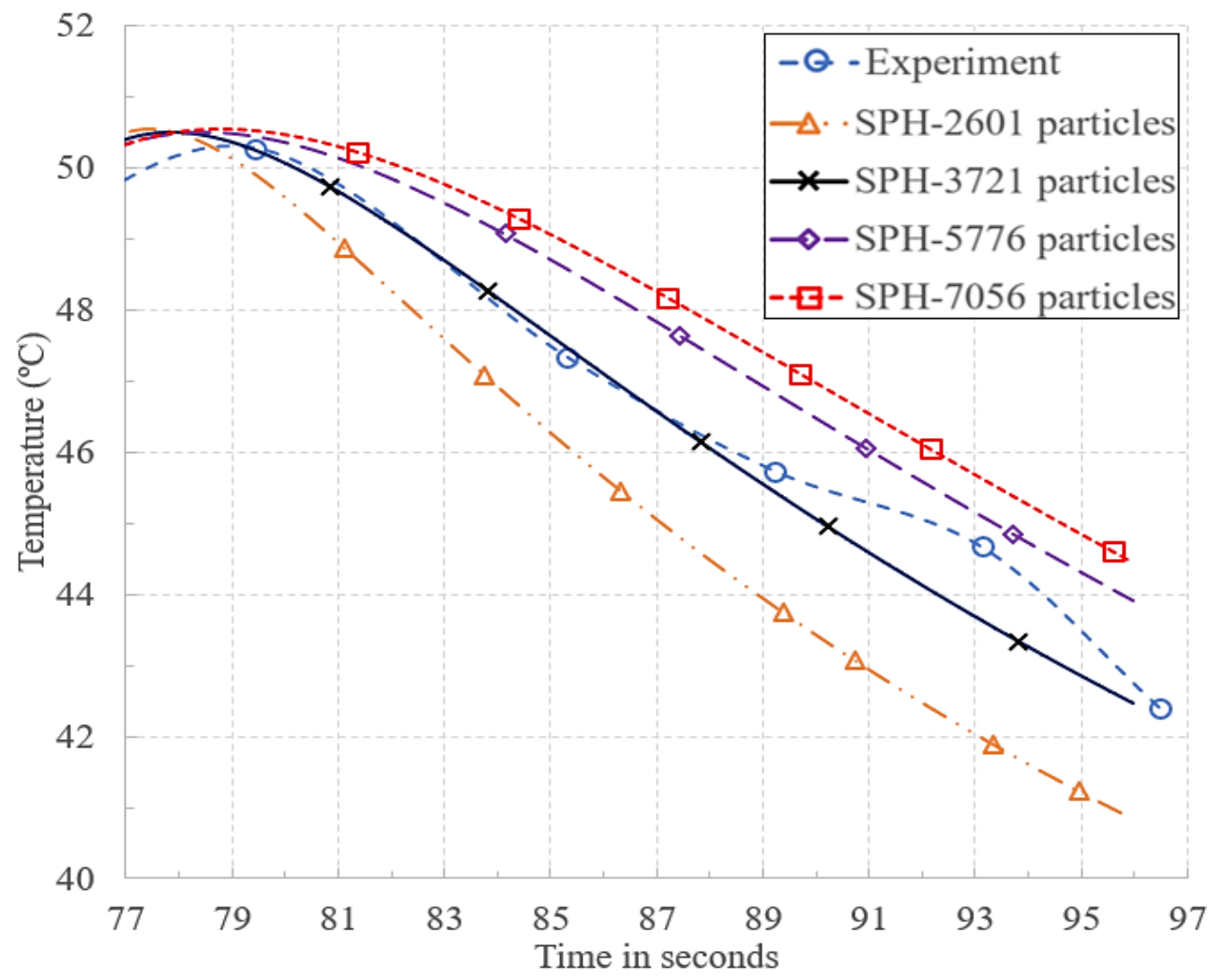

(c)

Fig. 9. Temperature variation with time after applying water film using our SPH model with different number of particles, experiment, Ansys-CFX and Autodesk-CFD: (a) At point P3; (b) At Point P18; (c) At Point P33.

Temperature $\left({ }^{\circ} \mathrm{C}\right)$

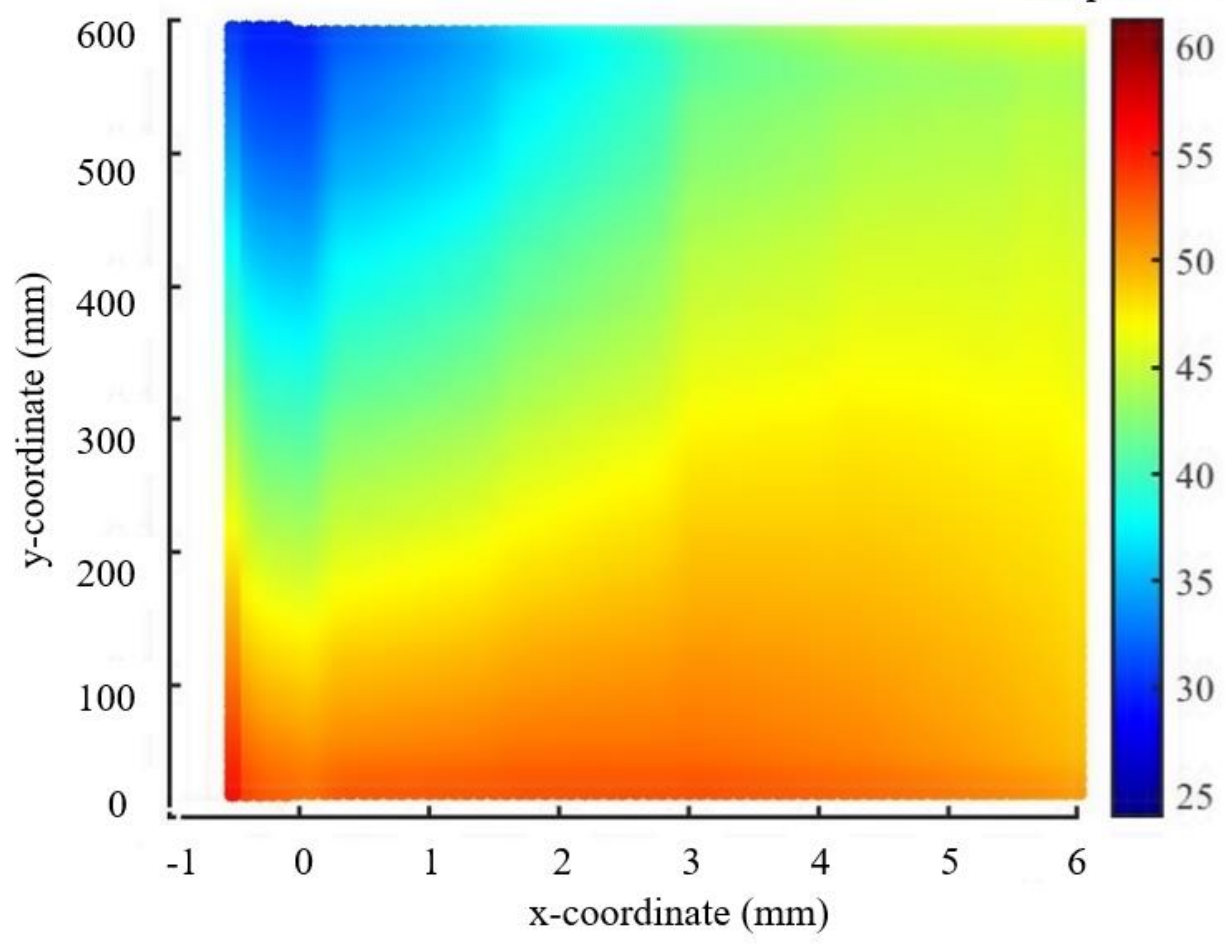

(a) 


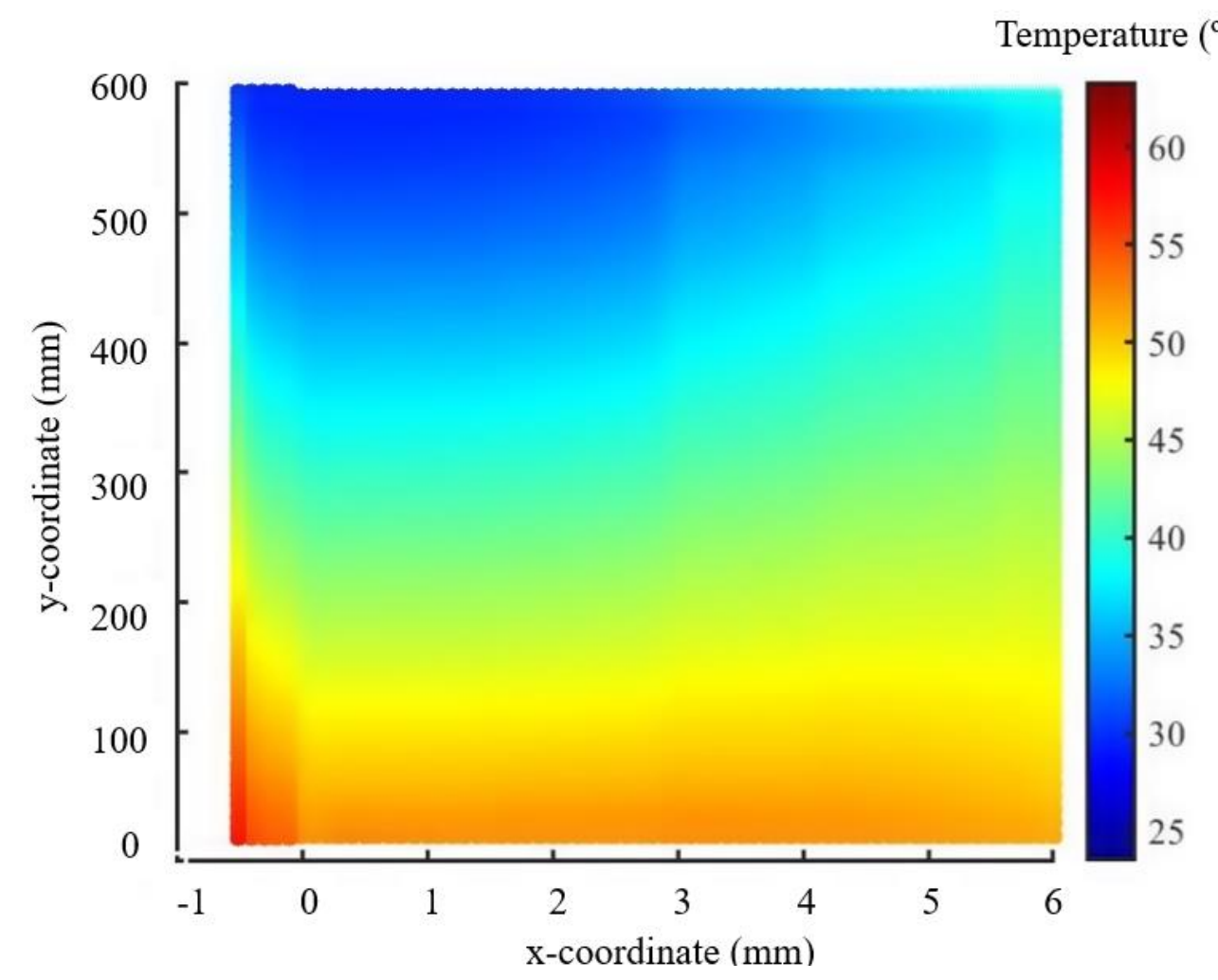

(b)

Fig. 10. Heat map of temperature $\left({ }^{\circ} \mathrm{C}\right)$ in glass and water film using our SPH model when down-flowing velocity of water film equals $0.4 \mathrm{~m} / \mathrm{s}$. Where water film particles are located at negative $x$-coordinate $(\mathrm{x}<0 \mathrm{~mm})$ : (a) At 85 seconds; (b) At 100 seconds.

Temperature $\left({ }^{\circ} \mathrm{C}\right)$

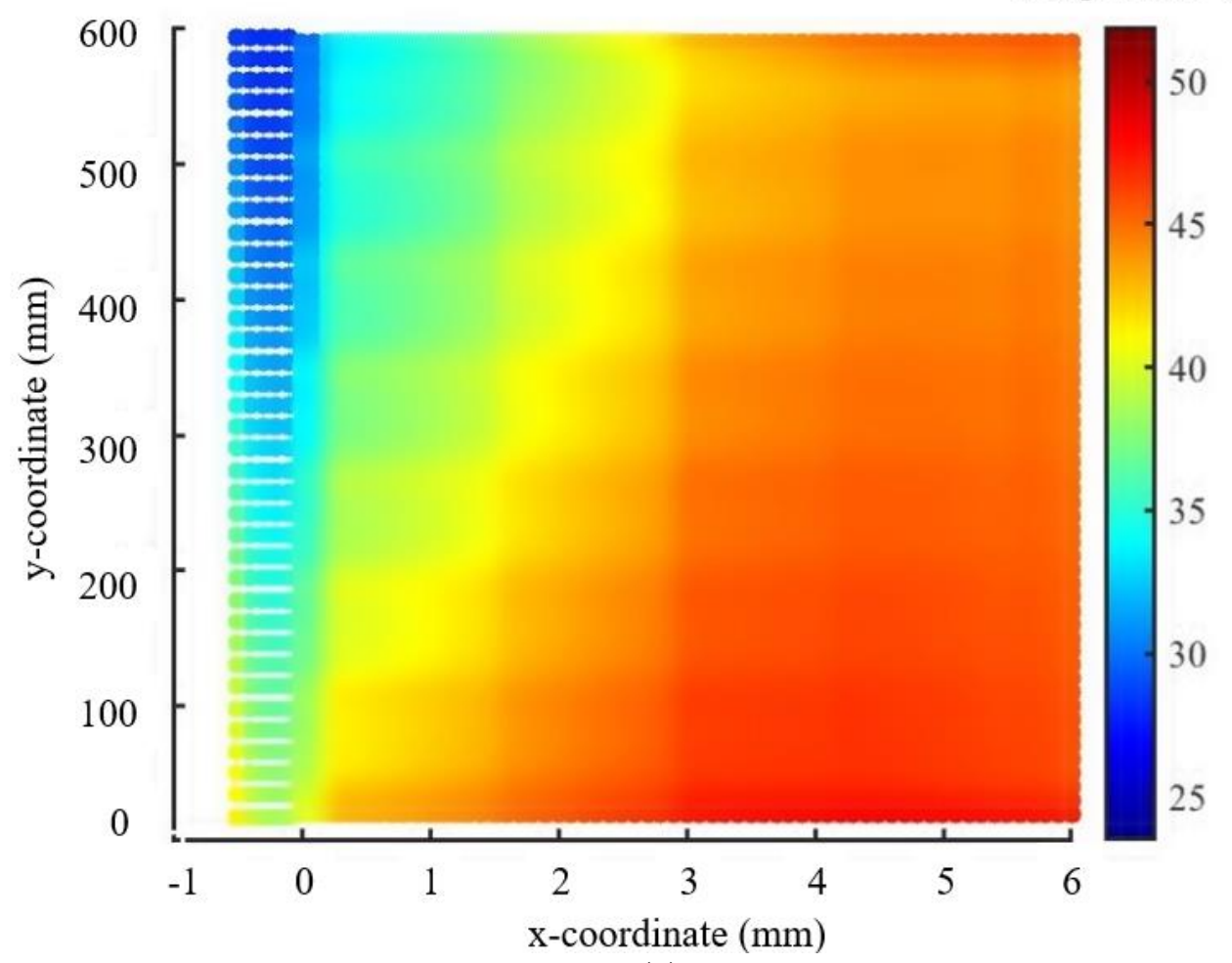

(a) 
Temperature $\left({ }^{\circ} \mathrm{C}\right)$

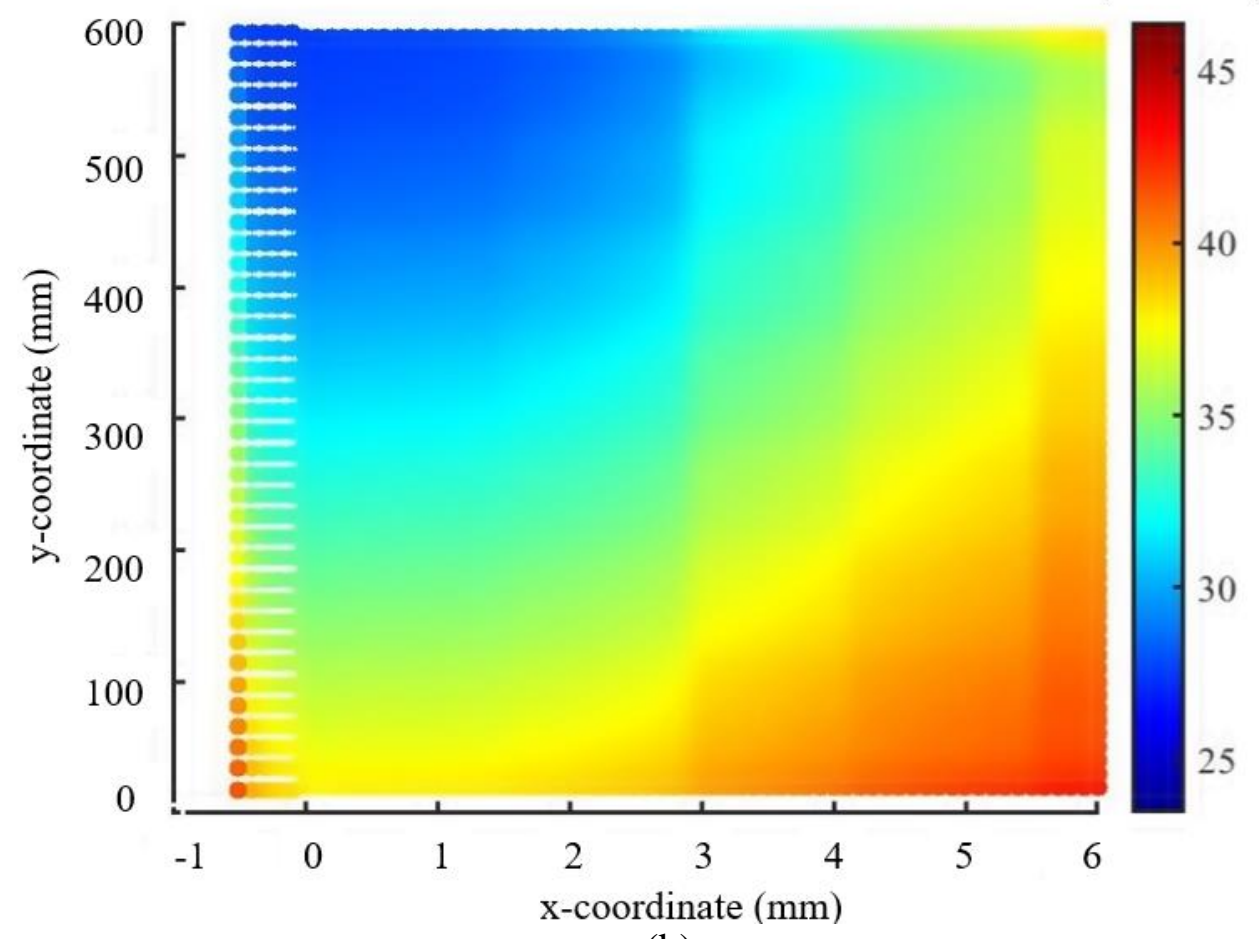

(b)

Fig. 11. Heat map of temperature $\left({ }^{\circ} \mathrm{C}\right)$ in glass and water film using our SPH model when down-flowing velocity of water film equals $0.8 \mathrm{~m} / \mathrm{s}$. Where water film particles are located at negative $x$-coordinate $(x<0 \mathrm{~mm}$ ): (a) At 85 seconds; (b) At 100 seconds.

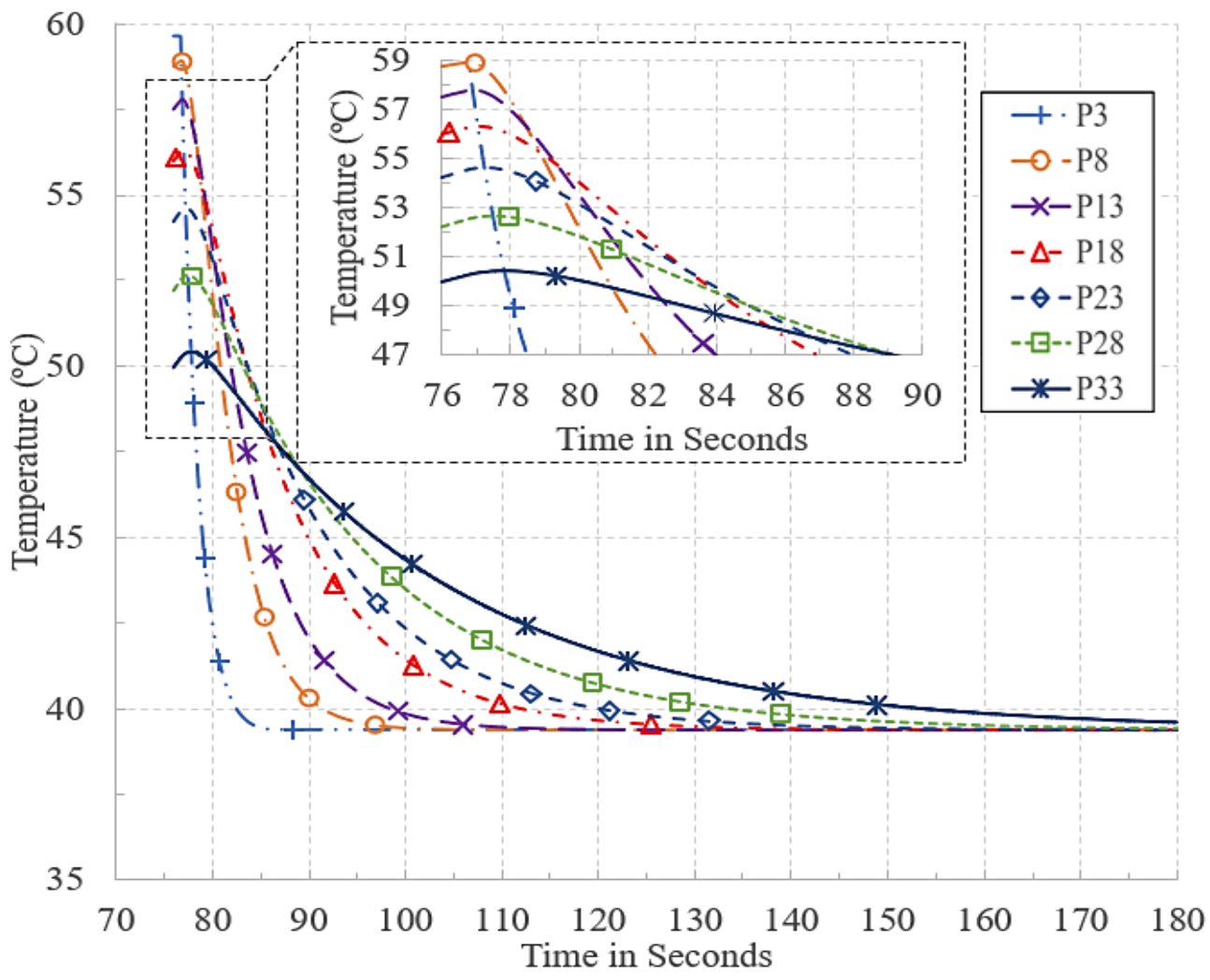

(a) 


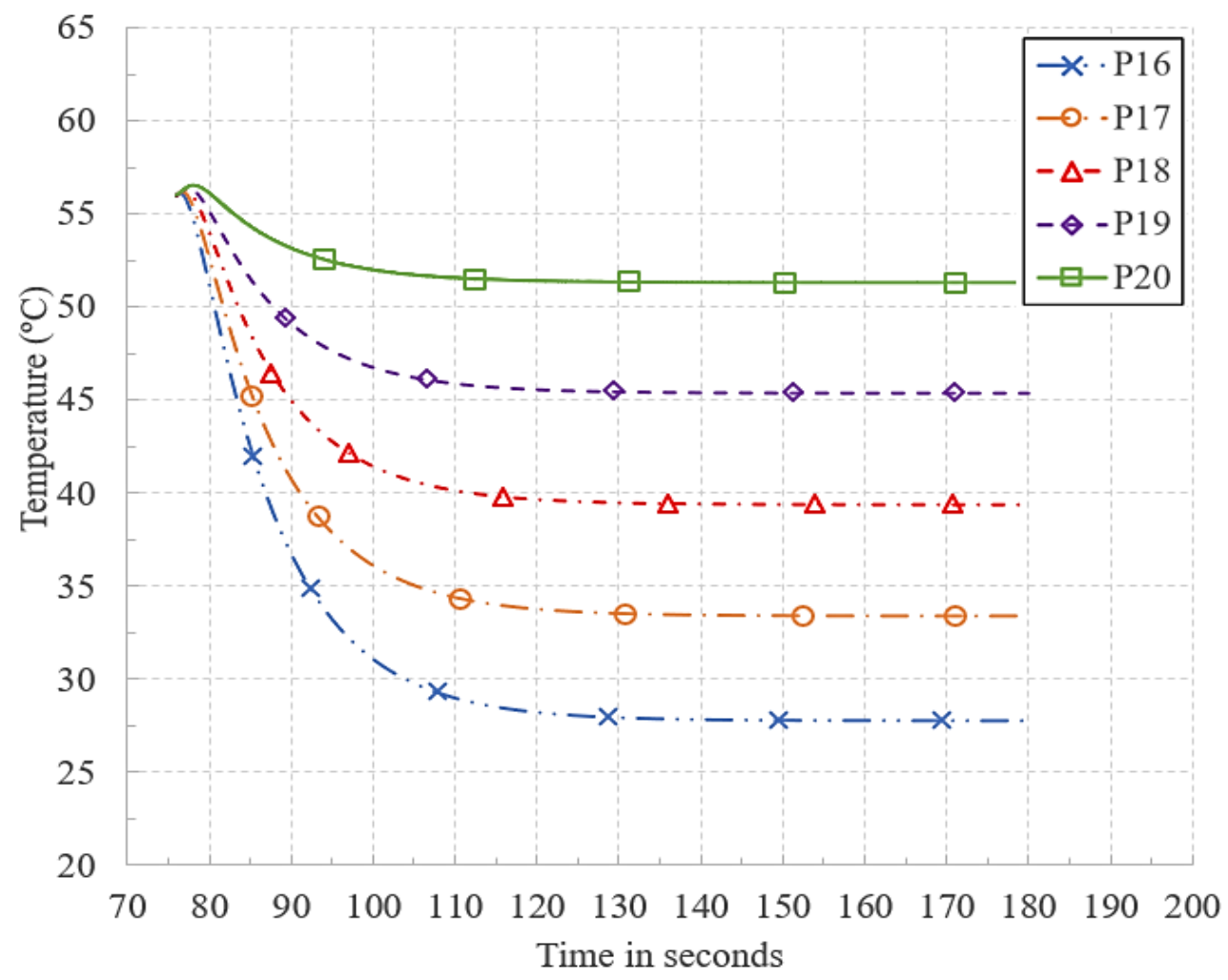

(b)

Fig. 12. Temperature variation with time after applying water film using our SPH model when down-flowing velocity of water film equals $0.4 \mathrm{~m} / \mathrm{s}$ : (a) At points P3, P8, P13, P18, P23, P28 and P33; (b) At Points P16, P17, P18, P19 and P20.

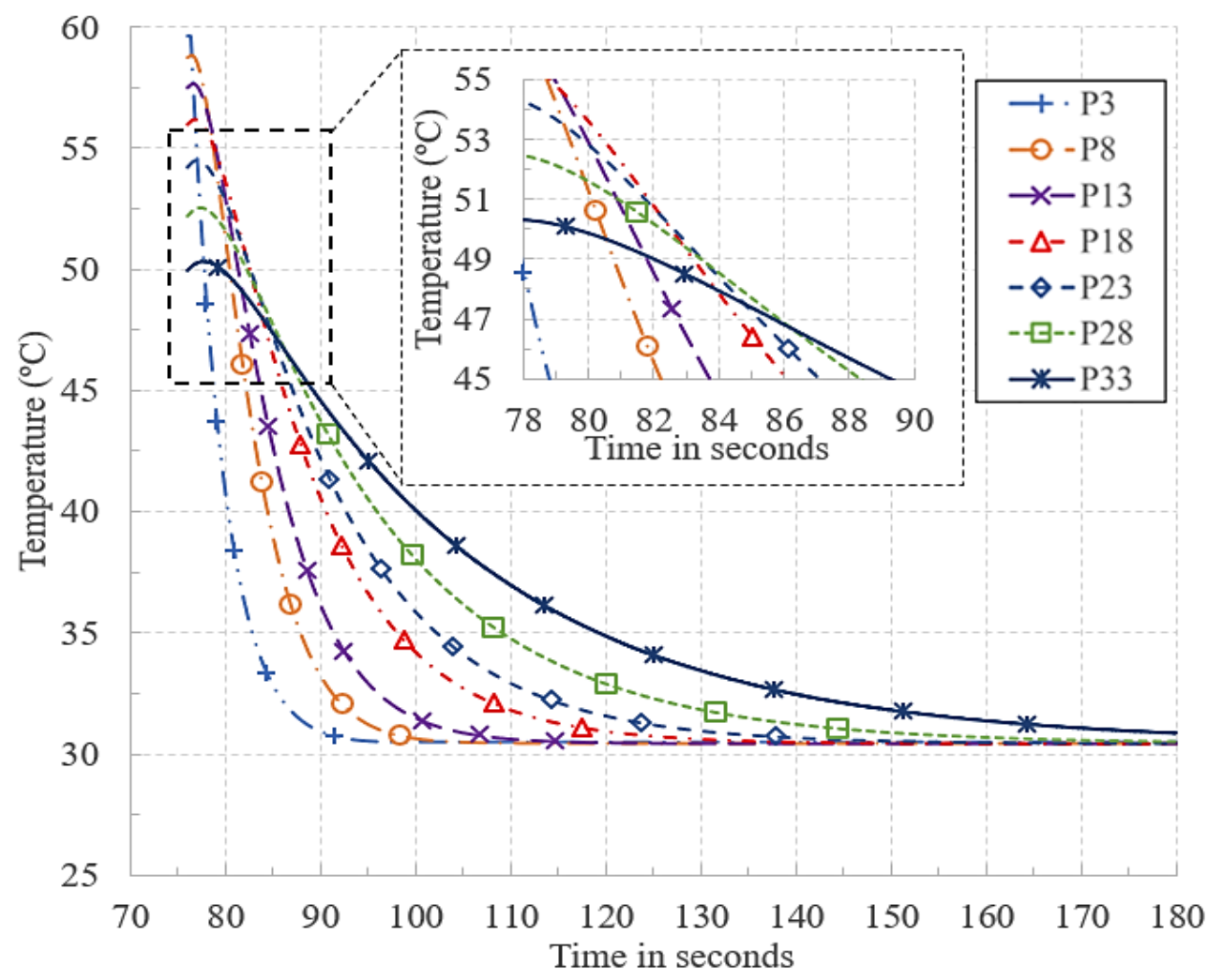

(a) 


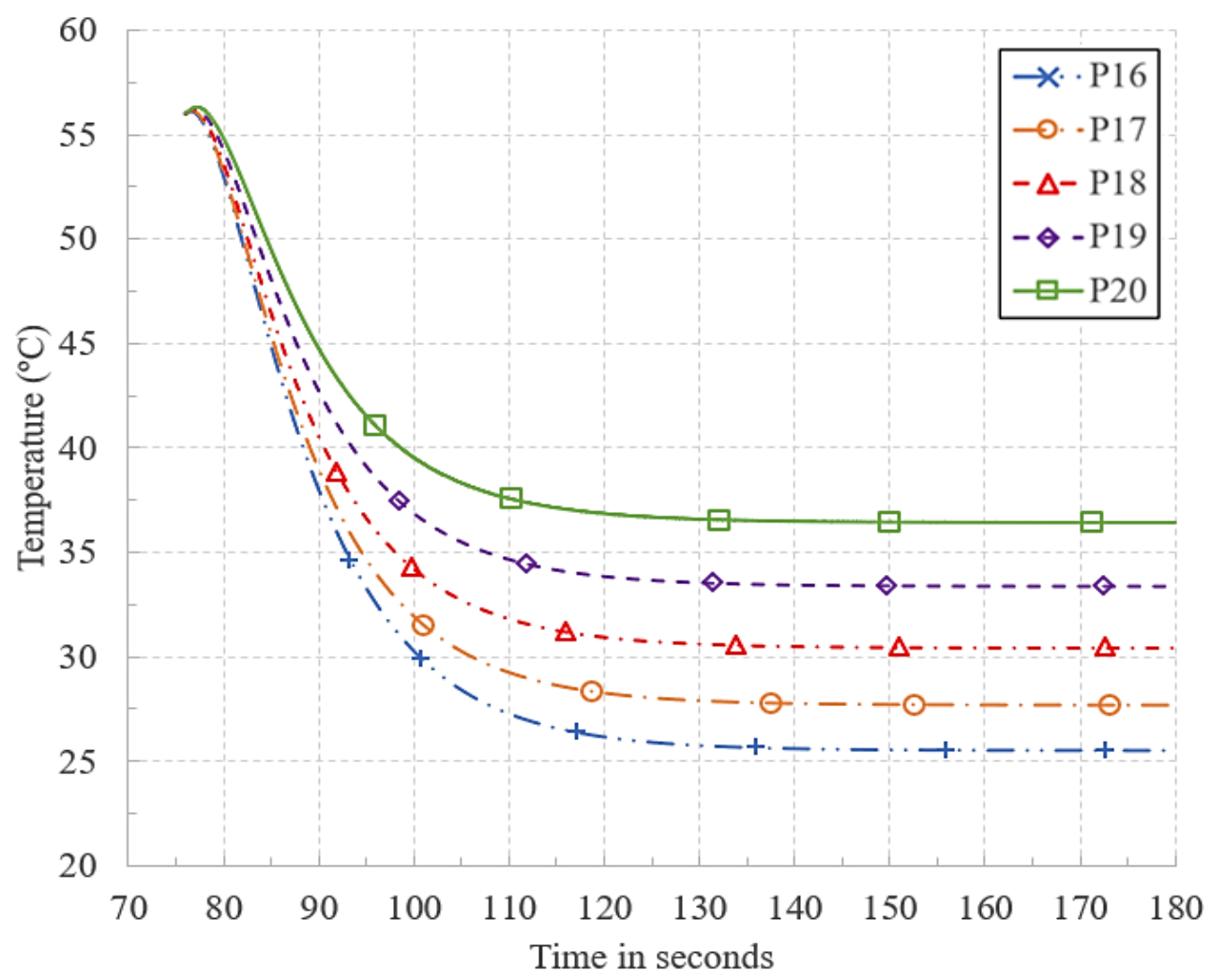

(b)

Fig. 13. Temperature variation with time after applying water film using our SPH model when down-flowing velocity of water film equals $0.8 \mathrm{~m} / \mathrm{s}$ : (a) At points P3, P8, P13, P18, P23, P28 and P33; (b) At Points P16, P17, P18, P19 and P20.

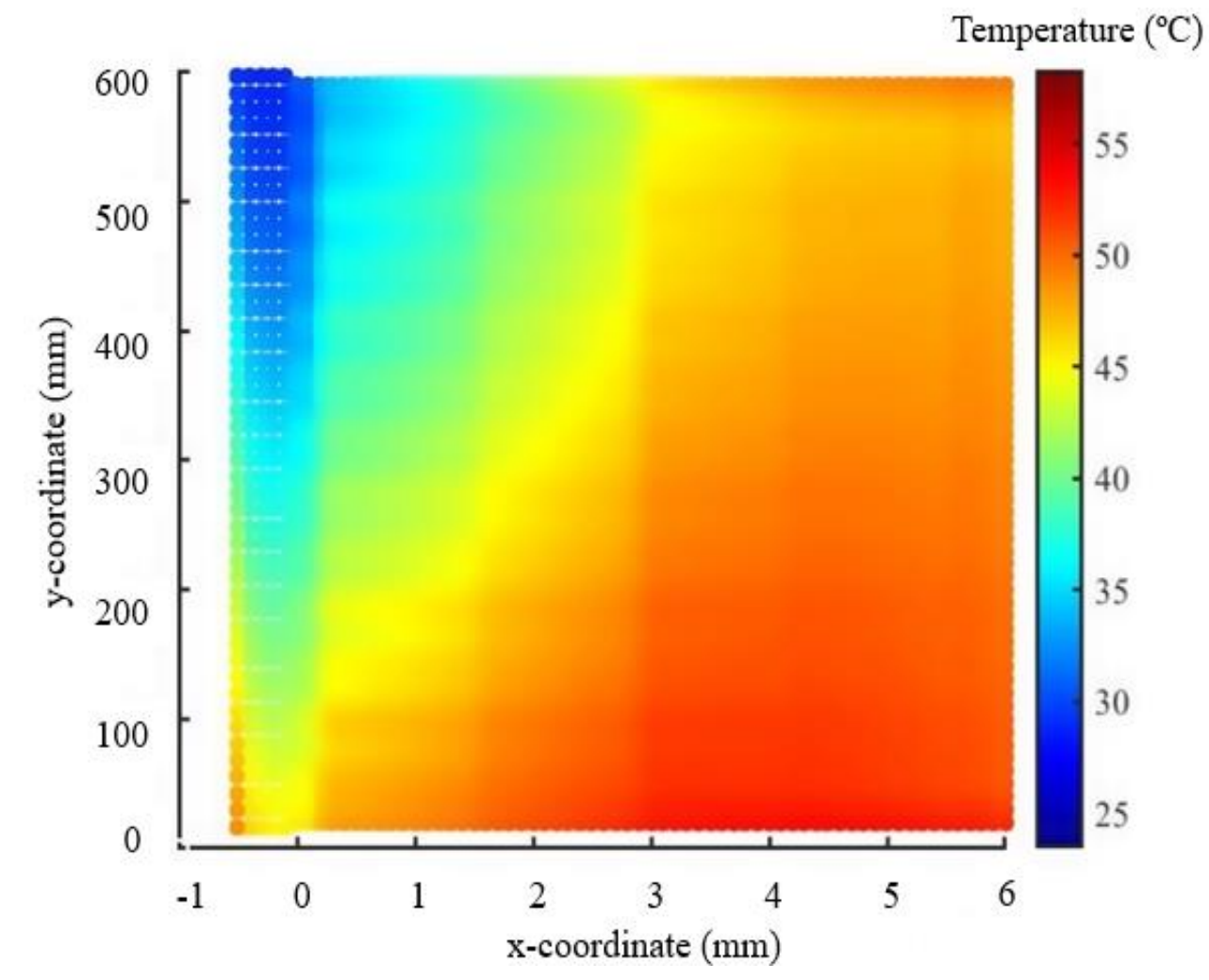

(a) 
Temperature $\left({ }^{\circ} \mathrm{C}\right)$

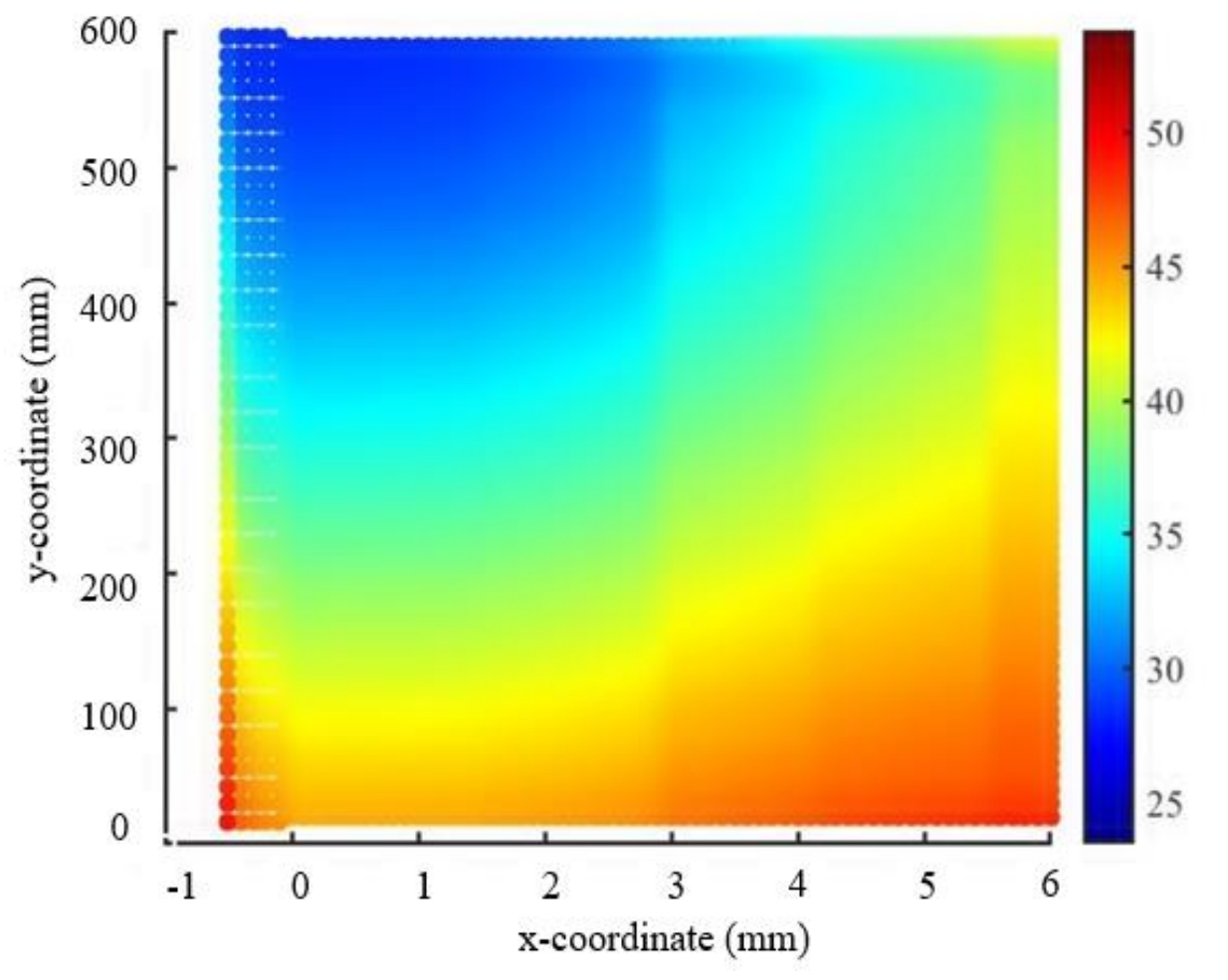

(b)

Fig. 14. Heat map of temperature $\left({ }^{\circ} \mathrm{C}\right)$ in glass and water film using our SPH model when maximum heat flux equals $18 \mathrm{~kW} \cdot \mathrm{m}^{-2}$. Where water film particles are located at negative $x$-coordinate $(x<0)$ : (a) At 85 seconds; (b) At 100 seconds.

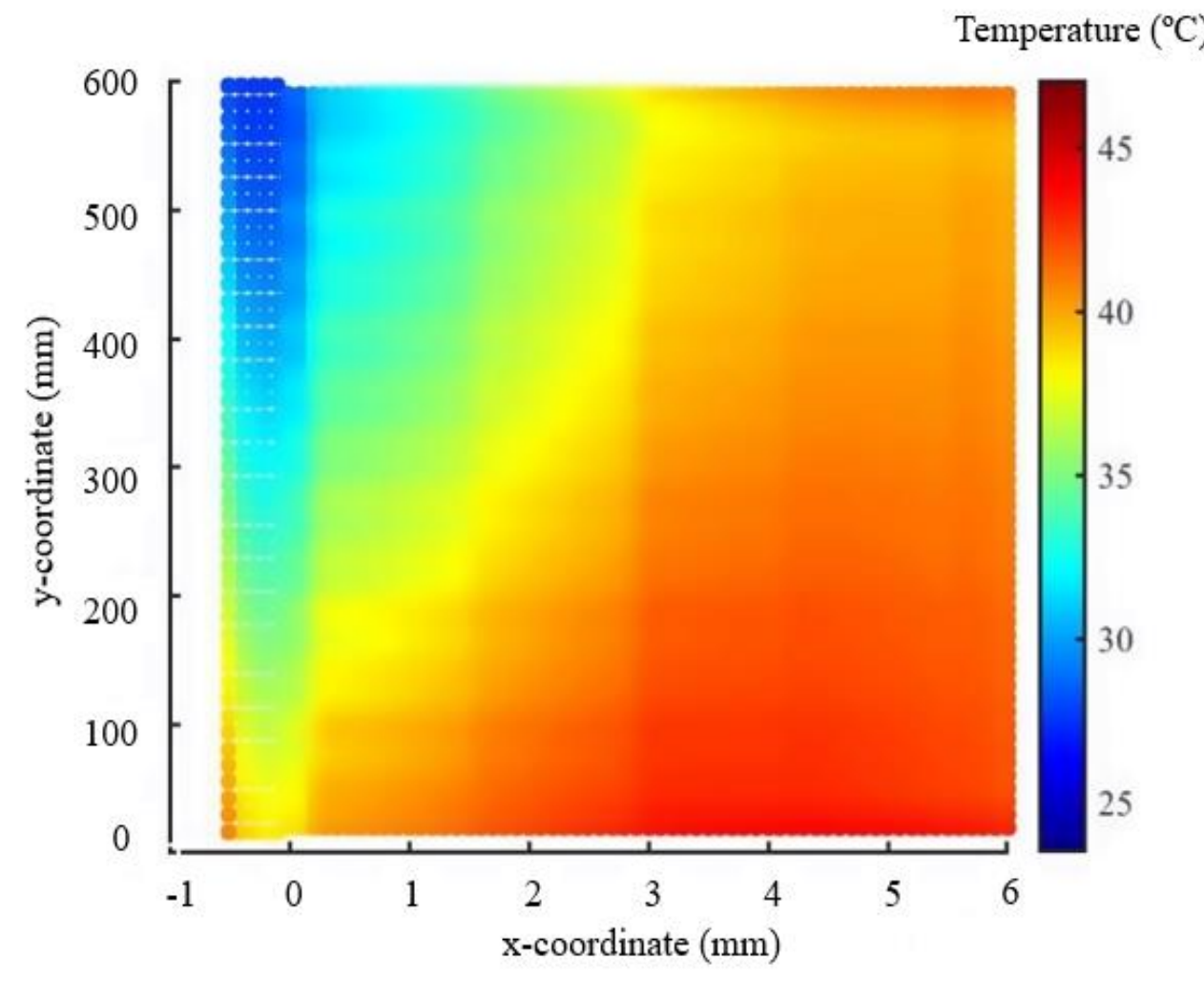

(a) 


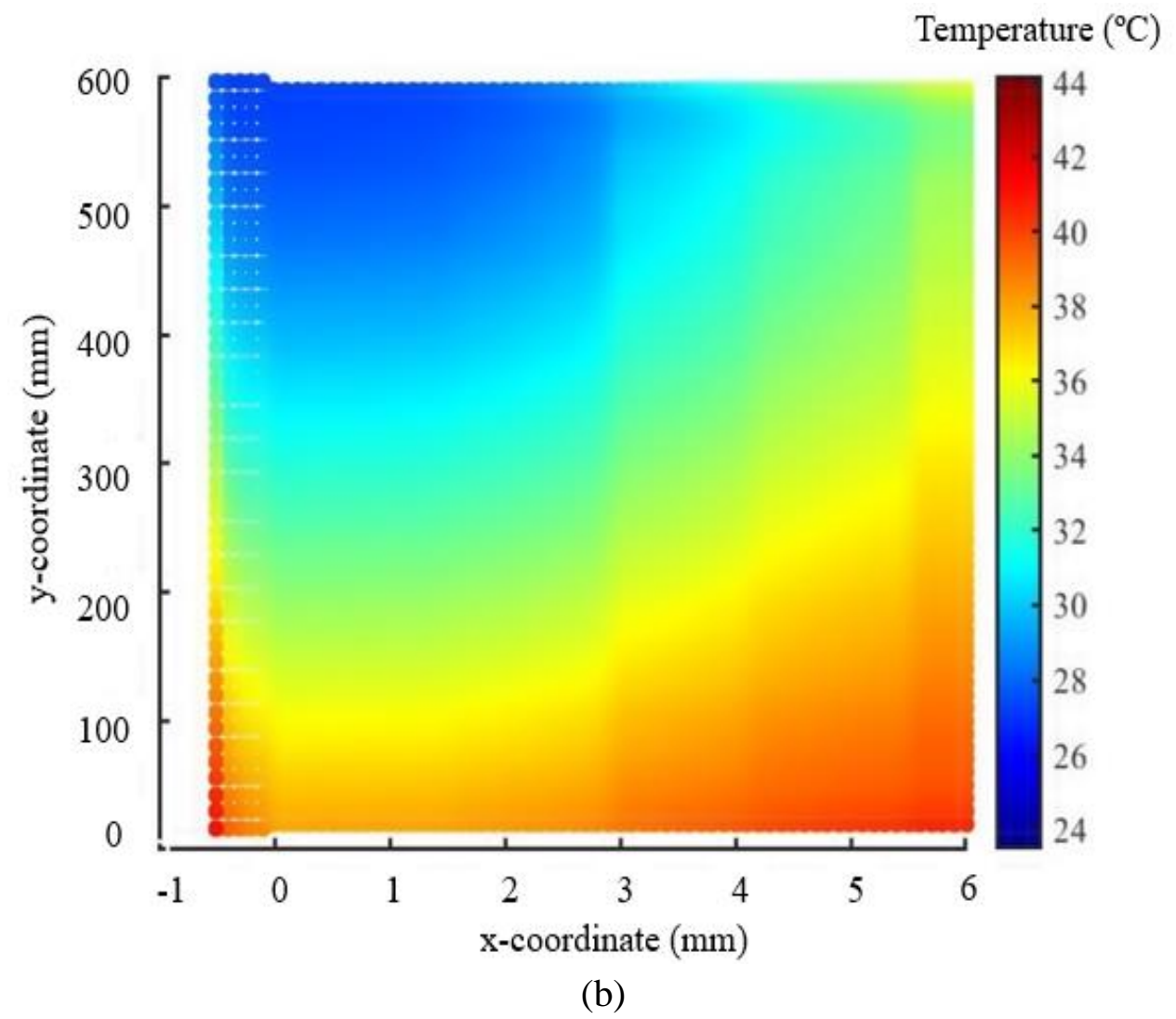

Fig. 15. Heat map of temperature $\left({ }^{\circ} \mathrm{C}\right)$ in glass and water film using SPH model when maximum heat flux equals $12 \mathrm{~kW} \cdot \mathrm{m}^{-2}$. Where water film particles are located at negative $\mathrm{x}$-coordinate $(x<0)$ : (a) At 85 seconds; (b) At 100 seconds.

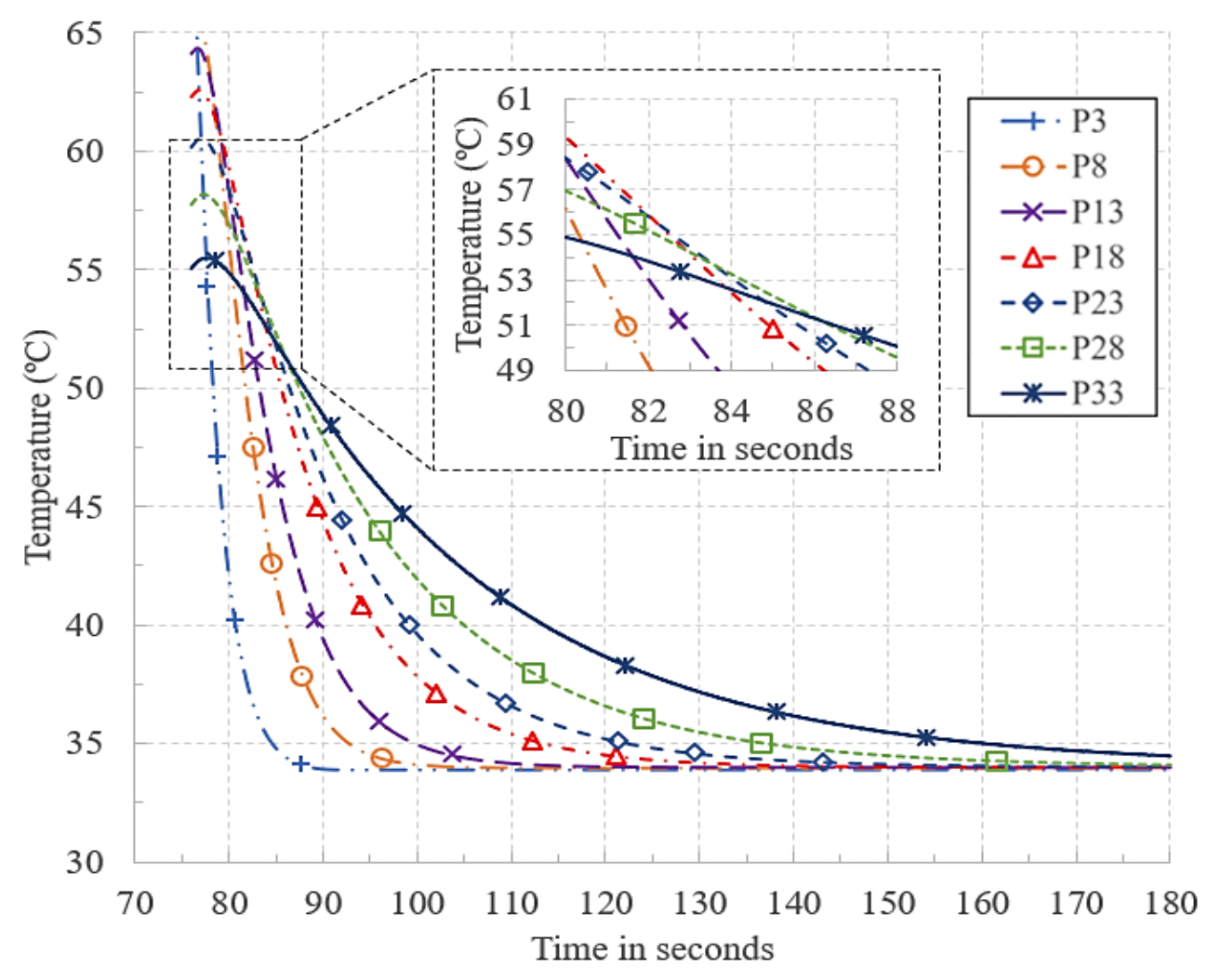

(a) 


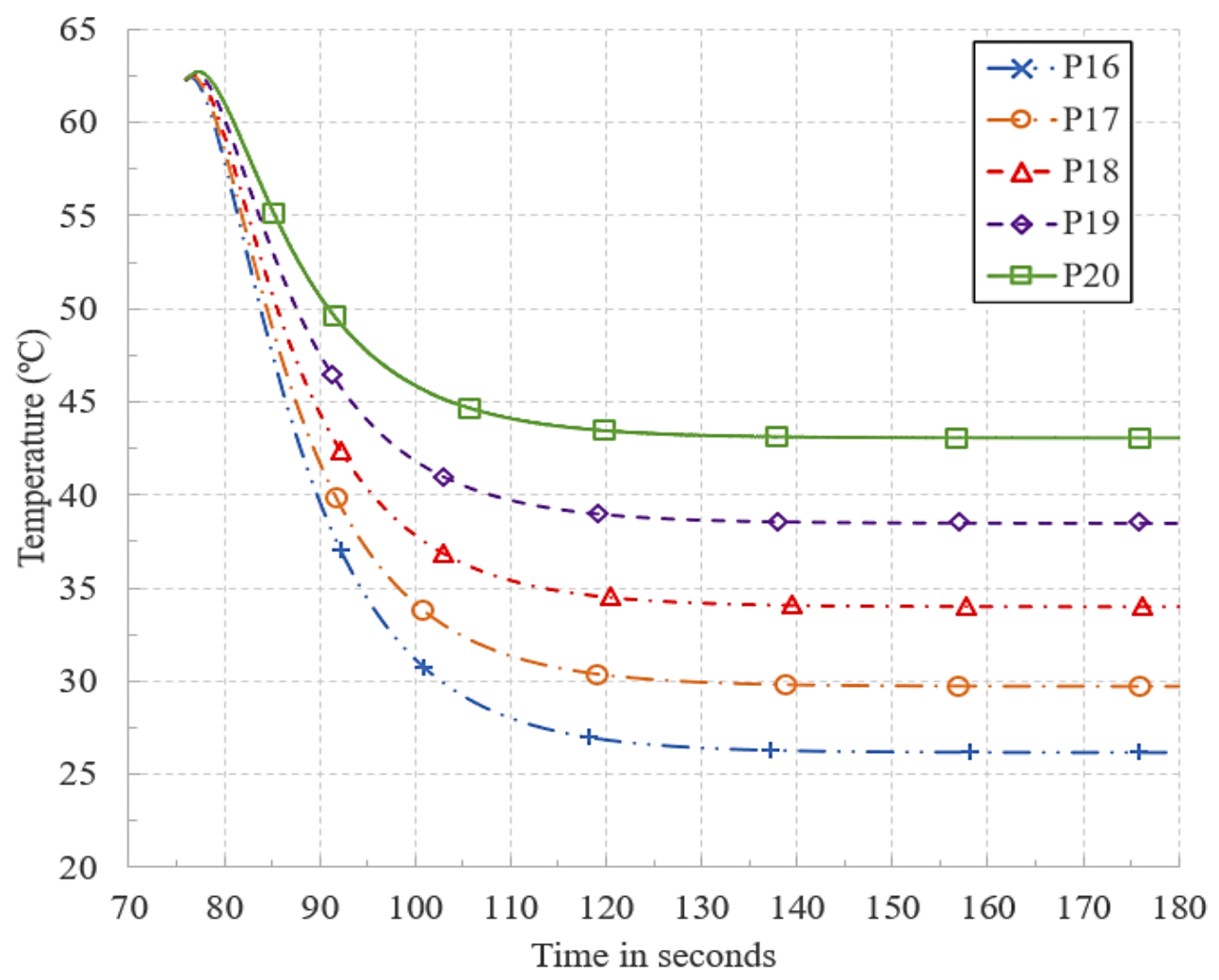

(b)

Fig. 16. Temperature variation with time after applying water film using SPH model when maximum heat flux equals $18 \mathrm{~kW} \cdot \mathrm{m}^{-2}$ : (a) At points P3, P8, P13, P18, P23,

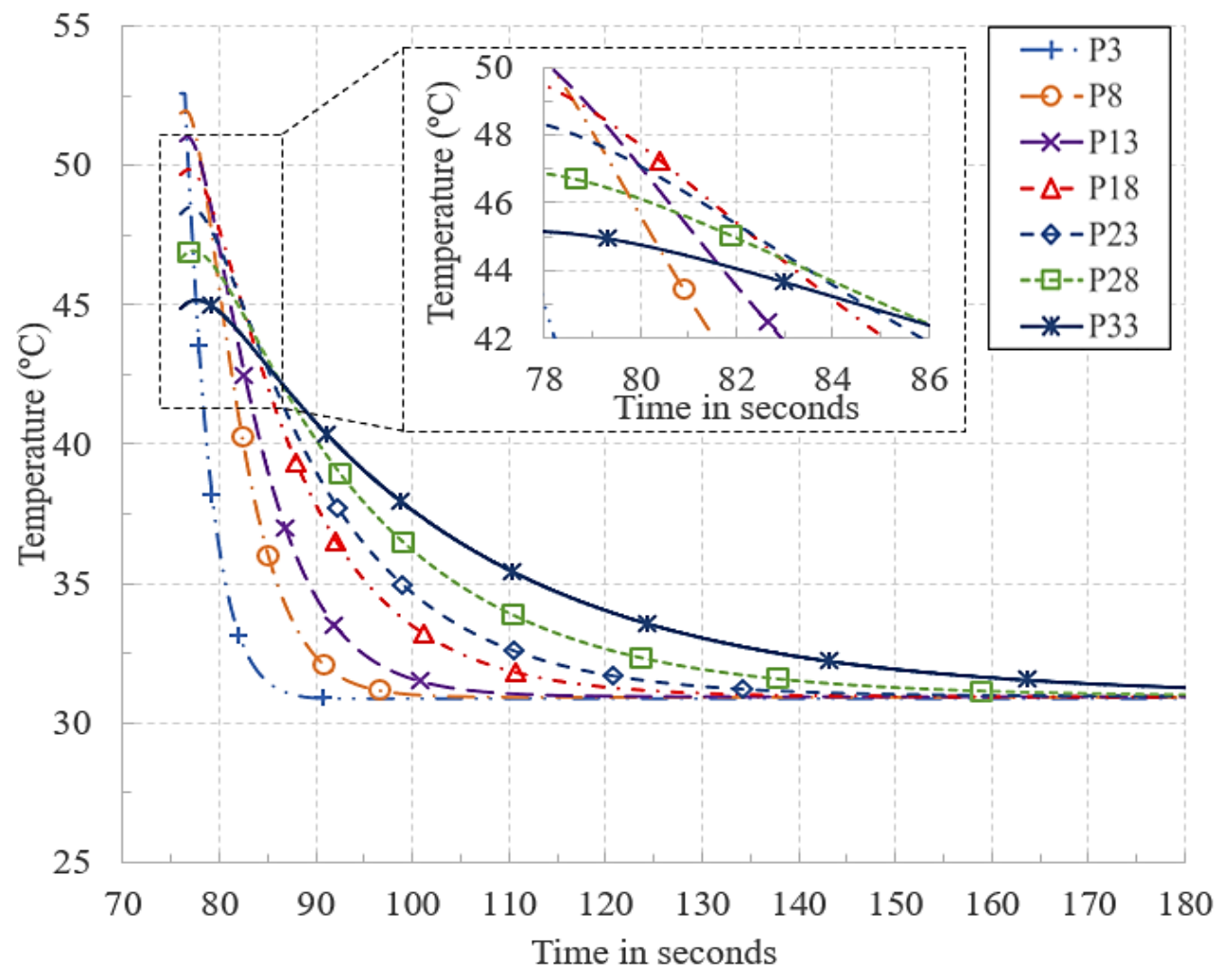

(a) 


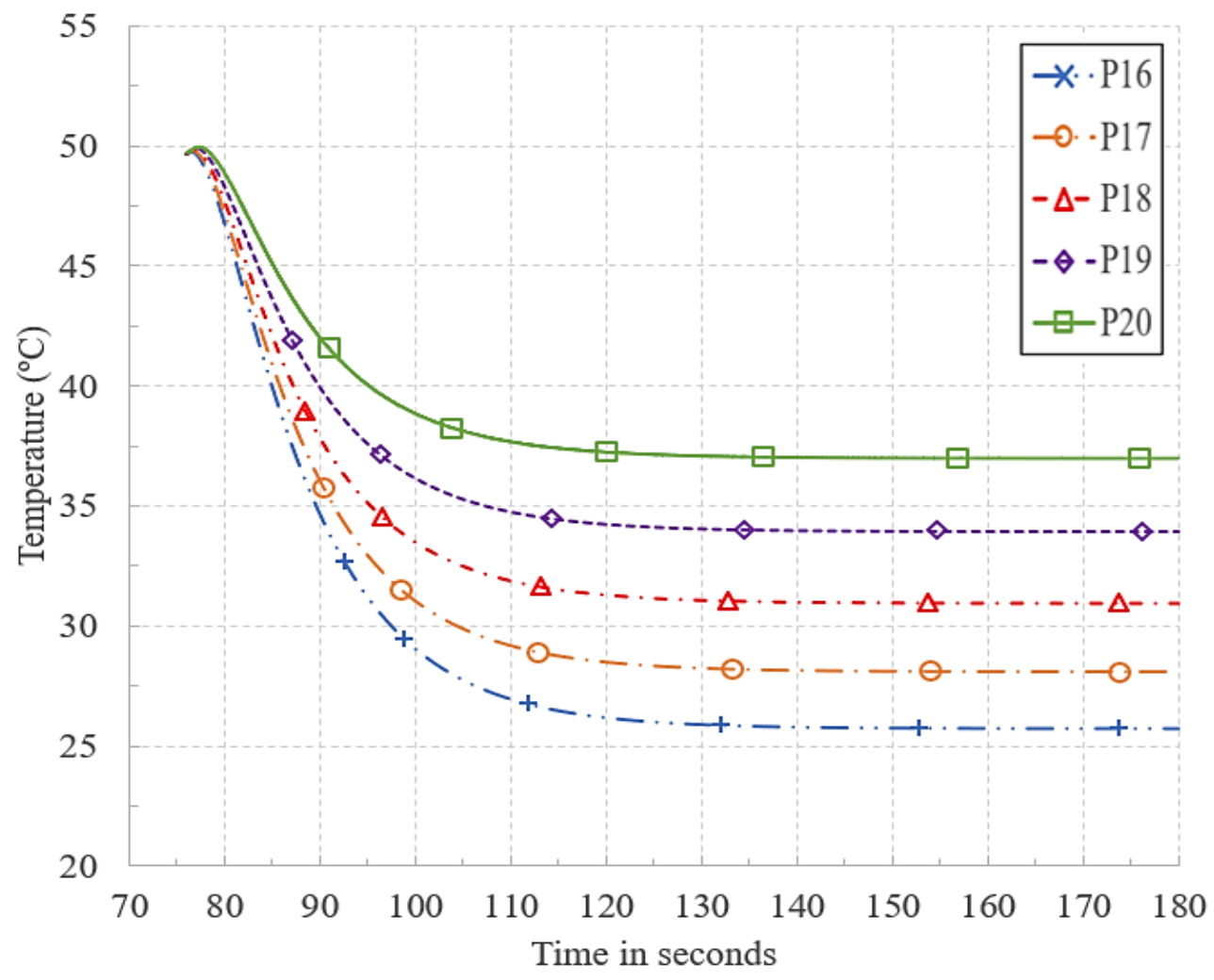

(b)

Fig. 17. Temperature variation with time after applying water film using SPH model when maximum heat flux equals $12 \mathrm{~kW} \cdot \mathrm{m}^{-2}$. Where water film particles are located at negative $x$-coordinate $(x<0)$ : (a) At points $\mathrm{P} 3, \mathrm{P} 8, \mathrm{P} 13, \mathrm{P} 18, \mathrm{P} 23, \mathrm{P} 28$ and P33; (b) At Points P16, P17, P18, P19 and P20. 


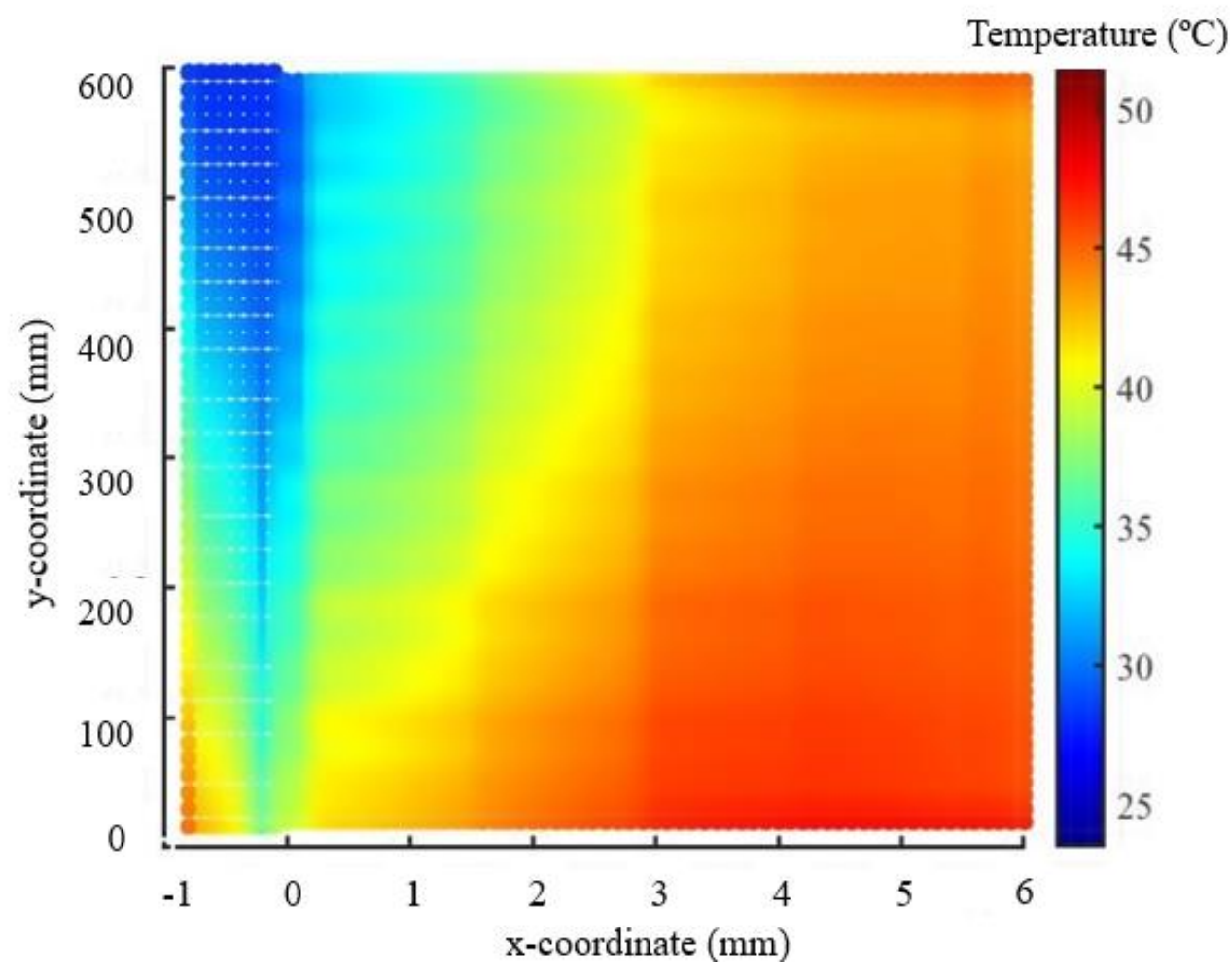

(a)

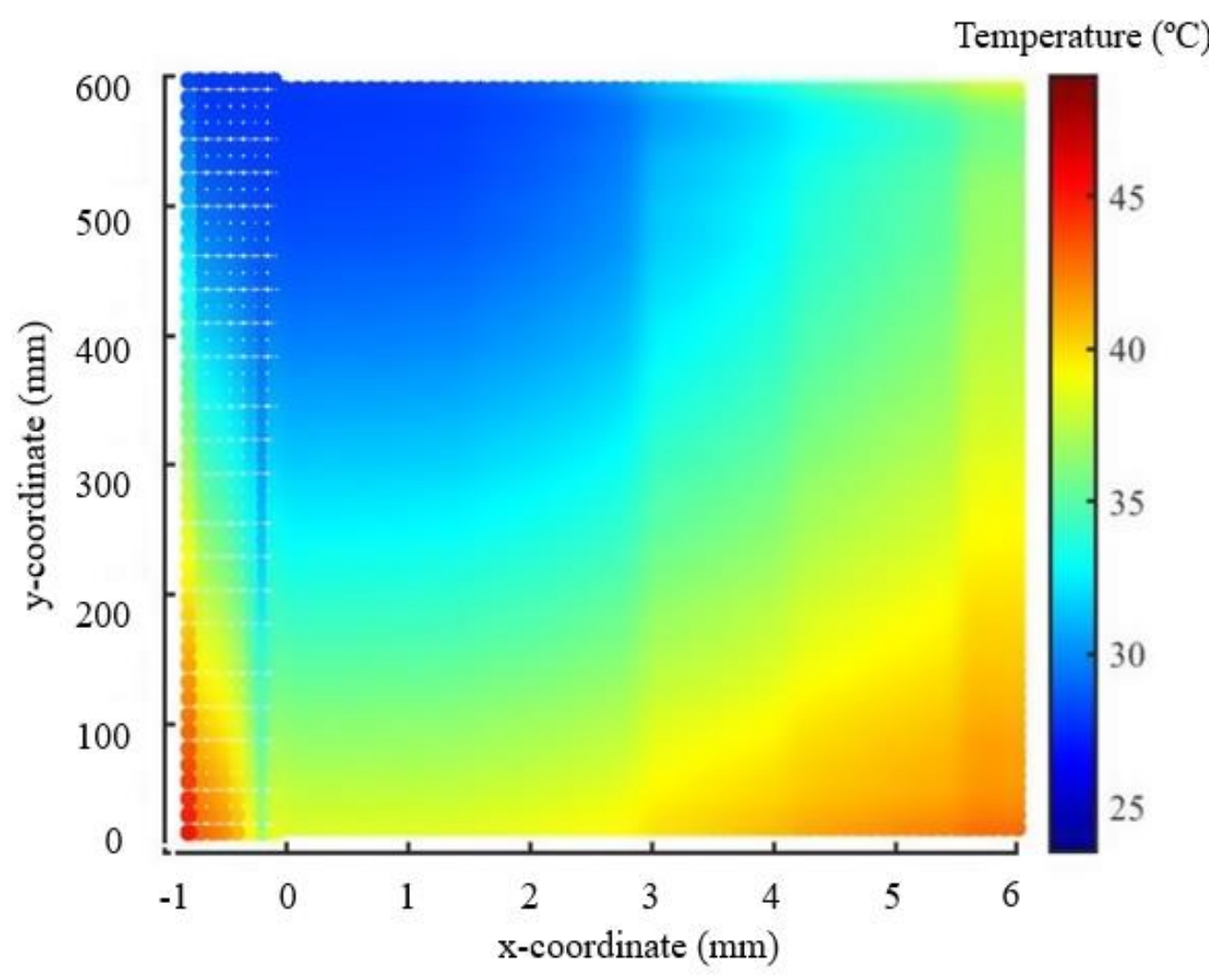

(b)

Fig. 18. Heat map of temperature $\left({ }^{\circ} \mathrm{C}\right)$ in glass and water film using SPH model when water film thickness equals $0.8 \mathrm{~mm}$. Where water film particles are located at negative $\mathrm{x}$-coordinate $(x<0 \mathrm{~mm})$ : (a) At 85 seconds; (b) At 100 seconds. 


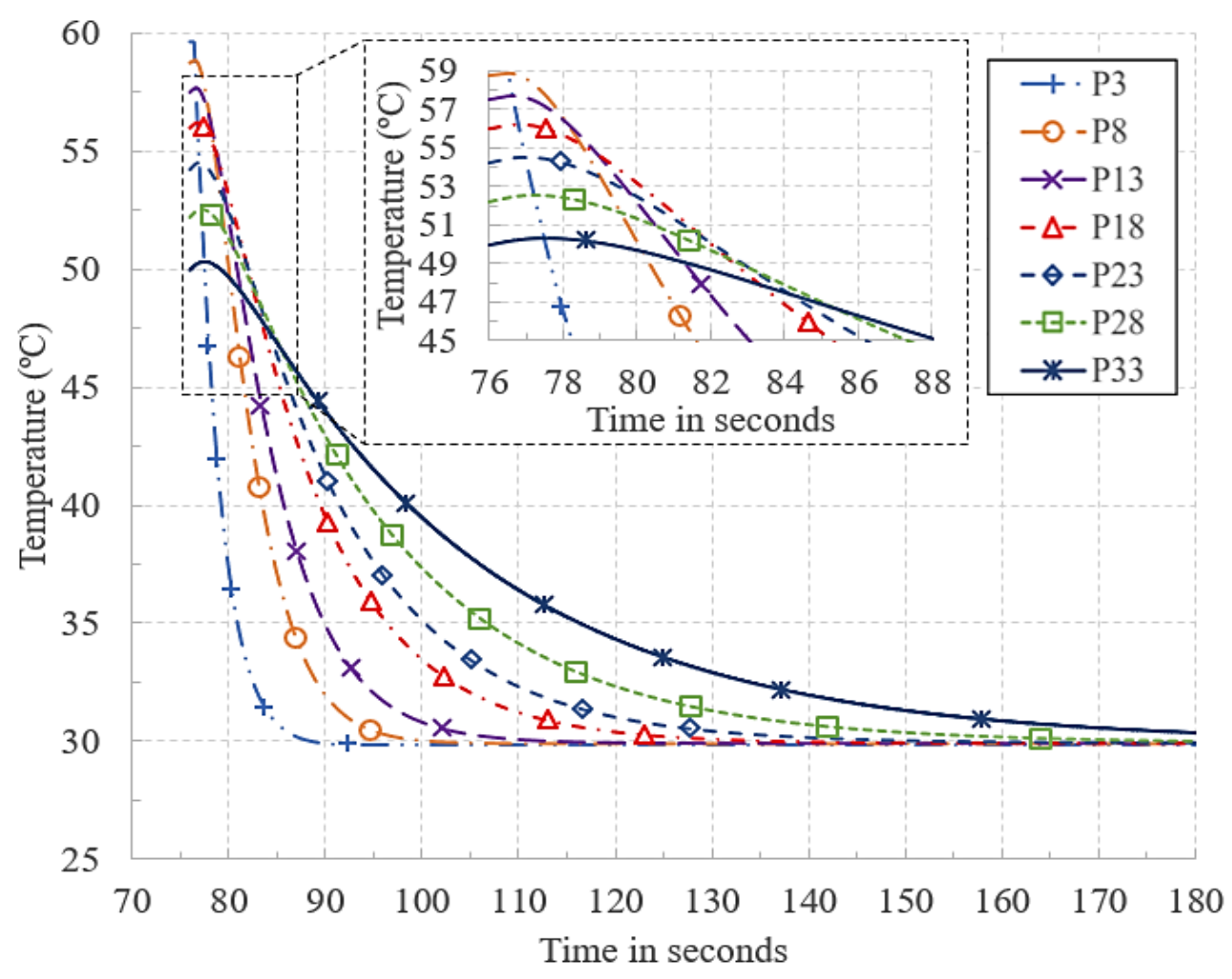

(a)

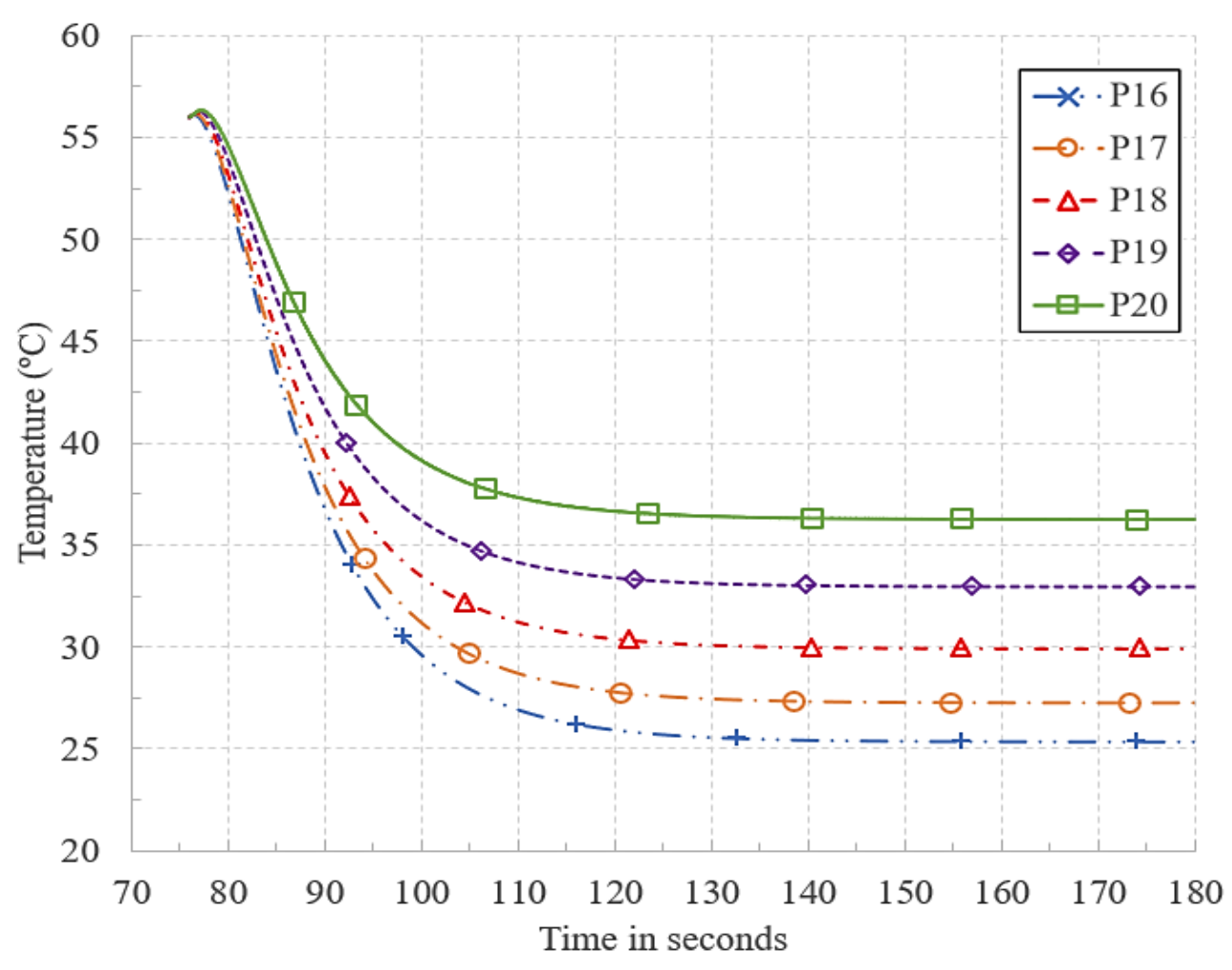

(b)

Fig. 19. Temperature variation with time after applying water film using SPH model when water film thickness equals $0.8 \mathrm{~mm}$ : (a) At points P3, P8, P13, P18, P23, P28 and P33; (b) At Points P16, P17, P18, P19 and P20. 
Table 1. The physical properties of glass and water.

\begin{tabular}{ccccc}
\hline Material & Property & Symbol & Value & Unit \\
\hline Glass & Density & $\rho_{G}$ & 2500 & $\mathrm{~kg} / \mathrm{m}^{3}$ \\
& Thermal conductivity & $K_{G}$ & 0.94 & $\mathrm{~W} / \mathrm{m} . \mathrm{k}$ \\
& Specific heat capacity & $C_{p G}$ & 820 & $\mathrm{~J} / \mathrm{kg} . \mathrm{k}$ \\
& Thermal diffusivity & $\alpha_{G}$ & $4.6 \times 10^{-7}$ & $\mathrm{~m}^{2} / \mathrm{s}$ \\
& linear thermal expansion & $\beta$ & $9 \times 10^{-6}$ & ${ }^{\circ} \mathrm{C}^{-1}$ \\
& & & & \\
Water & Density & $\rho_{W}$ & 998 & $\mathrm{~kg} / \mathrm{m}^{3}$ \\
& Thermal conductivity & $K_{W}$ & 0.6 & $\mathrm{~W} / \mathrm{m} . \mathrm{k}$ \\
& Specific heat capacity & $C_{p W}$ & 4182 & $\mathrm{~J} / \mathrm{kg} . \mathrm{K}$ \\
& Thermal diffusivity & $\alpha_{W}$ & $1.43 \times 10^{-7}$ & $\mathrm{~m}{ }^{2} / \mathrm{s}$ \\
& Initial Temperature & $T$ & 25 & ${ }^{\circ} \mathrm{C}$ \\
\hline
\end{tabular}

Table 2. Effects of number of SPH particles on computational time and results

\begin{tabular}{|c|c|c|c|c|c|}
\hline \multirow{2}{*}{ Description } & \multirow{2}{*}{$\begin{array}{c}\text { Number of steps / } \\
\text { Time (s) }\end{array}$} & \multicolumn{4}{|c|}{ Number of SPH particles } \\
\hline & & 2601 & 3721 & 5776 & 7056 \\
\hline \multirow{2}{*}{$\begin{array}{c}\text { Computational time in } \\
\text { seconds }\end{array}$} & Per 1000-time steps & 48.76 & 106.89 & 162.60 & 200.14 \\
\hline & Single time step & 0.049 & 0.107 & 0.163 & 0.2 \\
\hline \multirow{3}{*}{$\begin{array}{c}\text { Difference between } \\
\text { SPH and experiment at } \\
\text { P3 }(\%)\end{array}$} & At $85 \mathrm{~s}$ & 3.21 & 3.83 & 1.95 & 1.17 \\
\hline & At $90 \mathrm{~s}$ & 3.26 & 0.45 & 0.20 & 1.47 \\
\hline & At $95 \mathrm{~s}$ & 13.10 & 9.93 & 6.15 & 4.33 \\
\hline \multirow{3}{*}{$\begin{array}{c}\text { Difference between } \\
\text { SPH and experiment at } \\
\text { P33 (\%) }\end{array}$} & At $85 \mathrm{~s}$ & 3.61 & 0.77 & 1.48 & 1.98 \\
\hline & At $90 \mathrm{~s}$ & 11.74 & 8.42 & 5.54 & 4.53 \\
\hline & At $95 \mathrm{~s}$ & 15.56 & 12.20 & 9.22 & 8.10 \\
\hline \multirow{3}{*}{$\begin{array}{l}\text { Difference between } \\
\text { SPH and Autodesk- } \\
\text { CFD at P18 (\%) }\end{array}$} & At $85 \mathrm{~s}$ & 6.72 & 0.22 & 4.67 & 6.38 \\
\hline & At $90 \mathrm{~s}$ & 10.37 & 4.34 & 1.21 & 4.09 \\
\hline & At $95 \mathrm{~s}$ & 10.60 & 6.38 & 3.45 & 0.50 \\
\hline \multirow{3}{*}{$\begin{array}{c}\text { Difference between } \\
\text { SPH and Ansys-CFX at } \\
\text { P18 (\%) }\end{array}$} & At $85 \mathrm{~s}$ & 8.71 & 2.15 & 2.43 & 4.38 \\
\hline & At $90 \mathrm{~s}$ & 13.34 & 7.50 & 3.11 & 0.74 \\
\hline & At $95 \mathrm{~s}$ & 14.58 & 10.55 & 7.74 & 3.97 \\
\hline
\end{tabular}

